\title{
Effects of varying body forces on isothermal and non isothermal liquid jet impingement
}

\author{
Deepak Mehra \\ West Virginia University
}

Follow this and additional works at: https://researchrepository.wvu.edu/etd

\section{Recommended Citation}

Mehra, Deepak, "Effects of varying body forces on isothermal and non isothermal liquid jet impingement" (2007). Graduate Theses, Dissertations, and Problem Reports. 2769.

https://researchrepository.wvu.edu/etd/2769

This Dissertation is protected by copyright and/or related rights. It has been brought to you by the The Research Repository @ WVU with permission from the rights-holder(s). You are free to use this Dissertation in any way that is permitted by the copyright and related rights legislation that applies to your use. For other uses you must obtain permission from the rights-holder(s) directly, unless additional rights are indicated by a Creative Commons license in the record and/ or on the work itself. This Dissertation has been accepted for inclusion in WVU Graduate Theses, Dissertations, and Problem Reports collection by an authorized administrator of The Research Repository @ WVU.

For more information, please contact researchrepository@mail.wvu.edu. 


\title{
Effects of Varying Body Forces on Isothermal and Non Isothermal Liquid Jet Impingement
}

\author{
Deepak Mehra \\ Dissertation submitted to the \\ College of Engineering and Mineral Resources \\ at West Virginia University \\ in partial fulfillment of the requirements for the degree of
}

\section{Doctor of Philosophy \\ in}

Civil and Environmental Engineering

\author{
Committee: \\ Donald D. Gray, Ph.D., Chair \\ John M. Kuhlman, Ph.D. \\ Robert N. Eli, Ph.D. \\ Manfred Boehm, Ph.D. \\ Wade W. Huebsch, Ph.D. \\ Department of Civil and Environmental Engineering \\ Morgantown, WV \\ 2007
}

Keywords: Electric Kelvin force, Gravity, Liquid jet, Heat transfer 


\section{ABSTRACT \\ Effects of Varying Body Forces on Isothermal and Non Isothermal Liquid Jet Impingement}

\section{DEEPAK MEHRA}

Liquid jet impingement is often used to cool heated surfaces encountered in various industrial applications. Such applications include cooling of electronic components and annealing of metals. Liquid jet impingement investigations primarily involve submerged jets and less commonly free liquid jets. Most of the studies done on both submerged jet impingement and free liquid jet impingement are done under terrestrial gravity conditions. There have been few studies on liquid jet impingement under non terrestrial conditions in zero or non zero gravitational force or of electrical body forces. These conditions are expected to result in significantly different flow patterns and heat transfer compared to terrestrial gravity.

The relatively uncommon forces like the electric Kelvin force could significantly affect the heat transfer and flow characteristics of an impinging liquid jet. As per one of the objectives of this research, an electrode arrangement was designed to obtain a uniform electric Kelvin body force acting in a direction opposite to the impinging jet. Another objective was to assess the effects of varying gravity on heat transfer to an impinging jet. Simulation results involving liquid jet impingement with different body forces are presented in this dissertation. These results were obtained with the aid of a commercial multiphysics code called CFD-ACE+.

The isothermal set of simulations included the electric Kelvin force as the source term, while in the non isothermal cases gravity was varied from 0 to $1.5 \mathrm{~g}$ in the increments of $0.5 \mathrm{~g}$. The transient effects of the electric Kelvin force were observed in the isothermal simulations while in the non isothermal simulations it was found that for low velocities the heat transfer from an impinging liquid jet was enhanced as the gravitational force was increased. 


\section{Contents}

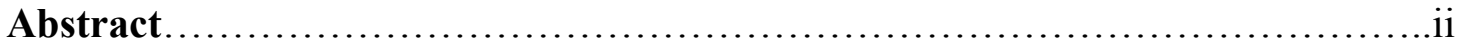

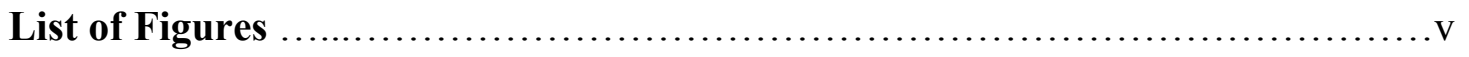

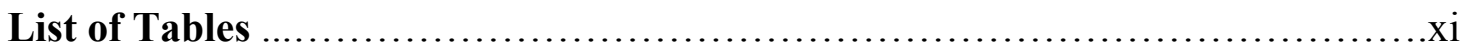

Acknowledgements.....................................................

Chapter 1 Introduction and Literature Review 1

1.1 Introduction 1

1.2 Survey of Prior Studies 4

Chapter 2 Numerical Scheme and Code Verification under Variable Gravity Conditions

2.1 CFD-ACE+ Numerical Scheme 9

2.2 Labus' Experiments: Liquid Jet Impingement on Sharp Edge Disk in $\begin{array}{ll}\text { Zero Gravity } & 17\end{array}$

2.2.1 Surface Tension Flow Regime 20

2.2.2 Inertial Flow Regime $\quad 24$

2.3 Liu and Lienhard's Experiments: Liquid Jet Impingement Heat

Transfer on a Uniform Heat Flux Surface

Chapter 3 Experimental Setup and Electrode Design 37

3.1 Introduction and the Experimental Setup 37

3.2 Electric Kelvin Force 39 
Chapter 4 Liquid Jet Simulations with VOF with Varying Body Forces

4.1 Isothermal Liquid Jet Simulations with Varying Body Forces

4.2 Case 1 Low Velocity Case with No Gravitational Force and No Kelvin Force

4.3 Case 2 Low Velocity Case with Gravitational Force and No Kelvin Force

4.4 Case 3 Higher Velocity Case with No Gravitational Force and No Kelvin Force

4.5 Case 4 Higher Velocity Case with Gravitational Force and No Kelvin Force

4.6 Case 5 Low Velocity Case with Gravitational Force Opposed by Kelvin Force

4.7 Case 6 Higher Velocity Case with Gravitational Force Opposed by Kelvin Force

5.1 Introduction and Setup

\section{References}




\section{List of Figures}

Figure 1.1 Boundary layer development for impinging circular liquid jet (Source: Ma, 1993).

Figure 1.2 Submerged jet (Source: Womac et al. (1990)).

Figure 2.1 Control volume (Source: CFD-ACE+ Manual (2006)). 12

Figure 2.2 Two dimensional cell volume and adjacent nodes. 13

Figure 2.3 Schematic of liquid jet impinging on a disk in Labus' experiment. $\quad 18$

Figure 2.4 Two dimensional axi-symmetric model for Labus' surface tension cases.

Figure 2.5 Grid distribution for Labus' surface tension case.

Figure 2.6 Zone distribution for the domain. Each quadrilateral represents one zone.

Figure 2.7 Labus' surface tension simulated case mirrored on y axis.

Figure 2.8 Streamlines shown for the surface tension case of Labus (1977).

Figure 2.9 Surface tension case as photographed by Labus (1977).

Figure 2.10 Two dimensional axi-symmetric model for Labus' inertial flow case. 25

Figure 2.11 Inertial grid for Labus’ inertial flow case.

Figure 2.12 Labus' inertial flow simulated case mirrored on y axis at $t=0.3 \mathrm{~s} . \quad 26$

Figure 2.13 Streamlines shown for the inertial flow case run by Labus (1977) at $\mathrm{t}=0.3 \mathrm{~s}$.

Figure 2.14 Inertial flow case as photographed by Labus (1977).

Figure 2.15 Location of the inertial flow free surface for the experiments and the simulations.

Figure 2.16 2D axi-symmetric model for liquid jet impingement heat transfer. 31

Figure 2.17 Coarse grid used to obtain the initial steady state solution for temperature. 
Figure 2.18 Fine grid system used to obtain the final steady state solution.

Figure 2.19 Streamlines for liquid jet impingement on a uniformly heated surface at steady state conditions (Red represents water, blue represents air). 34

Figure 2.20 Comparison of local Nusselt numbers based on jet diameter obtained experimentally to those obtained from simulations.

Figure 3.1. Schematic of apparatus (axi-symmetric geometry).

Figure 3.2 Location of the electrodes (Conductors are shown in black; dielectrics are shaded gray).

Figure 3.3 Electric field lines.

Figure 3.4 Lines tangent to gradient of the $\mathrm{E}^{2}$ lines.

Figure 3.5 X direction Kelvin force to mass ratio.

Figure 3.6 X direction Kelvin force to mass ratio plot.

Figure 3.7 Y direction Kelvin force to mass ratio plot.

Figure 4.1 Typical grid system used in the simulations (note that the grid is not curved as it may appear).

Figure 4.2 Case 1 HFE 7000 at $\mathrm{t}=0.0173$ seconds.

Figure 4.3 Case 1 streamlines at $\mathrm{t}=0.0173$ seconds.

Figure 4.4 Case $1 \mathrm{HFE} 7000$ at $\mathrm{t}=0.05622$ seconds.

Figure 4.5 Case 1 streamlines at $\mathrm{t}=0.05622$ seconds.

Figure 4.6 Case 1 HFE $7000 \mathrm{t}=0.136$ seconds.

Figure 4.7 Case 1 streamlines $\mathrm{t}=0.136$ seconds.

Figure 4.8 Case $1 \mathrm{HFE} 7000$ at $\mathrm{t}=0.1442$ seconds.

Figure 4.9 Case 1 streamlines at $\mathrm{t}=0.1442$ seconds.

Figure 4.10 Case $1 \mathrm{HFE} 7000$ at $\mathrm{t}=0.1619$ seconds.

Figure 4.11 Case 1 streamlines after 0.1619 seconds. 
Figure 4.12 Case 2 HFE 7000 at $t=0.02425$ seconds. 62

Figure 4.13 Case 2 HFE 7000 at $t=0.032$ seconds. 62

Figure 4.14 Case 2 HFE 7000 at $t=0.0475$ seconds. 63

Figure 4.15 Case 2 HFE 7000 at $t=0.063$ seconds. $\quad 64$

Figure 4.16 HFE 7000 after 0.0718 seconds. 65

Figure 4.17 Case 2 HFE 7000 at $\mathrm{t}=0.0795$ seconds. 66

Figure 4.18 Case $3 \mathrm{HFE} 7000$ at $\mathrm{t}=0.0183$ seconds. $\quad 67$

Figure 4.19 Case 3 streamlines at $\mathrm{t}=0.0183$ seconds. $\quad 68$

Figure 4.20 Case 3 HFE 7000 at $\mathrm{t}=0.0354$ seconds. $\quad 68$

Figure 4.21Case 3 streamlines at $\mathrm{t}=0.0354$ seconds. 69

Figure 4.22 Case 3 HFE 7000 at $t=0.0537$ seconds. $\quad 70$

Figure 4.23 Case 3 streamlines at $\mathrm{t}=0.0537$ seconds. $\quad 71$

Figure 4.24 Case $3 \mathrm{HFE} 7000$ at $\mathrm{t}=0.0599$ seconds. $\quad 72$

Figure 4.25 Case 3 streamlines at $t=0.0599$ seconds. 73

Figure 4.26 Case 3 HFE 7000 at $\mathrm{t}=0.0818$ seconds.

$\begin{array}{ll}\text { Figure } 4.27 \text { streamlines after } 0.0818 \text { seconds. } & 75\end{array}$

Figure 4.28 Case 4 HFE 7000 at $t=0.0126$ seconds. 76

Figure 4.29 Case 4 HFE 7000 at $t=0.0255$ seconds. 77

Figure 4.30 Case $4 \mathrm{HFE} 7000$ at $\mathrm{t}=0.0424$ seconds. $\quad 78$

Figure 4.31 Case 4 HFE 7000 at $t=0.0479$ seconds.

Figure 4.32 Case 5 Liquid jet at $\mathrm{t}=0.0344 \mathrm{~s} . \quad 80$

Figure 4.33 Case 5 liquid jet at $\mathrm{t}=0.042 \mathrm{~s}$.

Figure 4.34 Case 5 liquid jet at $\mathrm{t}=0.0496 \mathrm{~s}$. 81 
Figure 4.35 Case 5 liquid jet at $\mathrm{t}=0.0586 \mathrm{~s}$. 82

Figure 4.36 Case 5 liquid jet after $0.064 \mathrm{~ms}$. 83

Figure 4.37 Case 5 liquid jet at $\mathrm{t}=0.0691 \mathrm{~s}$. $\quad 84$

Figure 4.38 Case 5 electric potential at $0 \mathrm{~s}$ and at $0.0691 \mathrm{~s}$. 85

Figure 4.39 Centerline velocity measured from the inlet before the jet impingement for the low velocity cases.

Figure 4.40 Centerline axial velocity measured from the inlet after the jet impingement for the low velocity cases.

$\begin{array}{lr}\text { Figure 4.41 Case } 6 \text { liquid jet at } \mathrm{t}=0.0133 \mathrm{~s} . & 88\end{array}$

Figure 4.42 Case 6 liquid jet at $\mathrm{t}=0.0258 \mathrm{~s} . \quad 88$

Figure 4.43 Case 6 liquid jet at $\mathrm{t}=0.0351 \mathrm{~s}$. 89

Figure 4.44 Case 6 liquid jet after $0.041 \mathrm{~s} . \quad 90$

Figure 4.45 Case 6 electric potential before the jet enters the domain and after the liquid impinges on the pedestal.

Figure 4.46 Centerline velocity measured from the inlet before the jet impingement for the higher velocity cases.

Figure 4.47 Centerline velocity measured from the inlet after the jet impingement for the higher velocity cases.

Figure 5.1 An axi-symmetric model for liquid jet impingement with heat transfer. 94

Figure 5.2 Grid for the low and high velocity heat transfer case.

Figure 5.3 Case H1 steady state flow conditions.

Figure 5.4 Case H1 steady state temperature distribution (the heater surface is $0.1 \mathrm{~mm}$ from the bottom of the figure)

Figure 5.5 Case H2 steady state flow conditions.

Figure 5.6 Case H2 steady state temperature distribution.

Figure 5.7 Case H3 steady state flow conditions. 
Figure 5.8 Case H3 steady state temperature distribution.

Figure 5.9 Case H4 steady state flow conditions.

Figure 5.10 Case H4 steady state temperature distribution .

Figure 5.11 Free surfaces of liquid jets with varying gravity.

Figure 5.12 Nusselt number variation with the dimensionless radius.

Figure 5.13 Percentage increase in Nusselt numbers with varying body forces.

Figure 5.14 Average Nusselt number increase with the reciprocal of Stokes number.

Figure 5.15 Heat transfer coefficient as a function of rd.

Figure 5.16 Case H5 steady state flow conditions for $0 \mathrm{~g}$ high velocity regime.

Figure 5.17 Case H5 steady state temperature distribution for $0 \mathrm{~g}$ high velocity regime.

Figure 5.18 Case H6 steady state flow conditions for $0.5 \mathrm{~g}$ high velocity regime. 116

Figure 5.19 Case H6 steady state temperature distribution for $0.5 \mathrm{~g}$ high velocity regime.

Figure 5.20 Case H7 steady state flow conditions for $1 \mathrm{~g}$ high velocity regime.

Figure 5.21 Case H7 steady state temperature distribution for $1 \mathrm{~g}$ high velocity regime.

Figure 5.22 Case H8 steady state flow conditions for $1.5 \mathrm{~g}$ high velocity regime. 118

Figure 5.23 Case $\mathrm{H} 8$ steady state temperature distribution for $1.5 \mathrm{~g}$ high velocity regime.

Figure 5.24 Free surface plots of high velocity regime with varying gravity.

Figure 5.25 Nusselt number as a function of the dimensionless radius.

Figure 5.26 Heat transfer coefficient with dimensionless radial distance.

Figure 5.27 Percentage increase in Nusselt numbers with varying gravity. 
Figure 5.28 Average Nusselt number increase as a function of reciprocal of Stokes number. 


\section{List of Tables}

Table 2.1 Module functions in CFD-ACE+.

Table 2.2 Properties for the fluid used in the simulations and the flow velocities at inlet.

Table 2.3 Table showing the Reynolds and Weber numbers for the cases simulated.

Table 2.4 Properties used for the simulations of Liu and Lienhard (1989).

Table 2.5 Computed and experimental data for $\mathrm{Nu}_{\mathrm{r}}$.

Table 3.1 Properties of HFE 7000 at standard atmospheric conditions.

Table 4.1 Simulated isothermal cases.

Table 5.1 Simulated heat transfer cases with variable gravity.

Table 5.2 Comparison of computed $\mathrm{Nu}$ number with available correlations for Cases $\mathrm{H} 1$ to $\mathrm{H} 4$.

Table 5.3 Comparison of computed $\mathrm{Nu}$ number with available correlations for Cases H5 to H8. 


\section{Acknowledgements}

I would like to thank Dr. Donald Gray, my thesis advisor for giving me an opportunity to work with him. Dr. Gray has been has been a tremendous inspiration for me and he has helped me in every possible way to become a better researcher and a better person. I would also like to thank Dr. John Kuhlman for providing his expertise in my work and also for being an inspiration to me. I thank my committee members, Dr. Manfred Boehm, Dr. Robert Eli, and Dr. Wade Huebsch. Thank you all for being in my committee and for helping me whenever I needed any help.

I would also like to thank the Air Force Office of Scientific Research, USA for supporting my graduate studies under grant number F49620-03-1-0276. The views and conclusions contained herein are my own and should not be interpreted as necessarily representing the official policies or endorsements either expressed or implied of the Air Force Office of Scientific Research, or the U.S. government. Dr. Kirk Yerkes of the Air Force Research Laboratory and his team provided the necessary feedback required to finish this project and I thank him and his entire team for all their efforts to help advance this project and my own dissertation. I also thank Dr. Samuel Lowry and Dr. Vernon Cole of CFD Research Corporation for their tremendous help in working with the CFDACE + code. I must acknowledge that without their help it would have been very difficult to get many of our results. I thank Mr. Paul Krietzer, Mr. Andy Hunnell, Ms. Shannon Glaspell, and Mr. Rageey Youssef for all their help in the project. I also thank my friends and everyone else whose name is not included above but has helped me in any possible way while I had been working on this project. 
I thank my parents and my family to help me bring so far where I was able to work with as good mentors as Dr. Donald Gray and Dr. John Kuhlman along with the other committee members. All of the above provide me with the necessary motivation to work hard and do well in life. 


\section{Chapter 1}

\section{Introduction and Literature Review}

\subsection{Introduction}

Liquid jet impingement is frequently used in many industrial applications. For example, in the electronics industry liquid jet impingement is used for cooling of electronic components. Other applications of liquid jet impingement include annealing of metals, drying of textiles and tempering of glass. As these industries advance they need more efficient mechanisms to transfer heat from heated components to a moving liquid. Liquid jet impingement is used in two different modes. These are the submerged jet and the free jet. In the submerged case, the jet (gas or liquid) impinges on a surface submerged in a pool of the same fluid. In the free jet case liquid is discharged in a gas environment (usually air). When a free liquid jet whose axis is parallel to gravity strikes a flat surface, it spreads radially and forms a thin film. This film is primarily responsible for convective heat transfer from the plate to the flowing liquid. If the surface is large enough, a circular hydraulic jump may occur. Previous studies of the submerged jet impingement are more common than those done on free liquid jet impingement. In the case of free liquid jet impingement there are two common geometries, the jet of circular cross section and the planar jet. In the present research only axi-symmetric free jets directed normal to a plane surface are studied.

Most of the previous studies of liquid jet impingement have been conducted under normal terrestrial conditions. However, there has been little study done on liquid jet 
impingement under non terrestrial conditions. These non terrestrial conditions could mean a zero or non zero gravitational body force. Body forces such as gravity or other body forces like the electric Kelvin force could significantly affect the heat transfer and flow distribution from an impinging jet. The lesser known electric Kelvin body force was used in this research to study computationally body force effects on the heat transfer and flow distribution of an impinging free liquid jet. In this research an electrode system has been designed to obtain a nearly uniform electric Kelvin body force to affect the heat transfer from an impinging liquid jet. This force is obtained in such a way that its axial component acts in a direction opposite to that of the liquid jet. That is it acts upward for a downward facing jet. In this research simulation results involving liquid jet impingement with different body forces are presented. These simulations were performed with the aid of a commercial code called CFD-ACE+. The fluid properties of the industrial coolant HFE 7000 was used for such simulations. In the CFD-ACE+ code the electric Kelvin body force was added to the momentum equation as a source term. The isothermal set of simulations included the electric Kelvin body force whereas in the non isothermal cases the gravity was varied from 0 to $1.5 \mathrm{~g}$ in the increments of $0.5 \mathrm{~g}$.

The primary method as used in CFD-ACE + to simulate free jet impingement is the VOF or volume of fluid method. This method enables the simulation of a mixture of two immiscible fluids and can include the effects of surface tension, as well as heat transfer.

In Chapter 2 the numerical scheme used to solve for flow is described. The VOF method for flow was initially verified by simulating the unheated experiments run by Labus 
(1977) on liquid jet hitting a sharp edge disk in zero gravity. These experiments were done by Labus at one of NASA's drop towers. His experiments involved Reynolds numbers not exceeding 6014 and Weber numbers not exceeding 1180. The Reynolds number is the ratio of the inertial to viscous forces whereas the Weber number is the ratio of Inertial to surface tension forces. The regimes observed by Labus are described in Chapter 2 and are also validated with computations done with the aid of the numerical code CFD-ACE+. All three regimes as observed and classified by Labus in his experiments were observed in the present simulations: surface tension, transition and inertial flow regimes.

The VOF method for simulating both flow and heat transfer was validated by simulating the experiments run by Liu and Lienhard (1989). Liu and Lienhard (1989) performed studies on liquid jet impingement on a uniformly heated surface in the presence of terrestrial gravity. It involved a subcooled liquid and did not include phase change. These results, along with the computations done with the aid of CFD-ACE+, are shown in Chapter 2. The heat flux results obtained from such simulations are in good agreement with the experimental results of Liu and Lienhard. The Boussinesq approximation has been used herein to incorporate the effects of density variation with temperature.

In Chapter 3 the experimental setup which was the basis for the present simulations is described along with the electrode design. The predicted forces and the equations solved to reach the predicted values are also discussed in Chapter 3. Chapter 4 discusses the isothermal set of simulations along with the cases where the electric Kelvin force was 
added to the momentum equation as a source term. Chapter 5 describes the non isothermal set of simulations with the gravitational force varying from 0 to $1.5 \mathrm{~g}$ in increments of $0.5 \mathrm{~g}$. The conclusions and recommendations are discussed in Chapter 6.

\subsection{Survey of Prior Studies}

As mentioned in Ma, Gan, Tian, Lie, and Gomi's (1993) paper (which included a summary of important studies in the area of impingement heat transfer) there are four primary regions of interest after a free liquid jet impinges normally on a surface.

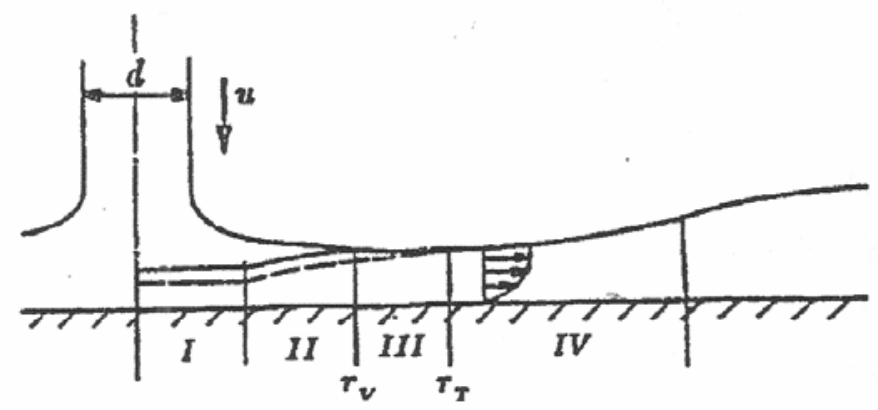

Figure 1.1 Boundary layer development for impinging circular liquid jet (Source: Ma etal., 1993).

The radius of the region 1 is less than the diameter of the liquid jet measured from the centerline of the jet and is also known as the stagnation zone. Ma et al. give the Nusselt number $(\mathrm{Nu}$, which is the non-dimensional heat flux at the wall) in terms of Prandtl number $(\operatorname{Pr})$ and the Reynolds number $(\operatorname{Re})$. For $\operatorname{Pr}=7$, Ma et al. give

$$
\mathrm{Nu}=0.7212 \varepsilon^{-0.4} \operatorname{Pr}^{0.4} \operatorname{Re}^{0.5}
$$


$2 \int^{r} \mathrm{q}_{\mathrm{o}}(\xi) \xi \mathrm{d} \xi$

where $\varepsilon=\frac{0}{\mathrm{q}_{\mathrm{o}}(\mathrm{r}) \mathrm{r}^{2}}$, and $\varepsilon=1$ for uniform heat flux condition $\quad \mathbf{1 . 2}$

$\operatorname{Pr}=\frac{\mu C_{p}}{k}$

$\xi$ has the dimensions of length

$r$ is the radial position

$\mathrm{q}_{\mathrm{o}}$ is the wall heat flux

$\mu$ is the dynamic viscosity

$\mathrm{k}$ is the thermal conductivity

$\mathrm{C}_{\mathrm{p}}$ is the specific heat

Re is the Reynolds number based on jet diameter

Region 2 as defined by Ma et al. consists of the region in which the thermal boundary layer and the viscous boundary layer both are less than the liquid layer thickness. Ma et al give the Nusselt number in this region as

$$
\mathrm{Nu}=0.668 \varepsilon^{-1 / 3} \operatorname{Pr}^{1 / 3} \operatorname{Re}^{1 / 2}(\mathrm{r} / \mathrm{d})^{-1 / 2}
$$

where $\mathrm{d}$ is the jet diameter

In region 3 as defined by Ma et al., the viscous boundary layer has reached the free surface but the thermal boundary layer is still thinner than the film thickness. The Nusselt number given by Ma et al. in this case is

$$
\mathrm{Nu}=1.5874 \varepsilon^{-1 / 3} \operatorname{Pr}^{1 / 3} \operatorname{Re}^{1 / 3}\left(\frac{25.735 \mathrm{r}^{3}}{\mathrm{~d}^{3} \operatorname{Re}}+0.8566\right)^{-2 / 3}
$$


Ma et al. defined region 4 as the region where both viscous and thermal boundary layers have reached the free surface. They gave the Nusselt number in this region as

$$
\mathrm{Nu}=\left\{\left[\frac{4 \varepsilon}{\operatorname{Pr} \operatorname{Re}}\left(\frac{\mathrm{r}}{\mathrm{d}}\right)\right]^{2}+\frac{272}{525}\left(\frac{\mathrm{R}}{\mathrm{d}}\right)\right\}^{-1}
$$

$$
\text { where } \mathrm{R}=\frac{5.147 \mathrm{r}^{2}}{\mathrm{~d} \operatorname{Re}}+0.17132\left(\frac{\mathrm{d}^{2}}{\mathrm{r}}\right)
$$

In comparing results from different authors, one of the main problems is that there is no standard length on which the Reynolds number is based. Barsanti, Faggiani, and Grassi (1989) performed studies on single phase convective heat transfer from a heated plate to an impinging liquid jet. Their experiments were similar to those done by Liu and Leinhard (1989). They used round tubes of various diameters as nozzles. Barsanti, Faggiani, and Grassi reported local Nusselt number as a function of dimensionless distance from the stagnation point. Their correlation for Nusselt number based on Prandtl number and Reynolds number seemed to fit their experimental results within $+/-15 \%$.

Womac, Aharoni, Ramdhyani, and Incropera (1990) also performed experiments on single phase liquid jet impingement cooling of heated surfaces using both free and submerged jets. They used both water and the industrial coolant FC-72 in their experiments. Their Re ranged from 200 to 50 000. As expected, Womac et al. found that the heat transfer coefficient was strongly dependent on the impingement velocity. They 
found that for low velocity flows gravity can significantly enhance the heat transfer from liquid jet impingement.

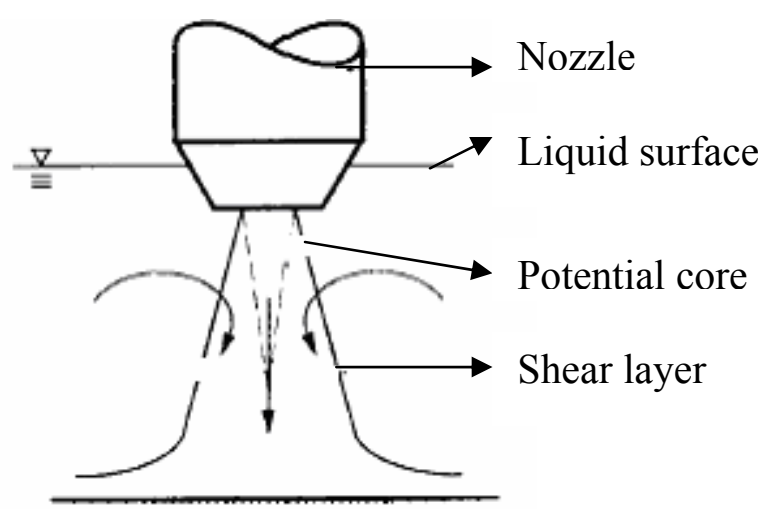

Figure 1.2 Submerged jet (Source: Womac et al (1989)).

Figure 1.2 shows the schematic of a submerged jet. The shear layer widens away from the nozzle until it displaces the potential core in which the velocity is not affected by the shear layer. Womac et al. (1990) state that the heat transfer is more sensitive to nozzle to heater separation distance in the case of submerged jets when compared to free jets. In the submerged jets and also in free jets, when the jet reaches the impingement surface it decelerates rapidly in the axial direction and accelerates in the radial direction. Womac et al (1990) also says that the submerged jet provides slightly improved in heat transfer performance when compared to free jets. Womac et al. found that average heat transfer coefficients obtained with single submerged jets are equal to or greater than those obtained with single free jets for Reynolds number greater than 4000 . They also found that the nozzle to heater spacing affects free jet heat transfer results only when this distance is large enough and the jet velocity is small enough for gravity to have an appreciable effect on the jet velocity. Ma et al. found that for horizontal jets the 
stagnation point heat transfer decreased with the increase in nozzle to plate spacing. Ma et al. attributed this to the influence of gravity since the center of the jet shifts from the horizontal axis under the influence of gravity if the nozzle to plate spacing is increased. When the jet axis is perpendicular to the impinged plate there is no radial component of velocity before the jet impinges on the plate. However, when this axis is inclined with the horizontal plate there is a non zero radial component and the axial velocity is reduced compared to the same case with perpendicular jet axis. Thus the heat transfer is also expected to be significantly different for different inclinations of jet with respect to the surface. Stevens and Webb (1991) performed experiments on the effect of inclination on heat transfer under an axi-symmetric free liquid jet. In their experiments the jet impingement axis was varied from 90 to 40 degrees from the horizontal plate. The Reynolds number was varied from 6600-52 000 in their experiments and the nozzle diameters were 4.6 and $9.3 \mathrm{~mm}$. Stevens and Webb found that the location of maximum heat transfer shifted as the inclination angle of the jet axis was changed. The inclination of the jet axis caused the fluid velocity to be higher on one side (if the jet was inclined to the left of the vertical the velocity was higher on the other side) thus causing this shift in heat transfer. Stevens and Webb also found the local Nusselt number profile to be steeper on the side with lower radial velocity and flatter on the side with higher radial velocity for the nozzle with $4.6 \mathrm{~mm}$ diameter and steeper on both sides for the larger $(9.3 \mathrm{~mm}$ diameter) nozzle. Steven and Webb concluded that for increasing inclination, the Nusselt number profiles displayed an increasing asymmetry around the point of maximum heat transfer. 


\section{Chapter 2}

\section{Numerical Scheme and Code Verification Under Variable Gravity Conditions}

\subsection{CFD-ACE+ Numerical Scheme}

Fluid motion, whether isothermal or non isothermal, is governed by conservation equations for mass, momentum and energy. The conservation equations of mass, momentum and energy are second-order nonlinear partial differential equations (PDE's). In order to obtain solutions these equations can be discretized by using various numerical schemes for each term. The resulting algebraic equations can then be solved numerically using a computer. There are many commercial Computational Fluid Dynamics (CFD) codes available which can solve complex flow problems numerically. One such code is CFD-ACE+, originally developed by CFD Research Corporation and now marketed by ESI Corporation. In CFD-ACE+ there are different types of modules which can be combined to solve complex multiphysics problems. For example the FLOW module solves for mass and momentum equations whereas the FLOW and HEAT modules together solve the mass, momentum and energy equations. The table showing the modules used in most of this research is shown in Table 2.1. 
Table 2.1 Module functions in CFD-ACE+.

\begin{tabular}{|l|l|}
\hline Module & Purpose \\
\hline FLOW & Solves continuity and momentum equations \\
\hline HEAT & Solves energy equation for non isothermal flow \\
\hline VOF & Tracks free surfaces, includes surface tension \\
\hline ELECTRIC & Solves electrostatic equations \\
\hline
\end{tabular}

The mass conservation or continuity equation requires that the time rate of change of mass in a control volume is equal to the net mass flow out of the control volume. This may be written as

$$
\frac{\partial \rho}{\partial \mathrm{t}}+\nabla \cdot(\rho \overrightarrow{\mathrm{V}})=0
$$

where $\rho$ is the density

$$
\vec{\nabla}=\frac{\partial}{\partial x} \vec{i}+\frac{\partial}{\partial y} \vec{j}+\frac{\partial}{\partial z} \vec{k}, \text { is the del operator }
$$

$\mathrm{x}, \mathrm{y}$, and $\mathrm{z}$ are the co-ordinate directions

$\mathrm{i}, \mathrm{j}$, and $\mathrm{k}$ are the unit vectors in $\mathrm{x}, \mathrm{y}$ and $\mathrm{z}$ directions respectively

$\mathrm{t}$ is the time

$$
\vec{V}=u \vec{i}+v \vec{j}+w \vec{k} \text { is the velocity vector }
$$

and $\mathrm{u}, \mathrm{v}$, and $\mathrm{w}$ are the velocity components in $\mathrm{x}, \mathrm{y}$ and $\mathrm{z}$ directions respectively

The momentum equation has components in all three directions. The $\mathrm{x}$ momentum equation as given in the CFD-ACE+ manual is

$$
\frac{\partial(\rho \mathrm{u})}{\partial \mathrm{t}}+\nabla \cdot(\rho \overrightarrow{\mathrm{V}} \mathrm{u})=\frac{\partial\left(-\mathrm{P}+\tau_{\mathrm{xx}}\right)}{\partial \mathrm{x}}+\frac{\partial \tau_{\mathrm{yx}}}{\partial \mathrm{y}}+\frac{\partial \tau_{\mathrm{zx}}}{\partial \mathrm{z}}+\mathrm{S}_{\mathrm{Mx}}
$$


where $\mathrm{S}_{\mathrm{Mx}}$ is the source term for $\mathrm{x}$ momentum and $\tau_{\mathrm{yx}}$ and $\tau_{\mathrm{zx}}$ represent the viscous stress tensor components.

Similarly the $\mathrm{y}$ and $\mathrm{z}$ momentum equations can be written as

$$
\frac{\partial(\rho \mathrm{v})}{\partial \mathrm{t}}+\nabla \cdot(\rho \mathrm{V} \mathrm{v})=\frac{\partial\left(-\mathrm{P}+\tau_{\mathrm{yy}}\right)}{\partial \mathrm{y}}+\frac{\partial \tau_{\mathrm{xy}}}{\partial x}+\frac{\partial \tau_{\mathrm{zy}}}{\partial \mathrm{z}}+\mathrm{S}_{\mathrm{My}}
$$

where $\mathrm{S}_{\mathrm{My}}$ is the source term for $\mathrm{y}$ momentum and

$$
\frac{\partial(\rho \mathrm{w})}{\partial \mathrm{t}}+\nabla \cdot(\rho \mathrm{V} \mathrm{w})=\frac{\partial\left(-\mathrm{P}+\tau_{\mathrm{zz}}\right)}{\partial \mathrm{z}}+\frac{\partial \tau_{\mathrm{xz}}}{\partial x}+\frac{\partial \tau_{\mathrm{yz}}}{\partial y}+\mathrm{S}_{\mathrm{Mz}}
$$

where $\mathrm{S}_{\mathrm{Mz}}$ is the source term for $\mathrm{z}$ momentum. For a Newtonian fluid the viscous stresses are proportional to the deformation rates of the fluid element. As shown in White (1991) using the Stokes hypothesis, the result is

$$
\begin{aligned}
& \tau_{\mathrm{xx}}=2 \mu \frac{\partial \mathrm{u}}{\partial \mathrm{x}}-\frac{2}{3} \mu(\nabla \cdot \overrightarrow{\mathrm{V}}) \\
& \tau_{\mathrm{yy}}=2 \mu \frac{\partial \mathrm{v}}{\partial \mathrm{y}}-\frac{2}{3} \mu(\nabla \cdot \overrightarrow{\mathrm{V}}) \\
& \tau_{\mathrm{zz}}=2 \mu \frac{\partial \mathrm{w}}{\partial \mathrm{z}}-\frac{2}{3} \mu(\nabla \cdot \overrightarrow{\mathrm{V}}) \\
& \tau_{\mathrm{xy}}=\tau_{\mathrm{yx}}=\mu\left(\frac{\partial \mathrm{u}}{\partial \mathrm{y}}+\frac{\partial \mathrm{v}}{\partial \mathrm{x}}\right) \\
& \tau_{\mathrm{yz}}=\tau_{\mathrm{zy}}=\mu\left(\frac{\partial \mathrm{v}}{\partial \mathrm{z}}+\frac{\partial \mathrm{w}}{\partial \mathrm{y}}\right) \\
& \tau_{\mathrm{xz}}=\tau_{\mathrm{zx}}=\mu\left(\frac{\partial \mathrm{u}}{\partial \mathrm{z}}+\frac{\partial \mathrm{w}}{\partial \mathrm{x}}\right)
\end{aligned}
$$


CFD-ACE + uses the finite volume method for the discretization of partial differential equations. The domain of interest is divided into a number of contiguous volumes, called cells which are also referred to as control volumes. Then the governing equations are integrated over every control volume. Figure 2.1 shows schematically a few cells with the cell in focus with center at $\mathrm{P}$. The geometric center of each control volume is also called its cell center. Figure 2.2 shows a two dimensional cell with cell faces and cell centers. Note that the cells with centers denoted by E, W, N, or S would be renamed as cell center $\mathrm{P}$ when that particular cell is in consideration. Most of the governing equations can be written as a generalized transport equation. This equation is given in CFD-ACE + manual and also in Patankar's text (Patankar, 1980).

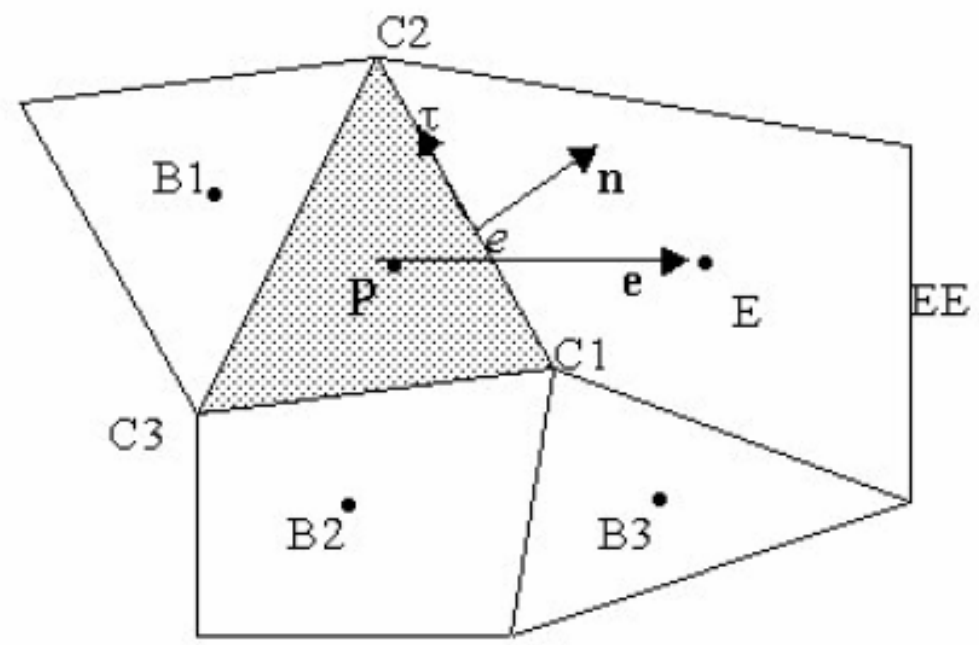

Figure 2.1 Control volume (Source: CFD-ACE+ Manual (2006)). 


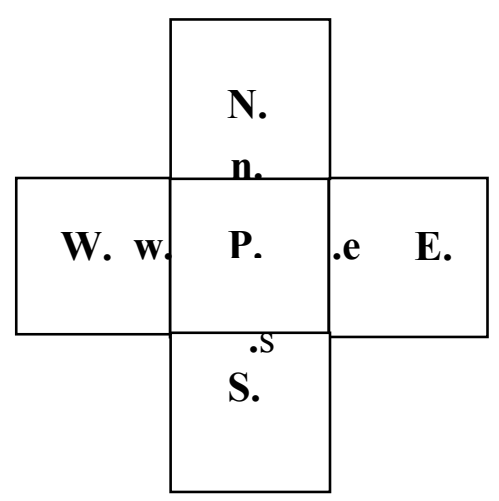

Figure 2.2 Two dimensional cell volume and adjacent nodes.

$$
\begin{aligned}
& \frac{\partial(\rho \varphi)}{\partial \mathrm{t}}+\nabla \cdot(\rho \overrightarrow{\mathrm{V}} \varphi)=\nabla \cdot(\Gamma \nabla \varphi)+\mathrm{S}_{\varphi} \\
& \text { transient convection diffusion source }
\end{aligned}
$$

where $\Gamma$ is the diffusion coefficient and $S_{\varphi}$ is a general source term

In the above equation $\varphi$ is any general scalar variable per mass, for example in case of the $\mathrm{x}$ momentum equation this will be equal to the $\mathrm{x}$ velocity. This equation when integrated over a control volume (cell volume denoted by Vol) is

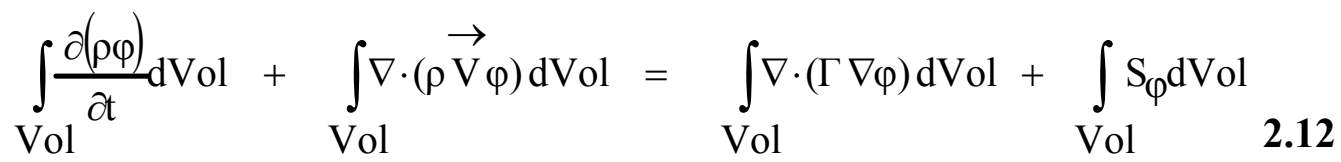

The discretization of the transient term given in the CFD-ACE+ manual is

$$
\int_{\mathrm{Vol}} \frac{\partial(\rho \varphi)}{\partial \mathrm{t}} \mathrm{dVol}=\frac{\rho \varphi \mathrm{Vol}-\rho^{\mathrm{o}} \varphi^{\mathrm{o}} \mathrm{Vol}^{\mathrm{o}}}{\Delta \mathrm{t}}
$$


where the superscript o means at the old time step whereas no superscript means the current time step value of that particular variable. The convection term is discretized in the CFD-ACE+ manual as

$$
\int_{\text {Vol }} \nabla \cdot(\rho \overrightarrow{\mathrm{V}} \varphi) \mathrm{dVol}=\oint_{\mathrm{A}} \rho \varphi \overrightarrow{\mathrm{V}} \cdot \overrightarrow{\mathrm{n}} \mathrm{dA}=\sum_{\mathrm{i}}\left(\rho_{\mathrm{i}} \varphi_{\mathrm{i}} \mathrm{V}_{\mathrm{i}}^{\mathrm{n}}\right) \mathrm{A}_{\mathrm{i}}=\sum_{\mathrm{i}} \mathrm{C}_{\mathrm{i}} \varphi_{\mathrm{i}}
$$

where subscript $i$ denotes a cell face and $V_{i}^{n}$ is the velocity normal to this cell face. There are two different ways to obtain the value of variable $\varphi_{\mathrm{i}}$ from the available cell center values. One of the popular methods used with this term is the upwind method. In this case if $\varphi_{\mathrm{i}}=\varphi_{\mathrm{e}}$ then $\varphi_{\mathrm{e}}$ will be equal to the variable value at $\mathrm{P}$ if the velocity direction is positive (to the right) and will be equal to the variable value at $\mathrm{E}$ if the velocity direction is negative. In this research upwind method was used. The diffusion term is discretized in the following way.

$$
\int_{\text {Vol }} \nabla \cdot(\Gamma \nabla \varphi) \mathrm{dVol}=\oint_{\mathrm{A}} \Gamma \nabla \varphi \cdot \overrightarrow{\mathrm{n}} \mathrm{dA}=\sum_{\mathrm{i}}\left(\Gamma_{i}\left(\frac{\partial \varphi}{\partial \mathrm{n}}\right)_{\mathrm{i}}\right) \mathrm{A}_{\mathrm{i}}
$$

Again if $\left(\frac{\partial \varphi}{\partial \mathrm{n}}\right)_{\mathrm{i}}=\left(\frac{\partial \varphi}{\partial \mathrm{n}}\right)_{\mathrm{e}}$ then the CFD-ACE+ manual gives

$\left(\frac{\partial \varphi}{\partial \mathrm{n}}\right)_{\mathrm{e}}=\frac{1}{\overrightarrow{\mathrm{n}} \cdot \overrightarrow{\mathrm{e}}}\left(\left(\frac{\partial \varphi}{\partial \mathrm{e}}\right)_{\mathrm{e}}-\overrightarrow{\mathrm{e}} \cdot \vec{\tau}\left(\frac{\partial \varphi}{\partial \tau}\right)_{\mathrm{e}}\right)$

where $\left(\frac{\partial \varphi}{\partial \mathrm{e}}\right)_{\mathrm{e}}=\frac{\varphi_{P}-\varphi_{E}}{\delta_{\mathrm{P}, \mathrm{E}}}$ 
$\left(\frac{\partial \varphi}{\partial \tau}\right)_{\mathrm{e}}=\frac{\varphi_{\mathrm{C} 2}-\varphi_{\mathrm{C} 1}}{\delta_{\mathrm{C} 2, \mathrm{C} 1}}$

where $\delta_{\mathrm{P}, \mathrm{E}}$ is the distance between $\mathrm{P}$ and $\mathrm{E}$ as shown in Figure 2.1

$\delta_{\mathrm{C} 2, \mathrm{C} 1}$ is the distance between $\mathrm{C} 1$ and $\mathrm{C} 2$.

The pressure gradient in the momentum equation is solved using the SIMPLEC algorithm (Doormal \& Raithby, 1984). In this scheme a guessed pressure field is updated and corrected until the velocity distribution satisfies the continuity equation with that pressure field.

The energy exchange between the fluid and the surroundings can be accounted for with the aid of the energy equation. The energy equation, like the mass and momentum equations, is a partial differential equation. The energy equation can be written in terms of enthalpy or temperature. The energy equation as given in the CFD-ACE+ manual is

$$
\begin{gathered}
\frac{\partial\left(\rho h_{\mathrm{o}}\right)}{\partial \mathrm{t}}+\nabla \cdot\left(\rho \mathrm{V}_{\mathrm{o}}\right)=\nabla \cdot(\mathrm{k} \nabla \Gamma)+\frac{\partial P}{\partial \mathrm{t}}+\left[\frac{\partial\left(\mathrm{u} \tau_{\mathrm{xx}}\right)}{\partial \mathrm{x}}+\frac{\partial\left(\mathrm{u} \tau_{\mathrm{yx}}\right)}{\partial \mathrm{y}}+\frac{\partial\left(\mathrm{u} \tau_{\mathrm{zx}}\right)}{\partial \mathrm{z}}\right] \\
+\left[\frac{\partial\left(\mathrm{v} \tau_{\mathrm{xy}}\right)}{\partial \mathrm{x}}+\frac{\partial\left(\mathrm{v} \tau_{\mathrm{yy}}\right)}{\partial \mathrm{y}}+\frac{\partial\left(\mathrm{v} \tau_{\mathrm{zy}}\right)}{\partial \mathrm{z}}\right]+\left[\frac{\partial\left(\mathrm{w} \tau_{\mathrm{xz}}\right)}{\partial \mathrm{x}}+\frac{\partial\left(\mathrm{w} \tau_{\mathrm{yz}}\right)}{\partial \mathrm{y}}+\frac{\partial\left(\mathrm{w} \tau_{\mathrm{zz}}\right)}{\partial \mathrm{z}}\right] \\
\mathrm{h}_{\mathrm{o}}=\mathrm{i}+\frac{\mathrm{P}}{\rho}+\frac{1}{2}\left(\mathrm{u}^{2}+\mathrm{v}^{2}+\mathrm{w}^{2}\right)=\text { total enthalpy }
\end{gathered}
$$

where $i$ is the internal energy per unit mass

$\mathrm{k}$ is the thermal conductivity

$\mathrm{p}$ is the pressure

$\mathrm{u}$ is the $\mathrm{x}$ direction velocity 
$\mathrm{v}$ is the $\mathrm{y}$ direction velocity

$\mathrm{w}$ is the $\mathrm{z}$ direction velocity

In CFD-ACE+ the activation of the HEAT module allows the activation of the energy equation. This allows the solution of both convection (involving fluid flow) and conduction (involving no fluid flow) problems.

Free surface flow is solved by a method called the Volume of Fluid or VOF method, published by Hirt and Nichols in 1981. This method can model the flow of two different fluids which are immiscible and incompressible. The two fluids are termed as the primary and secondary fluids. The secondary fluid is represented by a single scalar field variable $\mathrm{F}$ which is called the volume fraction. Volume fraction is the fraction of the computational cell which is occupied by the secondary fluid and varies from 0 to 1 . The volume fraction equal to 1 means that the cell only contains the secondary fluid. The value of $\mathrm{F}=0$ in a cell would then mean that the cell contains only the primary fluid. Any value of $\mathrm{F}$ between 0 and 1 in a cell means that it contains the fluid interface. The transport equation (2.11) for volume fraction $\mathrm{F}$ is simultaneously solved with the continuity and momentum equations.

$$
\begin{gathered}
\frac{\partial \mathrm{F}}{\partial \mathrm{t}}+\nabla \cdot(\overrightarrow{\mathrm{V}} \mathrm{F})=0 \\
\text { or } \frac{\mathrm{DF}}{\mathrm{Dt}}=0
\end{gathered}
$$


The free surface is dynamically reconstructed from the secondary liquid volume fraction F distribution in the computational grid. For surface reconstruction an upwind scheme with the piecewise linear interface construction (PLIC) method is used. In this scheme the fluid-fluid interface is allowed to take any orientation within the cell. The average value of any quantity per volume in a computational cell is given by

$$
\varphi_{\mathrm{v}_{\text {average }}}=\mathrm{F} \varphi_{\mathrm{v}_{2}}+(1-\mathrm{F}) \varphi_{\mathrm{v}_{1}}
$$

where $\varphi_{\mathrm{v}_{1}}$ is the value of that quantity for fluid 1 and $\varphi_{\mathrm{v}_{2}}$ is for fluid 2 .

For an intensive quantity per mass, the average value in a cell is obtained by

$$
\varphi_{\text {average }}=\frac{F \rho_{2} \varphi_{2}+(1-F) \rho_{1} \varphi_{1}}{\rho_{\text {average }}}
$$

The CFD-ACE+ code was validated for the present study by simulating the experiments of Labus (1977) and Liu and Lienhard (1989).

\subsection{Labus' Experiments:}

\section{Liquid Jet Impingement on Sharp Edge Disk in Zero Gravity}

Labus (1977) performed several experiments under microgravity conditions involving liquid jets hitting sharp edge disks normally. Figure 2.3 shows a schematic of the liquid jet impinging on a sharp edge disk in Labus' experiment. 


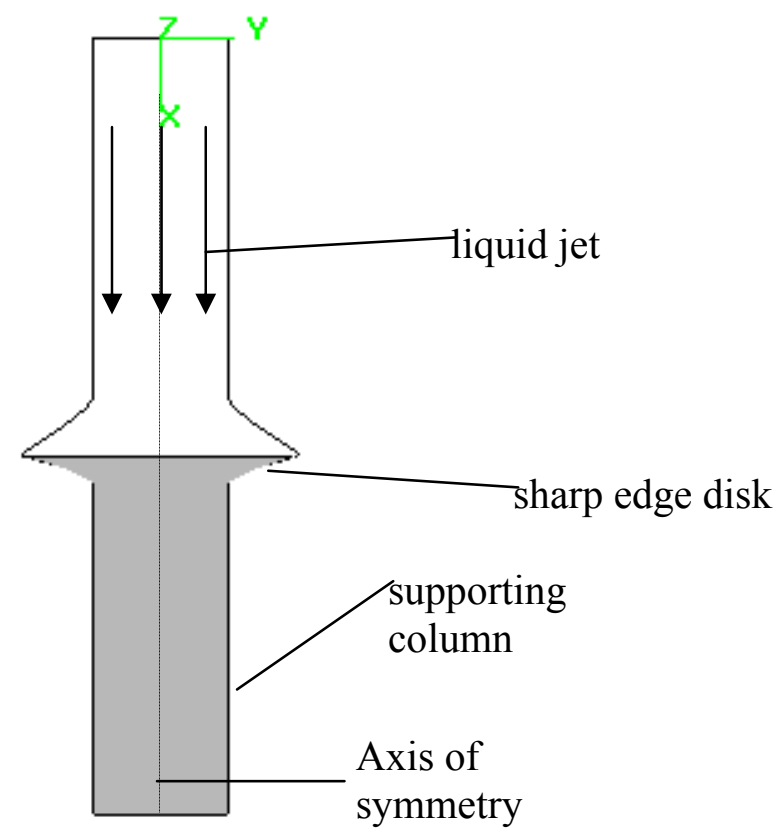

Figure 2.3 Schematic of liquid jet impinging on a disk in Labus' experiment.

Labus used two different fluids, anhydrous ethanol and trichlorotrifluroethane (Freon TF) in his experiments. Their properties at $20^{\circ} \mathrm{C}$ as given in Labus' Table 1 are specified in Table 2.2.

Table 2.2 Properties for the fluids used in the simulations and the flow velocities at inlet.

\begin{tabular}{|l|l|l|l|l|l|}
\hline $\begin{array}{l}\text { Fluid } \\
\text { Properties at 20 C }\end{array}$ & $\begin{array}{l}\text { Density } \\
\left(\mathrm{kg} / \mathrm{m}^{3}\right)\end{array}$ & $\begin{array}{l}\text { Viscosity } \\
(\mathrm{kg} / \mathrm{m} \cdot \mathrm{s})\end{array}$ & $\begin{array}{l}\text { Surface } \\
\text { tension }(\mathrm{N} / \mathrm{m})\end{array}$ & $\begin{array}{l}\mathrm{U} \\
(\mathrm{m} / \mathrm{s})\end{array}$ & $\begin{array}{l}\text { Flow } \\
\text { regime }\end{array}$ \\
\hline Anhydrous ethanol & 789 & 0.0012 & 0.0223 & 0.377 & $\begin{array}{l}\text { Surface } \\
\text { tension }\end{array}$ \\
\hline $\begin{array}{l}\text { Trichlorotrifluroethane } \\
\text { (Freon TF) }\end{array}$ & 1579 & 0.0007 & 0.0186 & 0.4275 & $\begin{array}{l}\text { Inertial } \\
\text { flow }\end{array}$ \\
\hline
\end{tabular}

Labus ran several cases with different combinations of the ratios of disk radius to jet radius, jet velocities and the type of fluid. These combinations gave a set of varying 
Weber numbers and corresponding Reynolds numbers for each of the two fluids. Weber number We as defined by Labus is

$\mathrm{We}=\frac{\rho \mathrm{V}^{2} \mathrm{R}_{\mathrm{o}}}{\sigma}$,

where $\rho$ is the fluid density;

$\mathrm{V}$ is the jet velocity,

$R_{0}$ is the jet radius

and $\sigma$ is the surface tension. The Reynolds number Re was defined by Labus to be

$\mathrm{Re}=\frac{\rho \mathrm{VR}_{\mathrm{o}}}{\mu}$,

2.26

Labus observed three different flow regimes dependent upon the initial jet Weber number for each fluid. He classified these as the surface tension, transition, and inertial flow regimes. For the radius to disk ratio of 0.33 as in the case of current simulations, the surface tension regime varied from Re of 868 and We of 12.2 to Re of 1240 and 25.1. The transition regime for the same nozzle to disk ratio varied from a Re of 3090 and We of 31.8 to Re of 1900 and We of 62 . The inertial regime varied had a Re of 4830 and We of 77.6. The surface tension regime is a low velocity flow where the surface tension force is dominating inertia in the absence of gravity. Inertial flow is a high velocity flow where surface tension has little effect on the general flow pattern. In the transition flow regime the Weber number and the Reynolds number lay between the surface tension and inertial flow regimes. The data reported by Labus included the disk radius to jet radius ratio for each fluid and the corresponding values of velocity, Reynolds number, Weber number, and the flow regime (surface tension, inertial or transition). Labus also provided a plot of the location of the free surface of the fluid for the inertial flow regime (velocity 
or fluid not specified). In this study the surface tension and the inertial flow regimes were simulated. Although the transition flow regime was also simulated it was stopped before completion because of the excessive amount of computational time it took to finish the transition flow regime simulation. The modules used to simulate Labus' experiments were FLOW and VOF only. The jet radius, fluid and the jet velocity were taken from the data reported by Labus.

\subsubsection{Surface Tension Flow Regime}

The experimental apparatus was modeled as two dimensional axi-symmetric as shown in Figure 2.4. This domain contains a nozzle inlet and a solid sharp edge disk. The remaining boundaries in the solution domain were modeled as fixed pressure outlets. This means that when solving for pressure at every time step, the input pressure at these boundaries was fixed. At the inlet a fixed velocity was specified. The contact angle at solid walls of the disk and the supporting column was specified to be a guessed value of $0^{\circ}$. The grid used was structured with 14 different zones to create the whole domain as shown in Figure 2.5. Figure 2.6 shows the zone distribution for the whole domain. The total numbers of cells in the simulations were 10182 . The grid distribution was refined near the sharp edge of the disk where the flow was expected to turn, thus improving the accuracy of the solution.

The VOF method requires at least 4 cells across the fluid's thickness to get a flow solution. In the surface tension case the grid was refined several times so as to have at least that many cells in the simulation. The VOF method would keep providing a better 
solution as the grid is refined since the surface reconstruction provides a better solution with more cells. However, further refinement in the grid would cause the computation time to increase significantly.

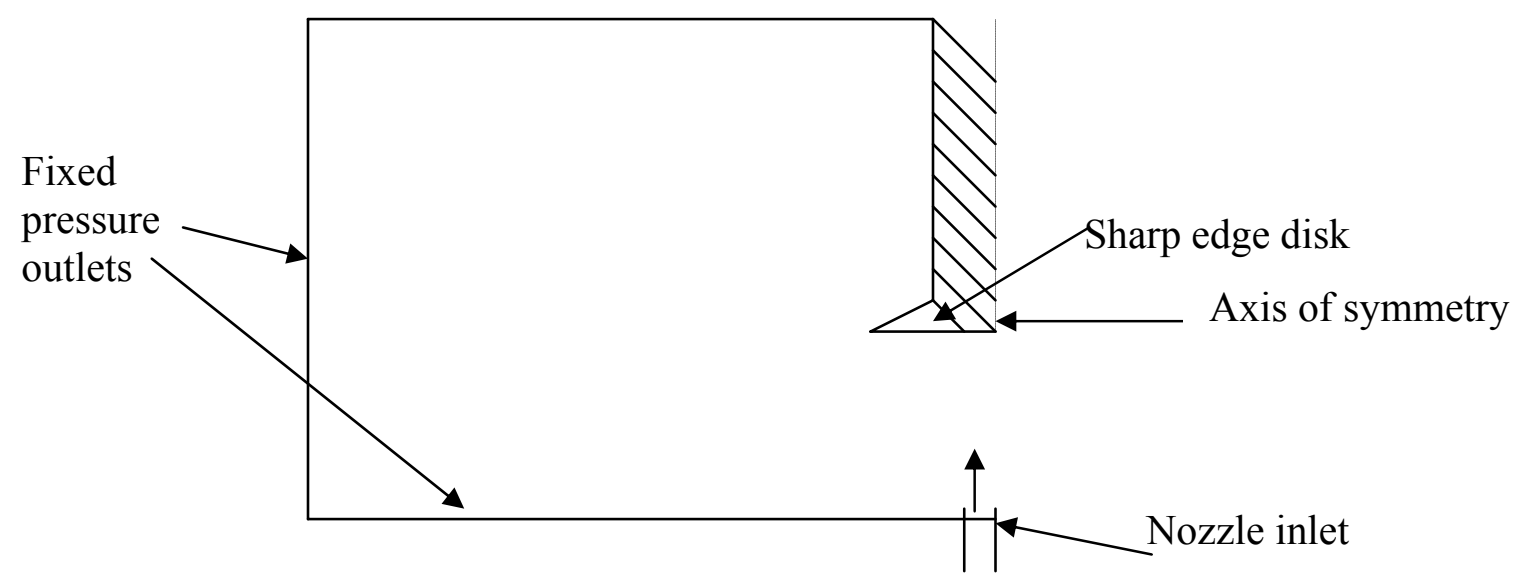

Figure 2.4 Two dimensional axi-symmetric model for Labus' surface tension cases.

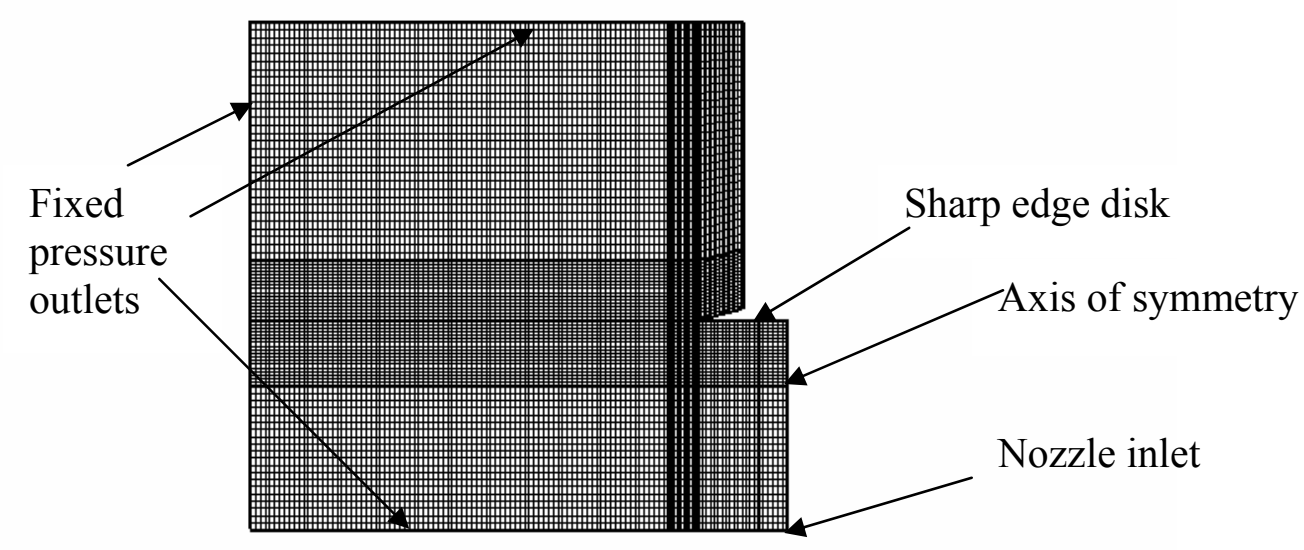

Figure 2.5 Grid distribution for Labus' surface tension case. 


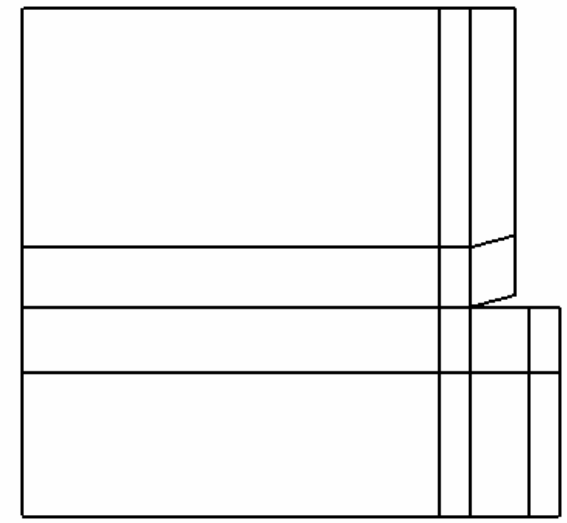

Figure 2.6 Zone distribution for the domain. Each quadrilateral represents one zone.

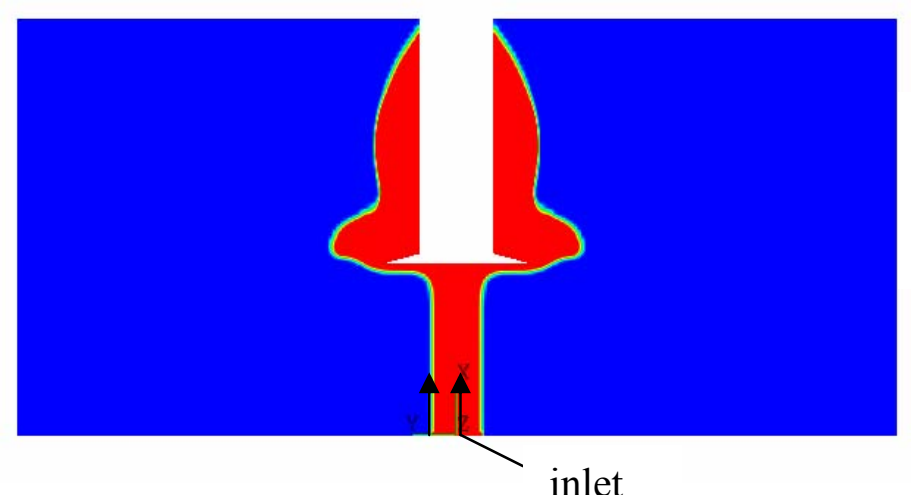

$\operatorname{Re}=1240$

$\mathrm{We}=25.1$

Time $=1.2 \mathrm{~s}$

Figure 2.7 Labus' surface tension simulated case mirrored on y axis.

(Red represents ethanol and blue represents air)

The simulation was performed for 1.2 seconds of physical time whereas the drop time was 2.2 seconds in the drop tower. Initially the domain contains motionless air. The liquid ethanol entered the solution domain at a fixed velocity of $0.377 \mathrm{~m} / \mathrm{s}$, hit the sharp edge disk normally, turned, and started moving radially as expected. Once the fluid reached the edge of the sharp edge disk it slowly started turning around the sharp edge due to surface tension. Figure 2.7 shows the simulation after 1.2 seconds. Ethanol, marked by red color, can be seen to have turned around the sharp outer disk edge and climbed the supporting column. Figure 2.8 shows the air flow after 1.2 seconds of flow. 
Figure 2.9 shows the photographs of the experimentl surface tension flow regime taken by Labus (1977) (time not specified). The basic flow was the same in the simulation when compared to the experiments. The primary difference was in the deviations from axi-symmetric flow which could only be captured in a three dimensional simulation. The three dimensional simulations were not performed in this study because of the excessive amount of computational time it takes to finish such simulations. The blobs on the liquid jet while turning around the disk were formed due to surface tension. These were also observed in the two dimensional axi-symmetric model as a single ring blob.

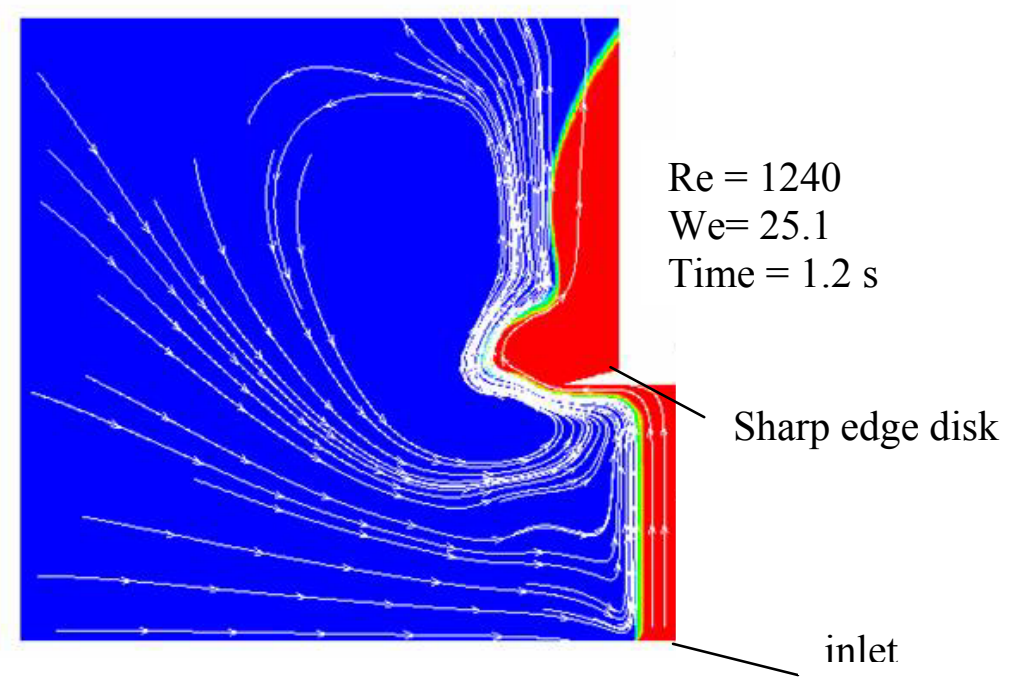

Figure 2.8 Streamlines shown for the surface tension case of Labus (1977). (Red represents ethanol and blue represent air) 


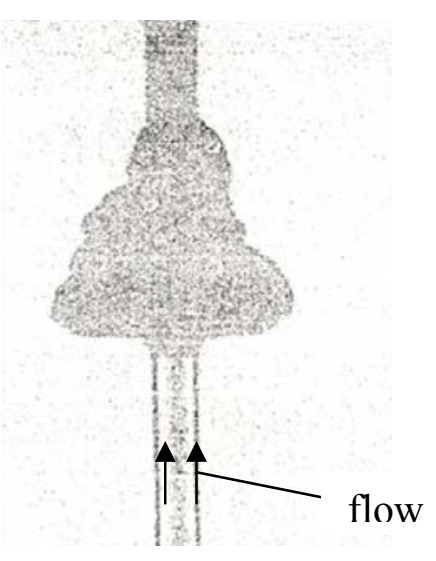

Figure 2.9 Surface tension case as photographed by Labus (1977).

The surface tension regime solution matched well with the video of Labus' physical experiments. Thus no further grid refinement was done after the solution matched "well", and the number of cells used was 10182 . The video shows the liquid jet hitting the disk and then moving around the corners to climb up the column. The same behavior was also seen in the simulation animation where the liquid, instead of moving radially, climbed up the column.

\subsubsection{Inertial Flow Regime}

Although Labus observed inertial flow in the same apparatus, it was necessary to change the computational domain by making it larger to take into account the radially outward flowing liquid. The domain for the inertial flow regime was again modeled as two dimensional axi-symmetric as shown in Figure 2.10. This model also consisted of a nozzle inlet and a solid sharp edge disk. The remaining boundaries in the solution domain were modeled as fixed pressure outlets as was done for surface tension flow regime. At 
the inlet a fixed velocity was specified. The contact angle at boundaries was again specified to be $0^{\circ}$. The grid used was structured with 9 different zones to create the whole domain.

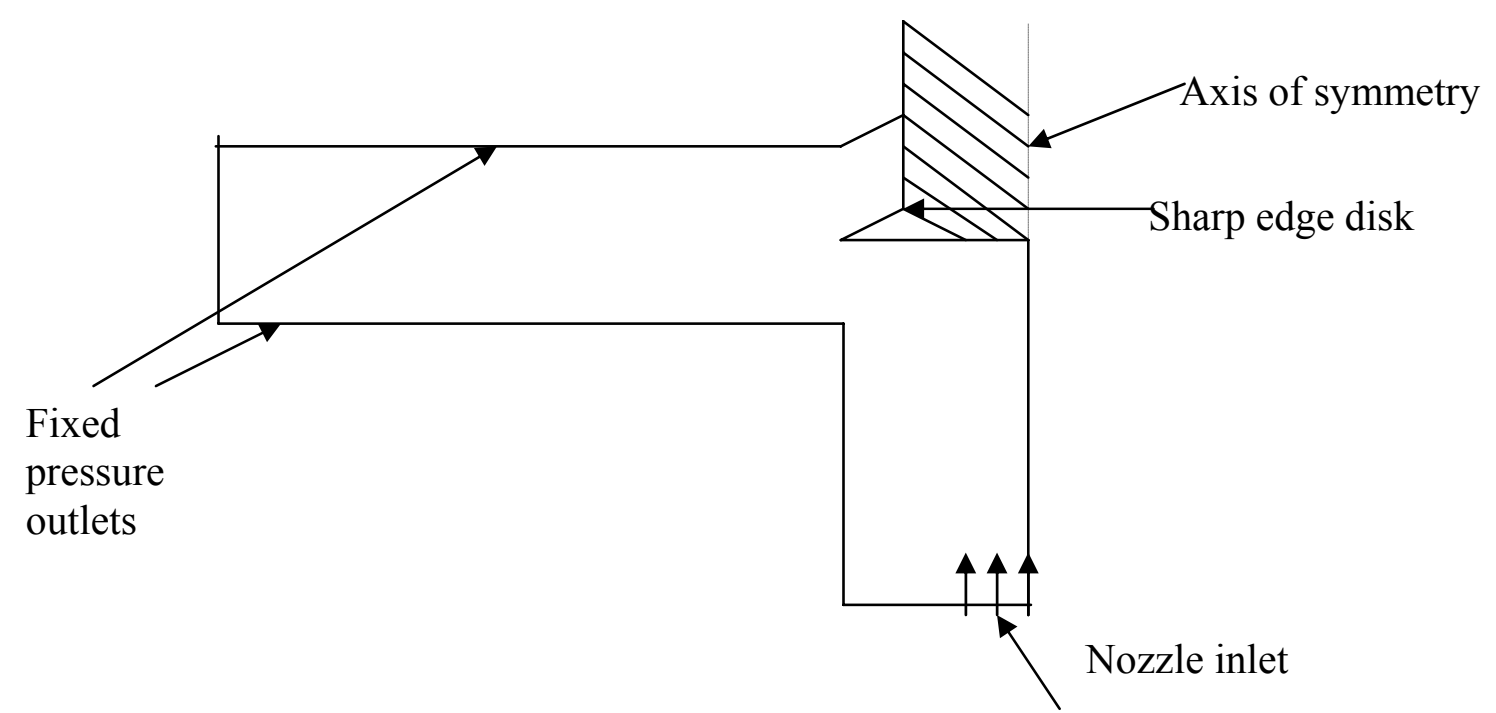

Figure 2.10 Two dimensional axi-symmetric model for Labus' inertial flow case.

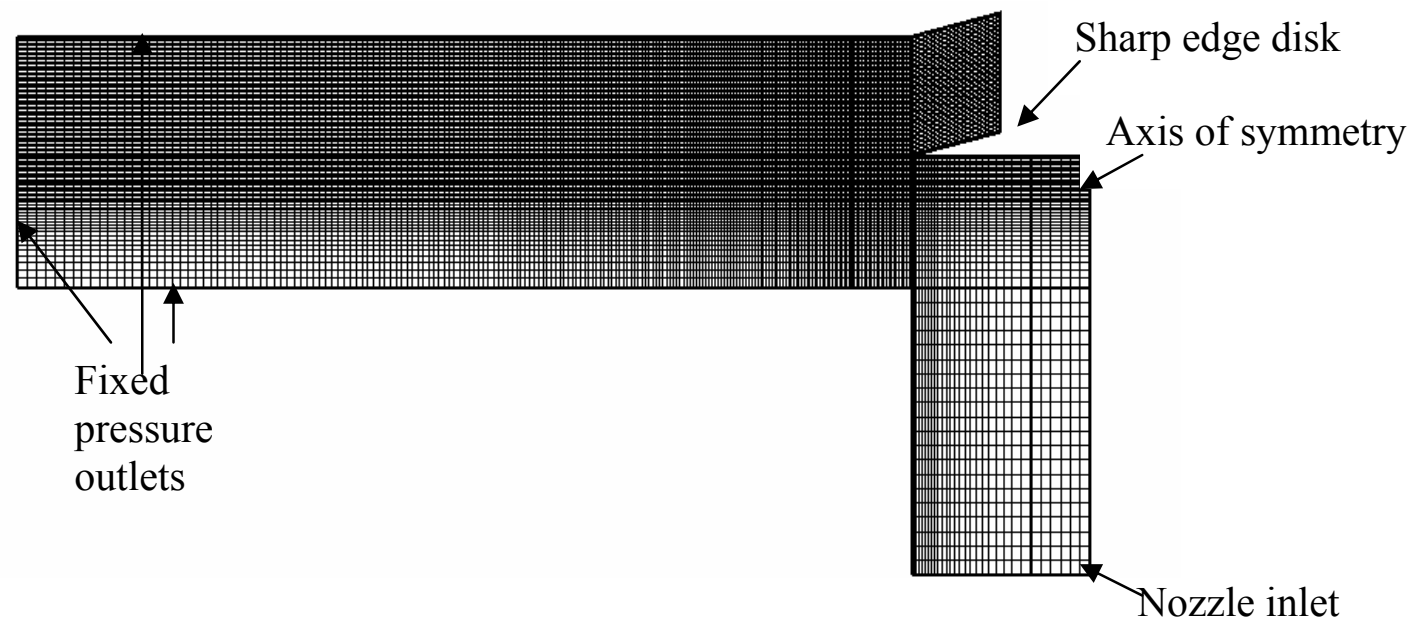

Figure 2.11 Grid for Labus' inertial flow case. 


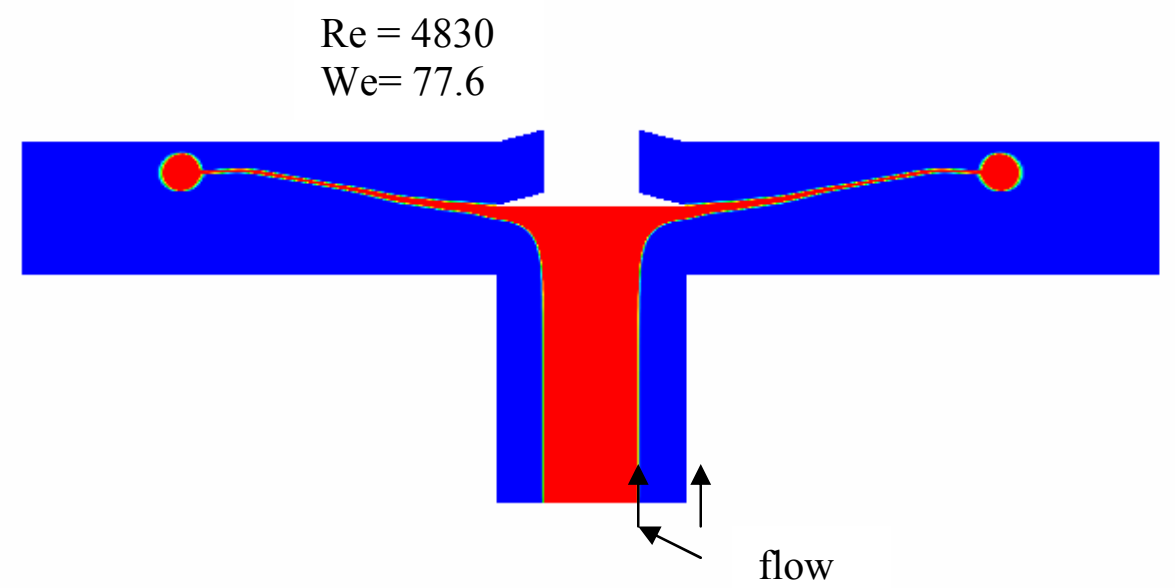

Figure: 2.12 Labus' inertial flow simulated case mirrored on y axis at $\mathrm{t}=0.3 \mathrm{~s}$. (Red represents Freon TF and blue represent air)

The total number of cells in the simulations was 22357 . The grid distribution was again refined near the sharp edge disk. This grid is shown in Figure 2.11. The simulation was performed for $0.5 \mathrm{~s}$ of flow time. Figure 2.12 represents the flow obtained at 0.3 seconds of flow. The fluid entered the solution domain at a fixed velocity of $0.43 \mathrm{~m} / \mathrm{s}$ and hit the sharp edge disk normally. After spreading radially the fluid, instead of turning around the sharp edge, kept moving out radially. The radial spread of the fluid was always positive in a sense that inertia did not allow the fluid to turn around the disk, thus preventing the radial inflow seen in the surface tension regime. The blob seen in the surface tension case was also observed in the inertial flow simulation at the leading edge of the liquid as seen in Figures 2.12 and 2.13. This blob is formed due to surface tension pulling the liquid into a cylindrical form. Due to the absence of the experimental video, it was not clear if such a blob was present around the periphery of the jet in Labus' experiment. 


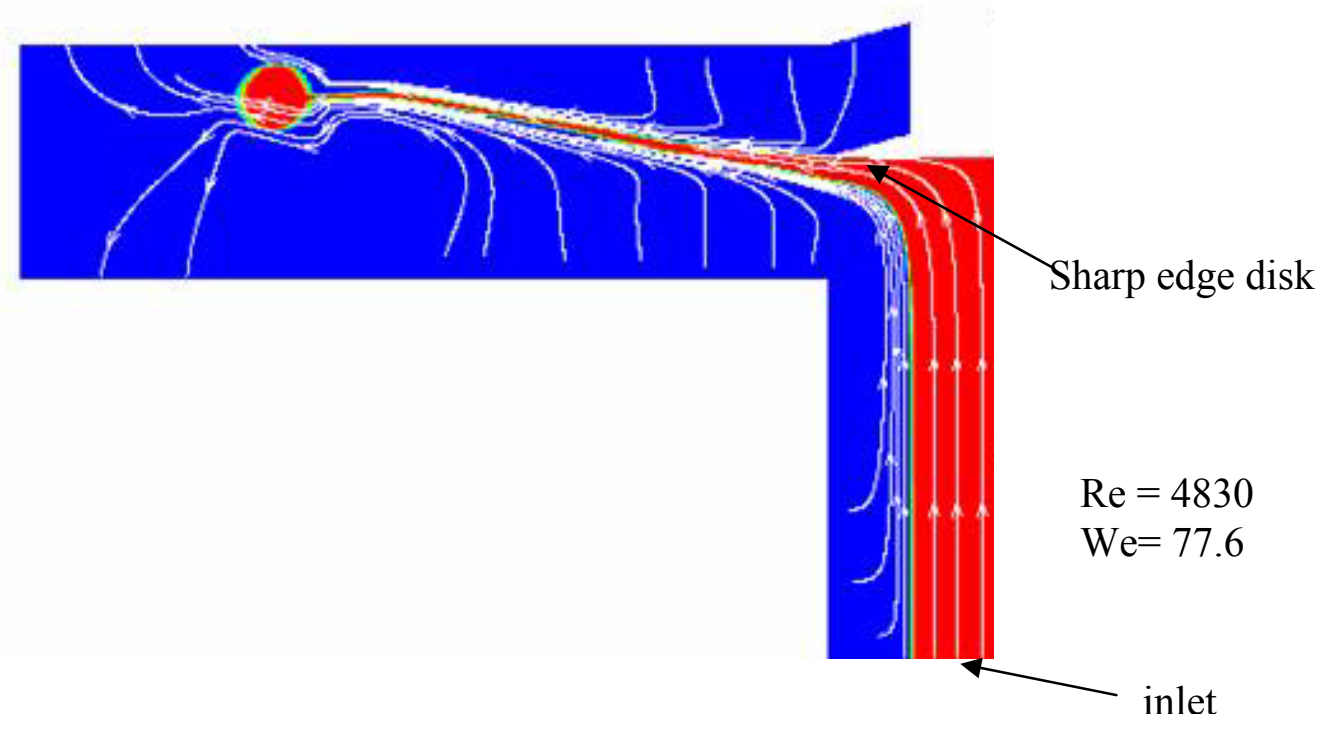

Figure 2.13 Streamlines shown for the inertial flow case run by Labus (1977) at $t=0.3 \mathrm{~s}$.

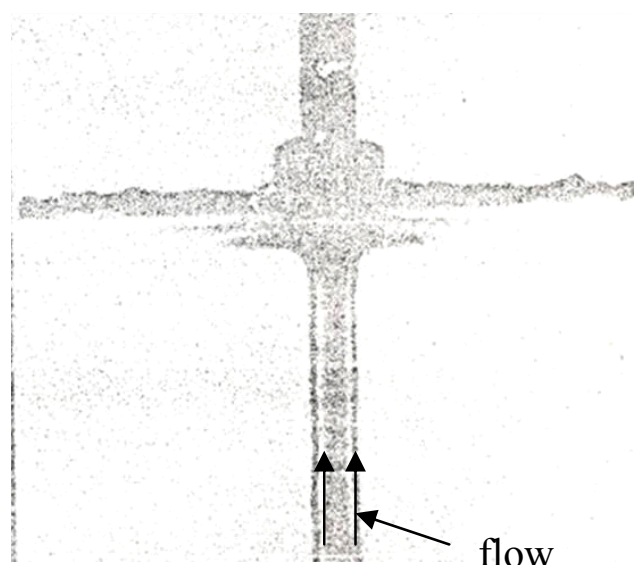

Figure 2.14 Inertial flow case as photographed by Labus (1977).

Figure 2.13 shows the air and liquid streamlines for inertial flow regime whereas Figure 2.14 shows the actual photograph taken by Labus (1977) of the same regime. There is a good agreement between the experimental picture and the simulated picture of inertial flow regime. The blob seen in the simulation could be interpreted to be the ring formed around the jet in the photograph. The plot of the top free surface obtained experimentally 
is compared to that obtained from the simulations for a nozzle to disk diameter ratio of one half in Figure 2.15. The data were reported by Labus only in the form of plots (with discrete points) and not in tabular form. These points have been re-plotted in Figure 2.15. The comparison looks good in the plot because the free surfaces from the experiments and the computations overlap each other even though the computational results are obtained by solving an axi-symmetric model and not by solving a three dimensional model. Moreover, the experimental plot does not give the Re and We numbers but only that this case belonged to the inertial flow regime. Thus it is possible, although unlikely, that there is a significant difference in the We and Re numbers between the computations and the experiments shown in Figure 2.15. The time was also not specified by Labus for the given figure. The Weber and Reynolds numbers used for both simulated surface tension and inertial flow regimes are given in Table 2.3. These numbers were the same as those used in the experiments according to Labus' Table II, even though it is not known if the simulated numbers also happen to be the exact same Re and We numbers as the video and photograph. This is the case because, like other regimes, the inertial regime had a range of Re and We numbers. The numbers of cells were chosen so that there were at least 5 cells across the fluid width. As the jet spread radially outward its radius became thinner and whenever the thickness of the sheet did not have at least 5 cells across it, the simulation was stopped and refined to increase the number of cells in that area. The simulation was then started again from the time at which it was stopped. Again no more than 22357 cells were used in the inertial flow regime simulation since a larger numbers of cells increased the solution time significantly. 


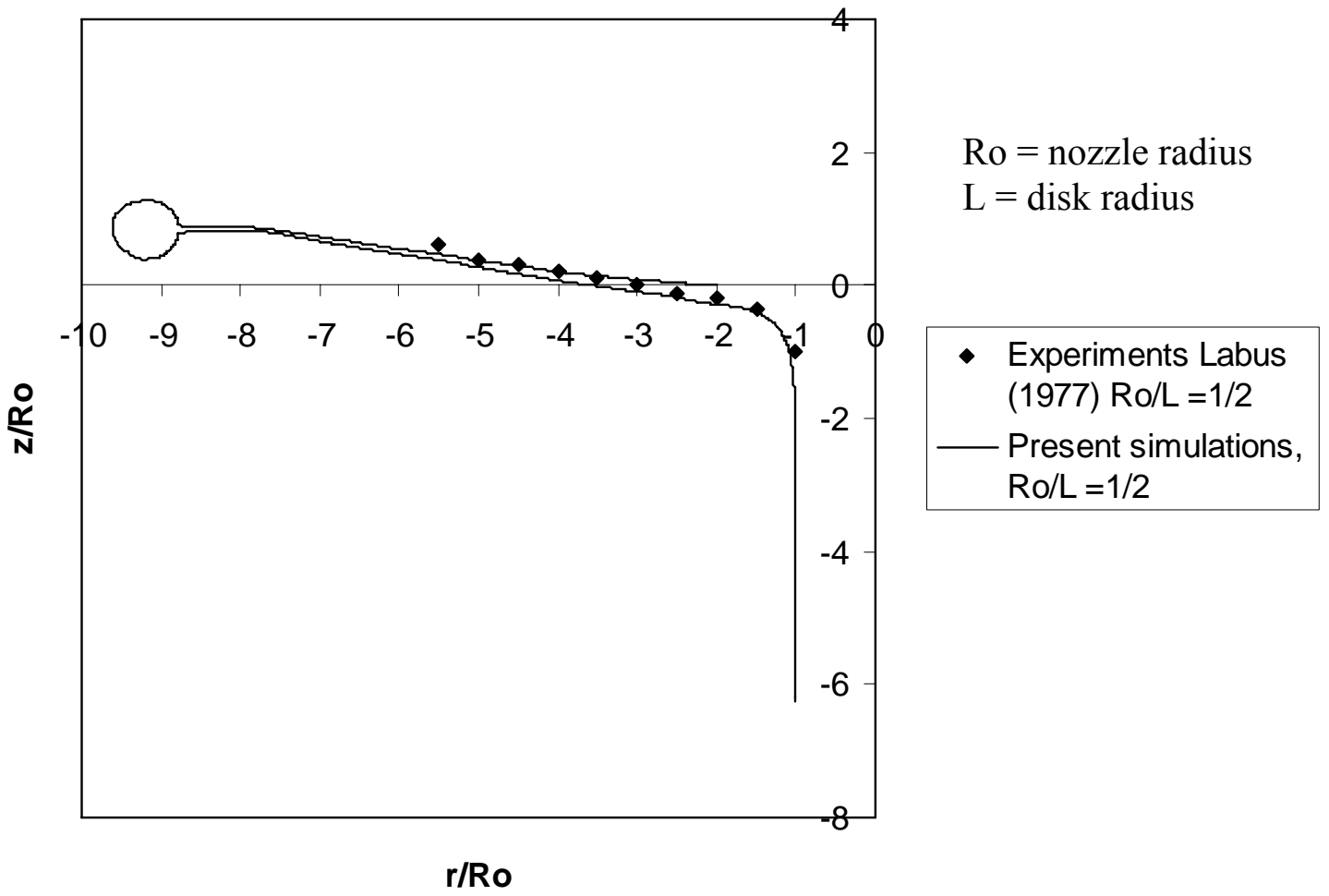

Figure 2.15 Location of the inertial flow free surface for the experiments and the simulation.

Table 2.3 Table showing the Reynolds and Weber numbers for the cases simulated.

\begin{tabular}{|l|l|l|l|}
\hline Fluid & $\begin{array}{l}\text { Reynolds } \\
\text { number }\end{array}$ & $\begin{array}{l}\text { Weber } \\
\text { number }\end{array}$ & Flow regime \\
\hline Anhydrous ethanol & 1240 & 25.1 & Surface tension \\
\hline Trichlorotrifluroethane & 4830 & 77.6 & Inertial flow \\
\hline
\end{tabular}




\subsection{Liu and Lienhard's Experiments: Liquid Jet Impingement Heat Transfer on a Uniform Heat Flux Surface.}

Liu and Lienhard (1989) investigated convective heat transfer to an impinging liquid jet. Their experiments involved a circular free jet hitting a heated surface kept at uniform heat flux. Water under atmospheric conditions (temperature of $288 \mathrm{~K}$ ) was used as the test fluid in the experiments. The water jet was ejected from an orifice facing downward towards the heated plate. Water was supplied to the orifice through a high pressure pump. The heated surface was a $0.1 \mathrm{~mm}$ thick stainless steel sheet. The dimensions of the rectangular plate were $7.8 \mathrm{~cm}$ by $15.2 \mathrm{~cm}$. The temperature distribution in the sheet was measured by twelve evenly spaced thermocouples which were attached to the underside of the heater with glue. The bottom of the heater and the thermocouples were covered with a plastic box which was filled with air. Free convection losses through the back of the heater were estimated by the authors to be negligible $\left(10 \mathrm{~W} / \mathrm{m}^{2}\right)$. The data obtained from the thermocouples along with the properties of water were used to calculate the local Nusselt numbers, $\mathrm{Nu}_{\mathrm{r}}=\frac{\mathrm{qr}}{\mathrm{k}\left(\mathrm{T}_{\mathrm{w}}-\mathrm{T}_{\mathrm{f}}\right)}$ where $\mathrm{q}$ is the heat flux, $\mathrm{r}$ is the radius of the jet, $\mathrm{k}$ is the thermal conductivity of the fluid, $\mathrm{T}_{\mathrm{w}}$ is the temperature of the wall, and $\mathrm{T}_{\mathrm{f}}$ is the bulk liquid temperature. Liu and Lienhard varied the heat flux and jet diameter to obtain different sets of data.

The computational model was developed as a two dimensional axi-symmetric case where the smaller dimension of the rectangular plate was used as the diameter $(7.8 \mathrm{~cm})$. Since the distance between the orifice and the plate was not clearly defined in the paper, this distance was fixed as five times the diameter of the jet in the present simulations. For 
relatively small ratios of $z / d$ (distance between the nozzle and the plate to the jet diameter) and large velocities this distance does not influence the solution significantly especially in the inertial flow regime. The axis of the jet was specified to be the axis of symmetry. The domain used for the simulation is shown in Figure 2.16. The heat flux from the experiments was specified to be $12378 \mathrm{~W} / \mathrm{m}^{2}$. A unique modeling technique was used to accelerate the solution to a steady state since the conventional method was excessively time consuming. First a fine grid was implemented near the heated plate and a coarse grid everywhere else. This grid system consisted of twelve zones and 2580 cells. The coarse grid system used as part of the initial solution is shown in Figure 2.17. A steady state solution for flow and temperature was obtained for this grid.

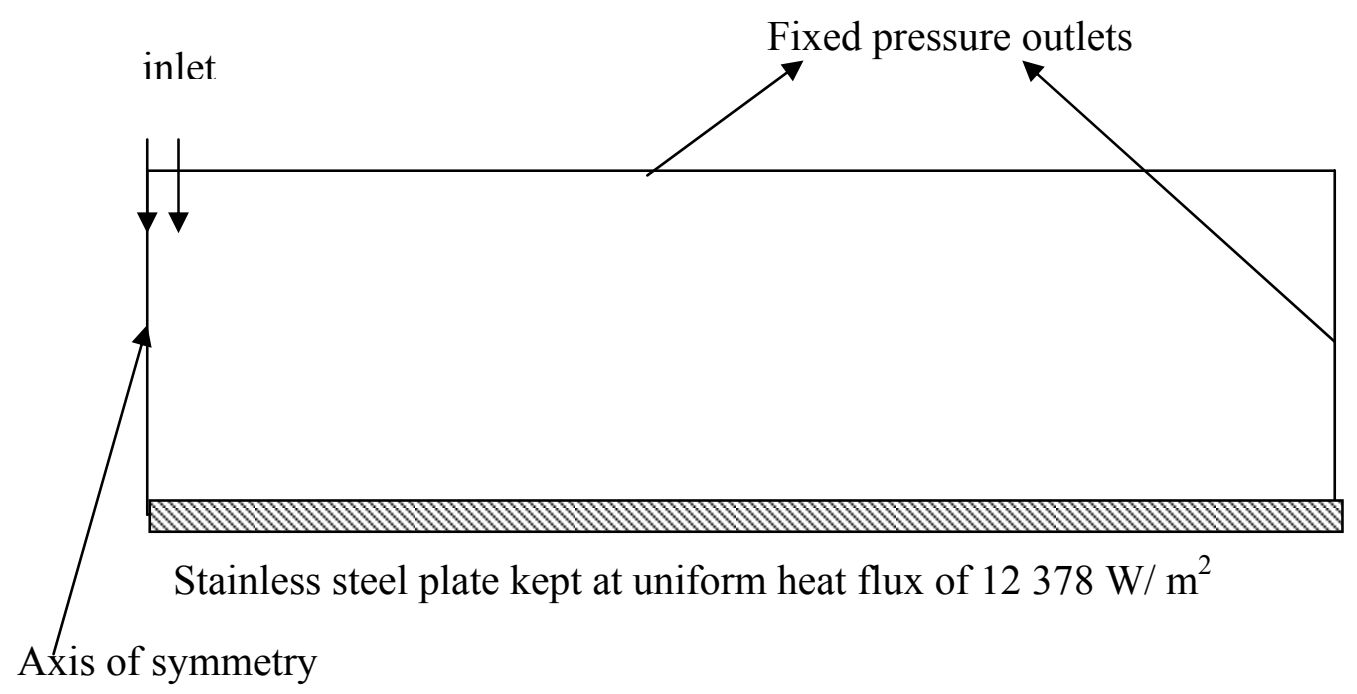

Figure 2.16 2D axi-symmetric model for liquid jet impingement heat transfer. 


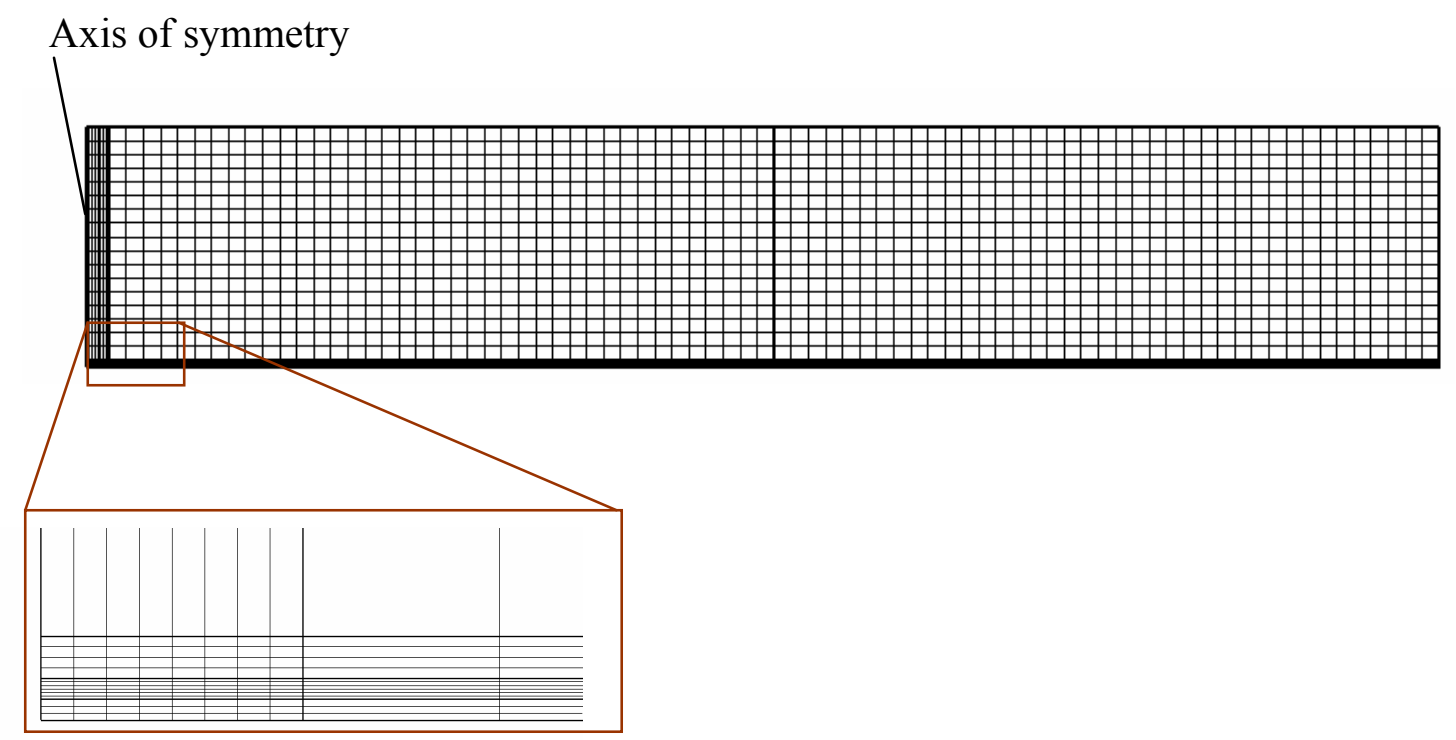

Figure 2.17 Coarse grid used to obtain the initial steady state solution for temperature.

The grid with 2580 cells was used to obtain the steady temperature distribution. A second grid with 33048 cells was used to obtain only the steady state flow distribution. In this case the HEAT module was not activated and thus a steady state flow solution was obtained more quickly than it would have been obtained with the heat transfer module on. The temperature distribution from the coarse grid steady state solution and the flow distribution from the fine grid steady state solution were mapped onto a single fine grid file to obtain an initial configuration for the final calculation. The total numbers of cells in this file was also 33 048, which was more than 12 times the number of cells in the grid system from which the temperature distribution was obtained. However, the grid on which flow was initialized also had 33048 cells. The fine grid system used for the final solution of flow and temperature is shown in Figure 2.18. The properties of water used in the simulations are shown in Table 2.4. The steady state free surface configuration from this grid system and the streamlines are shown in Figure 2.19. The computed data and the experimental data are compared in Figure 2.20. The percentage discrepancy between these data sets is shown in Table 2.5 . The error at $r / d=3.3$ is $13.6 \%$, slightly above than 
the reported experimental uncertainty of $13 \%$. At the larger radi, the discrepancy is well within the experimental error. The heat transfer solution matched well outside the jet radius for the fine grid $(33$ 048) and coarse grids $(2580$ cells). However, there was a significant difference within the jet radius between the coarse and the fine grid. This is most likely due to the thinness of the thermal boundary layer in the liquid jet impingement area. As the grid is refined in this region, the temperature solution is likely to change. As stated before the grid was not refined further to avoid spending a lot of computational time since the current solution was already close to the experiments. 


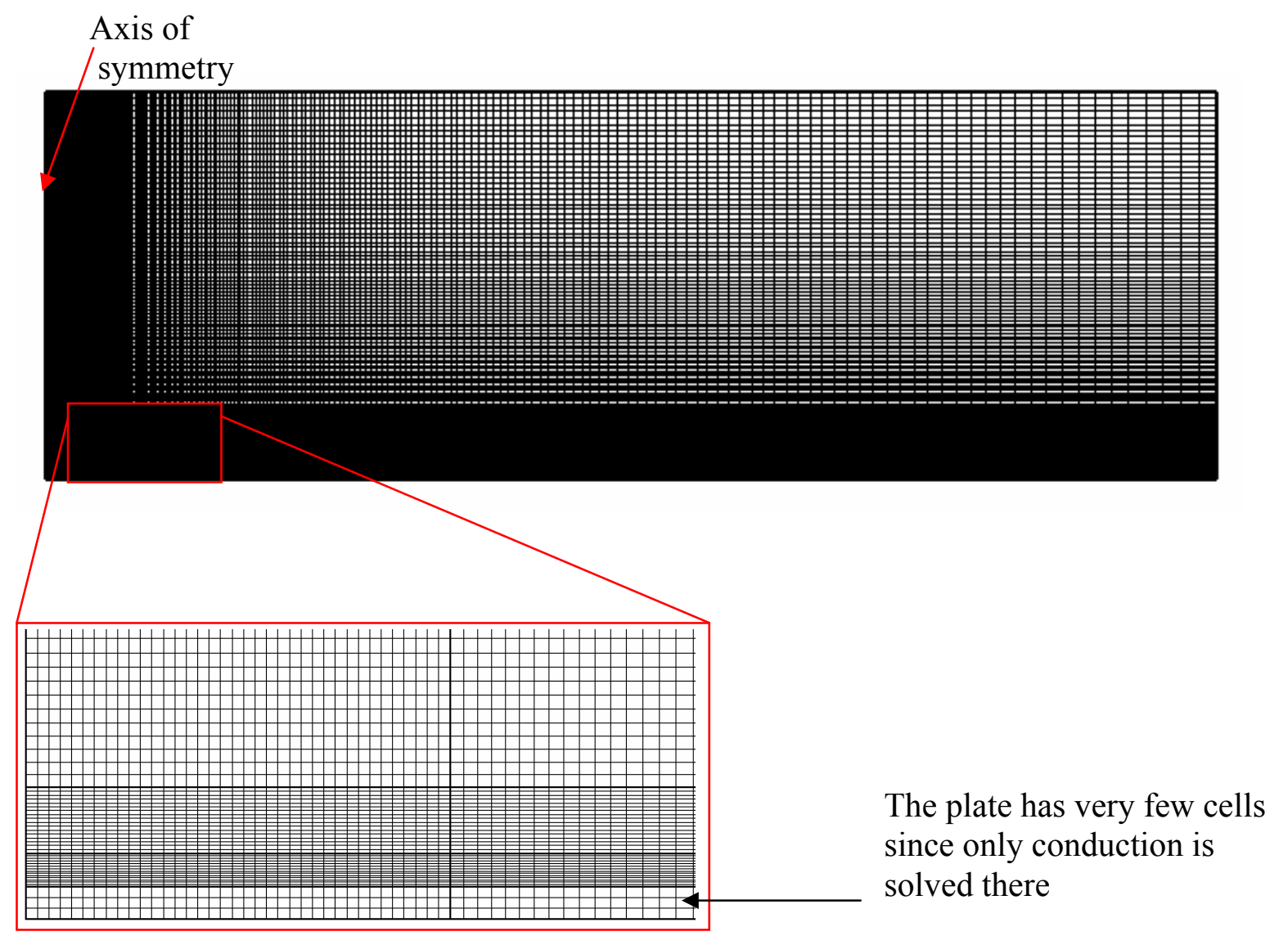

Figure 2.18 Fine grid system used to obtain the final steady state solution.

inlet

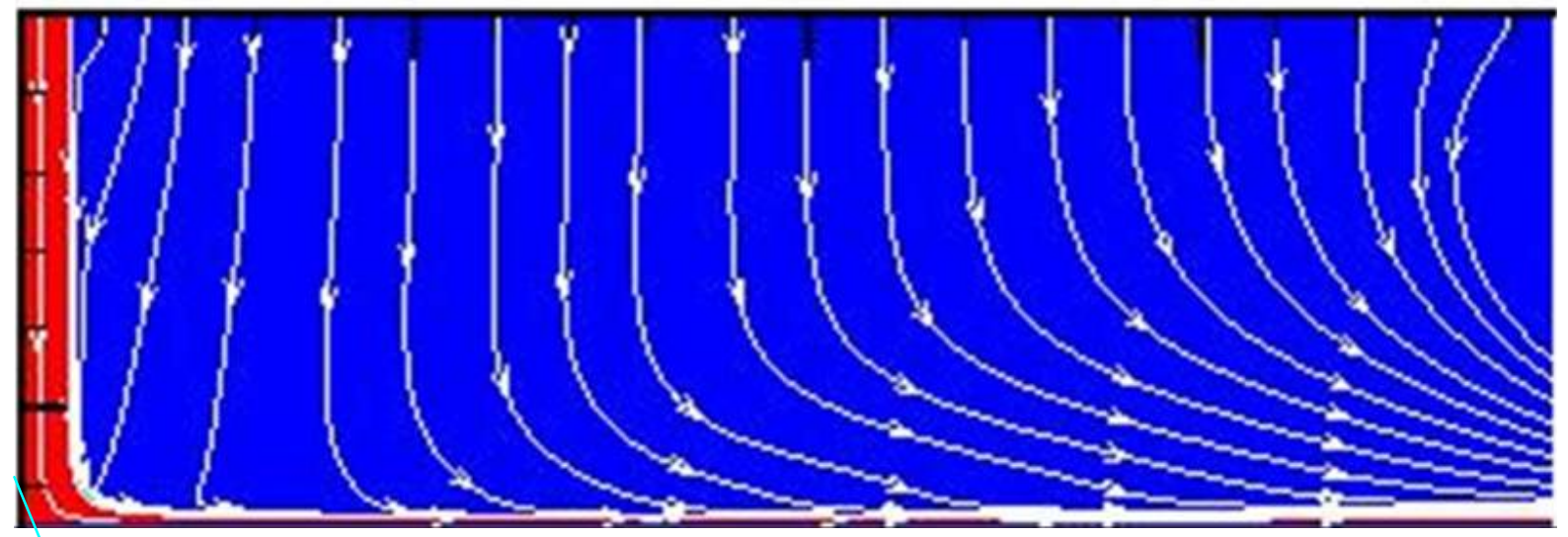

Axis of

symmetry

Figure 2.19 Streamlines for liquid jet impingement on a uniformly heated surface at steady state conditions (Red represents water, blue represents air). 
Table 2.4 Properties used for the simulations of Liu and Lienhard (1989).

\begin{tabular}{|l|l|l|l|l|l|l|}
\hline $\begin{array}{l}\text { Density } \\
\left(\mathrm{kg} / \mathrm{m}^{3}\right) \\
(\mathrm{T} \text { is the } \\
\text { temperature in } \\
\text { Kelvin })\end{array}$ & $\begin{array}{l}\text { Kinematic } \\
\text { viscosity } \\
\left(\mathrm{m}^{2} / \mathrm{s}\right)\end{array}$ & $\begin{array}{l}\text { Surface } \\
\text { tension } \\
(\mathrm{N} / \mathrm{m})\end{array}$ & $\begin{array}{l}\text { Coefficient } \\
\text { of thermal } \\
\text { expansion } \\
(1 / \mathrm{K})\end{array}$ & $\begin{array}{l}\text { Velocity } \\
(\mathrm{m} / \mathrm{s})\end{array}$ & $\begin{array}{l}\text { Heat flux } \\
\left(\mathrm{W} / \mathrm{m}^{2}\right)\end{array}$ & $\begin{array}{l}\text { Jet } \\
\text { diameter } \\
(\mathrm{mm})\end{array}$ \\
\hline $1206.68-0.6957^{*} \mathrm{~T}$ & $1 \mathrm{e}-6$ & 0.0725 & 0.0004 & 24.2 & 12378 & 2.58 \\
\hline
\end{tabular}

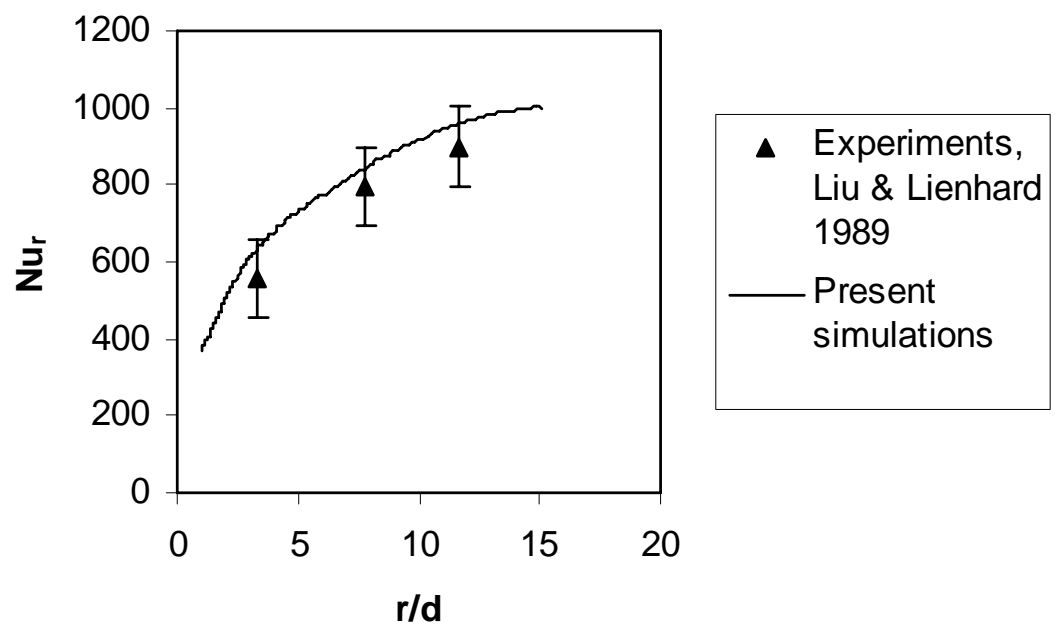

Figure 2.20 Comparison of local Nusselt numbers based on jet diameter obtained experimentally to those obtained from simulations.

Table 2.5 Computed and experimental data for $\mathrm{Nu}_{\mathrm{r}}$.

\begin{tabular}{|r|r|r|r|}
\hline \multicolumn{1}{r|}{$r / \mathrm{d}$} & $\begin{array}{l}\mathrm{Nu}_{\mathrm{r}} \\
\text { experiments }\end{array}$ & $\begin{array}{l}\mathrm{Nu}_{\mathrm{r}} \\
\text { computed }\end{array}$ & $\begin{array}{l}\text { Percent } \\
\text { discrepancy }\end{array}$ \\
\hline 3.3 & 555 & 631 & 13.6 \\
\hline 7.75 & 795 & 842 & 5.9 \\
\hline 11.6 & 900 & 955 & 6 \\
\hline
\end{tabular}


Based on the good agreement between the simulations and the experiments of Labus and Liu and Lienhard, it was concluded that the CFD-ACE+ code could be used to model jet impingement flows. 


\section{Chapter 3}

\section{Experimental Setup and Electrode Design}

\subsection{Introduction and the Experimental Setup}

This chapter reports on the design of an electrode system to create an electrical body force distribution intended to affect convective heat transfer in a specific experimental apparatus. The body force in this case was the electric Kelvin force. In this research it was hypothesized that the electric Kelvin force could potentially be used to affect the heat transfer of a liquid jet impinging on a heated surface. This electric force could be created with an appropriate electrode design, and its effects could be tested computationally and experimentally. This force can act as substitute for creating low gravity conditions on Earth. Currently there are two main methods to create such conditions on or near the surface of the earth. One method utilizes the concept of drop towers which create microgravity conditions only for an order of few seconds. Another method uses the concept of airplane following parabolic paths to create microgravity conditions for about twenty seconds each time. The advantage of the first method is that it requires less maintenance than the second method but also has the disadvantage of creating the desired zero gravity conditions for only less than 3 seconds. The disadvantage of using the second method is that it can be very expensive and time consuming and it needs high maintenance. Kelvin force can be a good substitute for creating such conditions with low cost, low maintenance and for longer durations. 
The test apparatus, which was to be used in a related project, consisted of several components. This project was similar to that of Yerkes et al (2004) where Yerkes etal studied the effects of reduced gravity on spray heat transfer. More details of these projects are given in Glaspell (06) and Krietzer (06). These include nozzle, cap, pedestal, sump, and electric heater, all enclosed inside a sealed chamber. Figure 3.1 shows the apparatus. The fluid flow from the nozzle impinged normally on the pedestal. The top surface of the pedestal was heated with an electric heater.

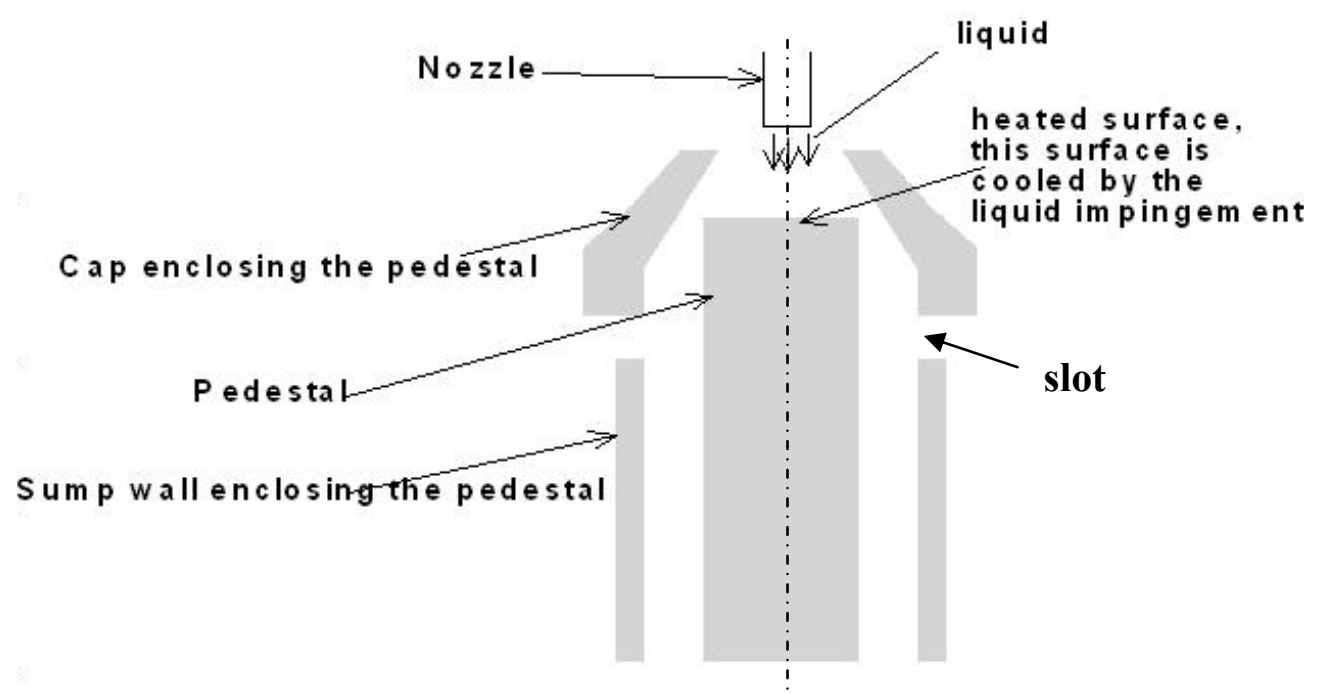

Figure 3.1. Schematic of apparatus (axi-symmetric geometry).

The cap confines the flow and thus aids in the flow management. The slots in the sump provided a way for excess fluid to be diverted back into the flow loop. The flow loop and the experimental apparatus have been described in detail in Hunnell's master's thesis (2005). The nozzle, cap, pedestal, and sump are non conducting dielectrics whereas the heater is a metallic conductor. 


\subsection{Electric Kelvin Force}

The electric forces per unit volume $\overrightarrow{\mathrm{f}}$ can be written as

$$
\overrightarrow{\mathrm{f}}=\rho_{\mathrm{f}} \overrightarrow{\mathrm{E}}+\frac{\varepsilon_{\mathrm{o}}}{2} \chi \nabla \mathrm{E}^{2}-\nabla\left(\frac{\varepsilon_{\mathrm{o}}}{2} \mathrm{E}^{2} \frac{\mathrm{d}(\chi v)}{\mathrm{d} v}\right)
$$

where $\varepsilon_{\mathrm{O}}=$ permittivity of free space $=8.85 \times 10^{-12} \mathrm{C}^{2} / \mathrm{N} \cdot \mathrm{m}^{2}$

$\chi=$ electric susceptibility (dimensionless)

$\mathrm{E}=$ electric field $\mathrm{N} / \mathrm{C}$

$\rho_{\mathrm{f}}=$ charge density $\mathrm{C} / \mathrm{m}^{3}$

$v=$ specific volume $\mathrm{m}^{3} / \mathrm{kg}$

The first term on the right hand side, the Coulomb force, is zero in the absence of free charge. The third term on the right side is zero when the electric susceptibility is linearly proportional to the density as is usually the case. The second term on the right hand side is termed the electric Kelvin force.

Thus this force can be controlled by two variables, the electric field and the electric susceptibility (which is always positive). The gradient of $E^{2}$ can be controlled by the positioning of electrodes, the shape of the electrodes and the amount of voltage applied to the electrodes. The gradient of $E^{2}$ is independent of the polarity of the electrodes. The electric susceptibility is fluid dependent and varies only with different fluids and fluid distributions in isothermal cases. The fluid used was HFE 7000. This industrial coolant was chosen since it has a high electric susceptibility and at the same time it is electrically insulating. The properties of HFE 7000 obtained from www. $3 \mathrm{~m}$.com are shown in Table 3.1. It is important to realize that the presence of the liquid alters the electric field because of the difference between its permittivity and that of a gas or vacuum. In the 
absence of a free charge the normal component of the electric displacement $\vec{D}$ is continuous across a boundary. Since $\vec{D}=\varepsilon \vec{E}$, in the absence of a free charge the electric field on the side of the boundary which has lower permittivity will be higher. Therefore the spatial distribution of the liquid affects the spatial distribution of the electric field and hence that of the electric Kelvin force.

Table 3.1 Properties of HFE 7000 at standard atmospheric conditions (Source: $3 \mathrm{~m}$ ).

\begin{tabular}{|l|l|}
\hline Density $\left(\mathrm{kg} / \mathrm{m}^{3}\right)$ & 1400 \\
\hline Dynamic viscosity $(\mathrm{kg} / \mathrm{m} \cdot \mathrm{s})$ & $4.48 \times 10^{-4}$ \\
\hline Surface tension $(\mathrm{N} / \mathrm{m})$ & 0.0125 \\
\hline Electric susceptibility & 6.4 \\
\hline Resistivity $(\mathrm{Ohm} \cdot \mathrm{cm})$ & $10^{8}$ \\
\hline Specific heat $(\mathrm{J} / \mathrm{kg} \cdot \mathrm{k})$ & 1300 \\
\hline Thermal conductivity $(\mathrm{W} / \mathrm{m} \cdot \mathrm{k})$ & 0.075 \\
\hline Pr & 7.92 \\
\hline
\end{tabular}

\subsection{Electric Field Calculations and Electrode Design}

The electric field was calculated using CFD-ACE+, which solves the electrostatic equations when the ELECTRIC module is activated. The total number of cells was 55 711. There were a total number of 87 zones in the domain. The electrostatic equation in the presence of dielectrics can be written as

$$
\nabla \cdot \vec{D}=\rho_{f}
$$

where $\vec{D}$ is the electric displacement and $\rho_{\mathrm{f}}$ is the amount of free charge available per unit volume. In the absence of free charge equation 3.2 is reduced to

$$
\nabla \cdot \overrightarrow{\mathrm{D}}=0
$$


By definition

$$
\overrightarrow{\mathrm{D}}=\varepsilon \overrightarrow{\mathrm{E}}
$$

where $\varepsilon=\varepsilon_{0}(1+\chi)$

$$
\overrightarrow{\mathrm{E}}=-\vec{\nabla} \Phi \text { (true in the presence of stationary charges only) }
$$

where $\Phi$ is the electric potential.

Equation 3.3 is reduced to $\vec{\nabla} \cdot\left(-\varepsilon_{0}(1+\chi) \vec{\nabla} \Phi\right)=0$, and if the susceptibility is constant in a given region then

$$
\nabla^{2} \Phi=0
$$

Thus the Laplace equation (3.7) determines the distribution of electric potential in regions of constant permittivity. In CFD-ACE + the electrostatic equation is solved in the presence of metals and dielectrics. Metals are assumed to be at constant potential (voltage) so that the electrostatic equations are not solved inside the metal. However, in case of dielectrics, equation 3.7 is solved inside the dielectric region. The appropriate jump conditions are enforced between dielectrics of differing permittivity. Electric displacement is continuous across the surfaces. The electric Kelvin force was applied only in the regions where the fluid fraction was greater than 0.5 or where the cell was more than half filled with the fluid. The permittivity of HFE 7000 was used with a value equal to 6.4 and this value was used for all the cells where the electric Kelvin force was applied. The number of cells where the fluid occupied less than half the cell volume is very small and thus would not affect the final solution significantly.

Since the electric Kelvin force is proportional to the gradient of $E^{2}$, as long as a varying electric field can be obtained, a Kelvin force will be present. In this research it was 
desired to have a Kelvin force acting away from the heated surface on which the impingement took place. The Kelvin force acing away from the surface could reduce the gravitational force in the moving liquid layer away from the surface and thus could predict the effect of lowering gravity on heat transfer to a moving liquid. The electrode system was designed to provide as uniform as possible an electric Kelvin force normal to the surface on which jet impingement is taking place. Therefore with the help of CFD$\mathrm{ACE}+$ and with the knowledge that electric field lines needed to get denser when moving away from the heated surface, several electrode configurations were tested to get maximum uniformity in the gradient of $E^{2}$ lines along the heater surface. The final system of electrodes consisted of three different electrodes. As shown in Figure 3.2, one electrode was attached to the nozzle, another to the cap surrounding the impingement surface, and the third was attached to the pedestal.

The electrode attached to the cap forced the electric field lines to turn towards it just above the impingement surface thus creating a significant gradient in $E^{2}$. Since the experimental geometry was axi-symmetric, the electrode design was also axi-symmetric, although it might be possible to envision an electrode which is not axi-symmetric but could provide a somewhat uniform electric Kelvin force. Figure 3.2 shows that the heater is sandwiched about $2 \mathrm{~mm}$ below the top surface of the pedestal. Since the heater is a metal it is an equipotential surface at 12 volts, so the field lines will be perpendicular to its surface. Thus if the heater is on the top surface of the pedestal the chances of getting a uniform Kelvin force just next to it are almost nil. Therefore the heater was moved from its initial location at the top surface of the pedestal. Various set of electrodes were used 
so that the electric field points radially with the distance away from the electrode. It was found after testing several arrangements that as the electric field lines get denser near the nozzle electrode the gradient of $\mathrm{E}^{2}$ increased near the surface in a direction away from the surface. Therefore more electrode arrangements were tested to get an "optimum value" of the gradient of $E^{2}$. This was done through trial and run procedure and the current configurations was achieved once it was found that it does provide an "optimum value". However, even after repeated testing different arrangements it can not be said with certainty that this is an "optimal value" although this provided a range of forces which could affect the flow and heat transfer. 


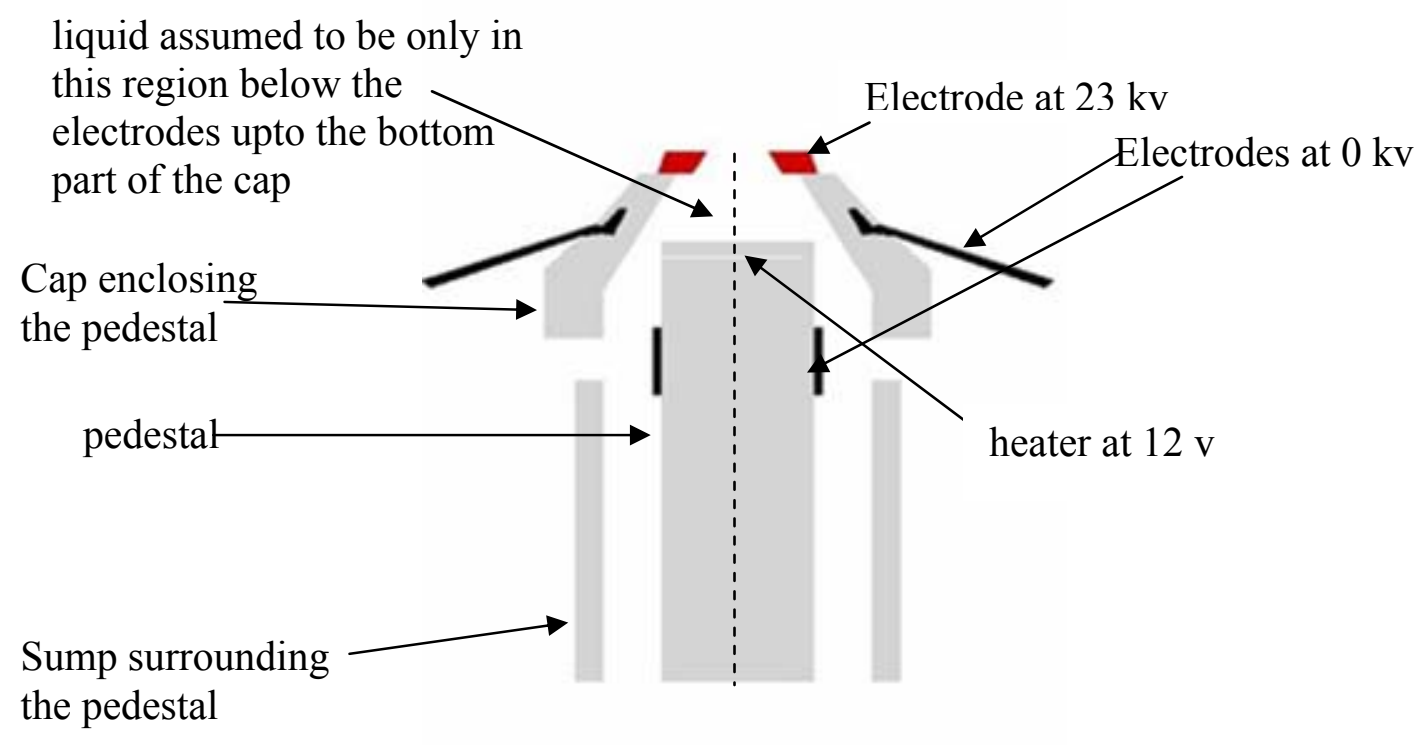

Figure 3.2 Location of the electrodes (Conductors are shown in black; dielectrics are shaded gray). 


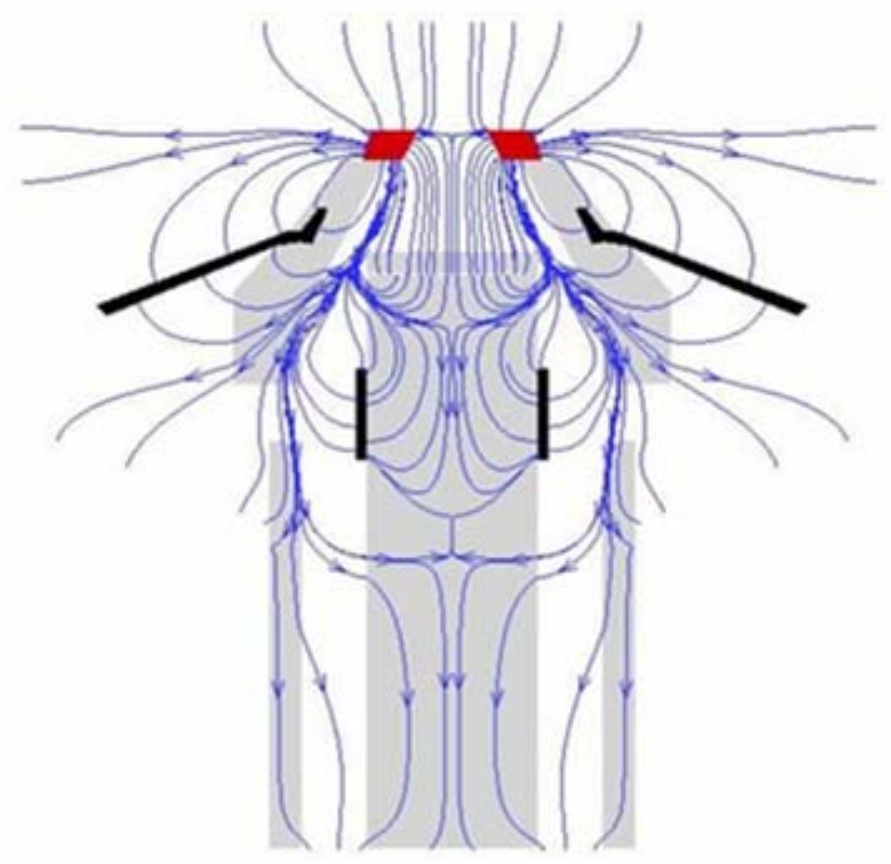

Figure 3.3 Electric field lines.

Figure 3.3 shows the electric field lines when the voltages are applied to the electrodes. The electric field and thus the electric Kelvin force was calculated by assuming HFE 7000 present in a region shown in Figure 3.1. The electric field lines, as expected, begin on the electrode at a higher voltage (shown in red in the figure) and terminate on the electrodes with lower voltage (shown in black in the figure) or extend to infinity. The glass dielectric and the PTFE dielectric were given the dielectric constant of 5. The gradient of $\mathrm{E}^{2}$ was obtained from the computed values of $\overrightarrow{\mathrm{E}}$ by using the central differencing technique and the backward/forward differencing technique. The backward/forward differencing technique was used next to the domain boundary whereas central differencing was used everywhere else. 


$$
\begin{aligned}
& \frac{\partial E^{2}}{\partial x}=\frac{E^{2}{ }_{i+1}-E^{2}{ }_{i-1}}{x_{i+1}-x_{i-1}} \text { Central differencing } \\
& \frac{\partial E^{2}}{\partial x}=\frac{E_{i}^{2}-E_{i-1}^{2}}{x_{i}-x_{i-1}} \text { Backward differencing } \\
& \frac{\partial E^{2}}{\partial x}=\frac{E^{2}{ }_{i+1}-E^{2}}{x_{i+1}-x_{i}} \quad \text { Forward differencing }
\end{aligned}
$$

where $\mathrm{E}^{2}$ is the magnitude of electric field squared

i, $i+1, i-1$ denote the cell centers for each variable

Lines tangent to $\nabla \mathrm{E}^{2}$ are shown in Figure 3.4. These lines point in the negative $\mathrm{x}$ direction, away from the impingement surface. The ratio of $\mathrm{x}$-force to mass $(\mathrm{N} / \mathrm{kg})$ for the above mentioned configuration is shown in Figure 3.5. This ratio averages around -5 for the region just above the impingent surface (up to 200 microns away from the surface). Figure 3.6 shows the ratio of the $\mathrm{x}$ direction Kelvin force to mass along the radius of the impingement surface at various axial distances from the surface. This force is directed away from the surface. Figure 3.7 shows the ratio of the y direction Kelvin force to mass along the radius of the impingement surface at various axial distances. This force is in the radial direction. The plot of this force (in both $\mathrm{x}$ and $\mathrm{y}$ directions) to mass ratio about 175 microns away from the heater surface is not much different from those just next to the impingement surface. This result can be improved by increasing the voltage up to $40 \mathrm{kv}$ which will increase the magnitude of the electric Kelvin force near the jet impingement surface. This electrode was built and was tested by Glaspell (06) upto $23 \mathrm{kV}$. Glaspell reported a $5.2 \%$ increase in heat transfer coefficient when a voltage of $23 \mathrm{kV}$ was applied. 


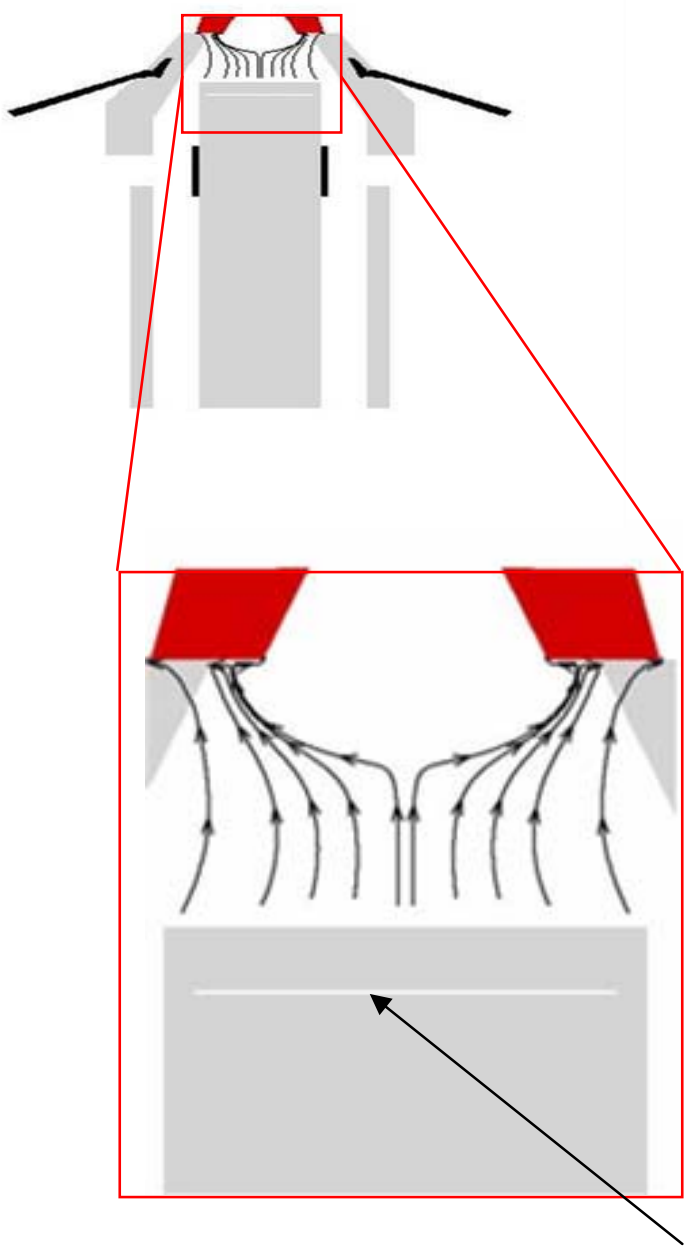

Heater

Figure 3.4 Lines tangent to gradient of the $\mathrm{E}^{2}$ lines. 


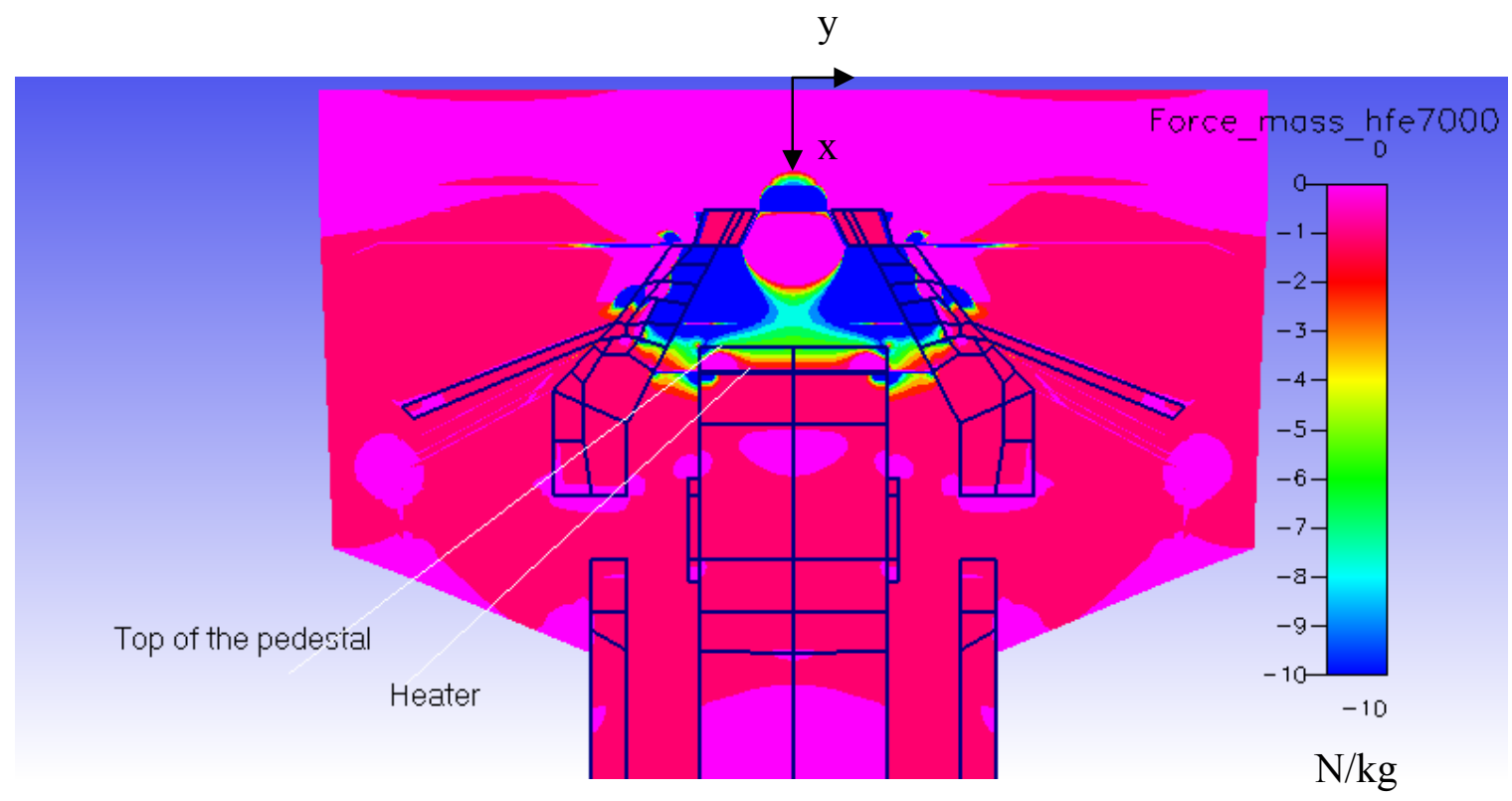

Figure 3.5 X direction Kelvin force to mass ratio.

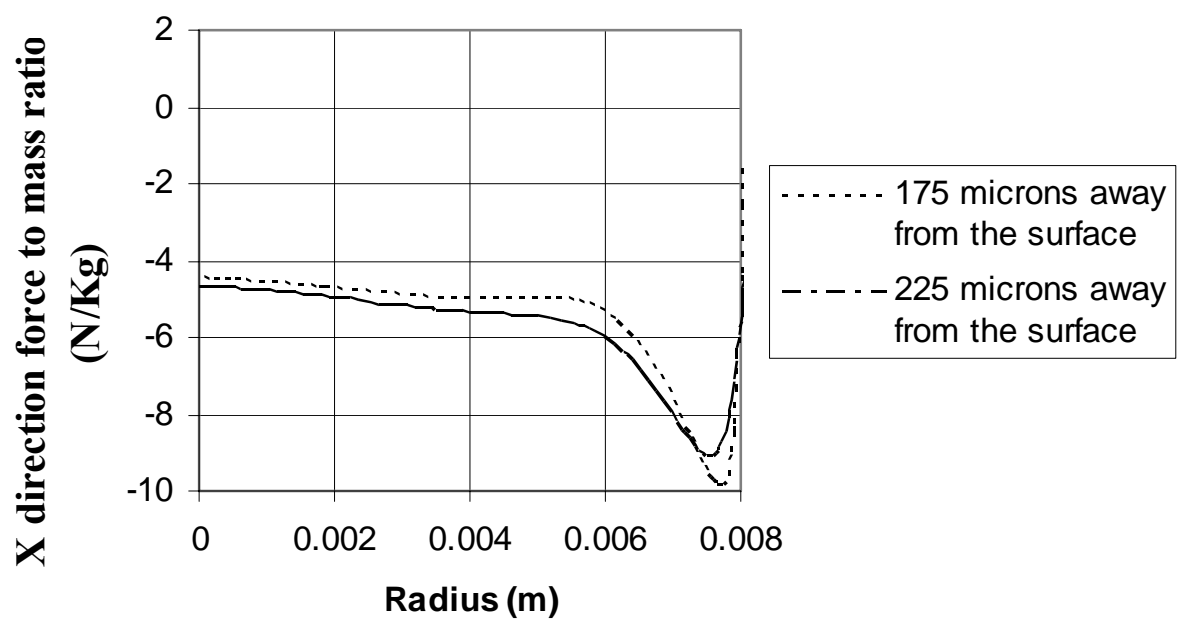

Figure 3.6 X direction Kelvin force (opposing the jet motion) to mass ratio plot. 


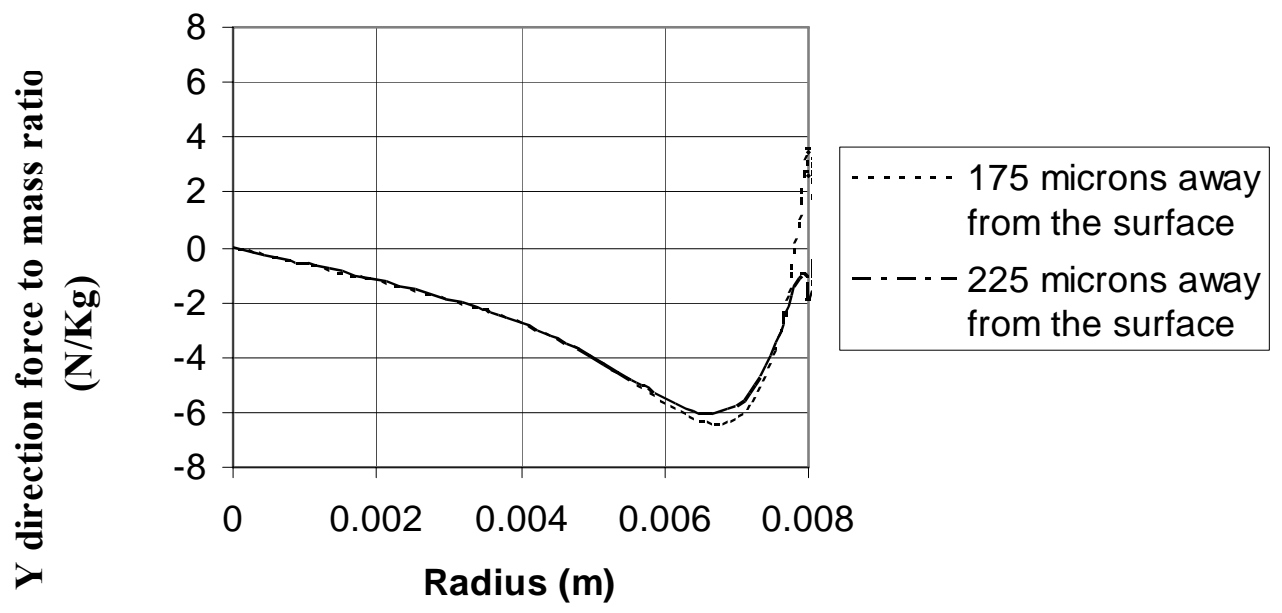

Figure 3.7 Y direction Kelvin force to mass ratio plot. 


\section{Chapter 4}

\section{Isothermal Liquid Jet Simulations with VOF with Varying Body Forces}

\subsection{Isothermal Liquid Jet Simulations and Varying Body Forces}

The purpose of this research was to predict the effect of the varying body force on the flow and on the heat transfer for an impinging liquid jet. The varying electric Kelvin body force for the isothermal cases was created by the electrode system described in the previous chapter. The effect of the electric Kelvin force on the flow (isothermal cases) and its comparison with the cases without its activation is described in this chapter. These isothermal liquid jet simulations were performed with CFD-ACE+ using the FLOW and VOF modules. The body forces included gravity and the electric Kelvin force which was calculated using the ELECTRIC module. The FLOW, VOF and ELECTRIC modules were directly coupled when the electric field was activated. The set of simulations performed is shown in Table 4.1.

The problem in each case was two dimensional axi-symmetric. As described in the previous chapter, Figures 3.1 and 3.2 show this axi-symmetric arrangement. The typical grid system used in the simulations is shown in Figure 4.1. The grid was refined near the top surface of the pedestal and at the edges of the pedestal. There were a total number of 87 zones in the domain. The total number of cells were 55711 . The modules used for all isothermal simulations included the FLOW module and the VOF module. When electric field needed to be calculated the ELECTRIC module was also used along with the FLOW 
and VOF modules. That means that the presence of liquid altered electric field which was then used to calculate the electric Kelvin force and so on. The electric Kelvin force was updated each time the jet changed geometry since moving jet causes the electric field to change.

The two regimes classified by Labus as surface tension and inertial flow regimes were renamed the low velocity case and the higher velocity case. These regimes are defined in Chapter 3. The initial jet diameter was $4 \mathrm{~mm}$ for all the cases and the Re and We were calculated based on this diameter. For the low velocity cases the velocity was $0.2263 \mathrm{~m} / \mathrm{s}$ and body forces were $0 \mathrm{~g}, 1 \mathrm{~g}$, and $1 \mathrm{~g}$ plus the electric Kelvin force computed for the electrode geometry of Figure 3.2. For the higher velocity cases the velocity was $0.5 \mathrm{~m} / \mathrm{s}$ for each body force. The jet velocity profile was specified to be flat in all cases. The geometry is described in Chapter 3 with the liquid jet coming out from the nozzle location. The figures shown in the following sections have been mirrored and were solved with an axi-symmetric model. HFE 7000 was used as a fluid for all the cases shown in Table 4.1. 
Table 4.1 Simulated isothermal cases.

\begin{tabular}{|l|l|l|l|l|l|l|}
\hline & Case 1 & Case 2 & Case 3 & Case 4 & Case 5 & Case 6 \\
\hline Gravity $\left(\mathrm{m} / \mathrm{s}^{2}\right)$ & 0 & 9.8 & 0 & 9.8 & 9.8 & 9.8 \\
\hline Voltage(kv) & 0 & 0 & 0 & 0 & 24 & 24 \\
\hline Velocity(m/s) & 0.2263 & 0.2263 & 0.5 & 0.5 & 0.2263 & 0.5 \\
\hline We & 23.4 & 23.4 & 114.2 & 114.2 & 23.4 & 114.2 \\
\hline Re & 2828 & 2828 & 6250 & 6250 & 2828 & 6250 \\
\hline
\end{tabular}

The CFL (Courant-Friedrichs-Lewy) number used was 0.2 and the initial time step was $10^{-8} \mathrm{~s}$. The CFL number specifies how much distance the fluid or the interface crosses in one time step.

$\mathrm{CFL}=\frac{\mathrm{v} \Delta \mathrm{t}}{\mathrm{d}}$

where $\mathrm{v}$ is the fluid velocity,

$\Delta \mathrm{t}$ is the time step

$\mathrm{d}$ is the local length (cell) scale.

Thus a CFL value of 0.2 allows the fluid to cross at most only $20 \%$ of the width of a cell. The contact angle at the solid walls was fully wetting or $0^{0}$ contact angle. At the outlet flow boundaries the pressure was fixed to be equal to the atmospheric pressure. 


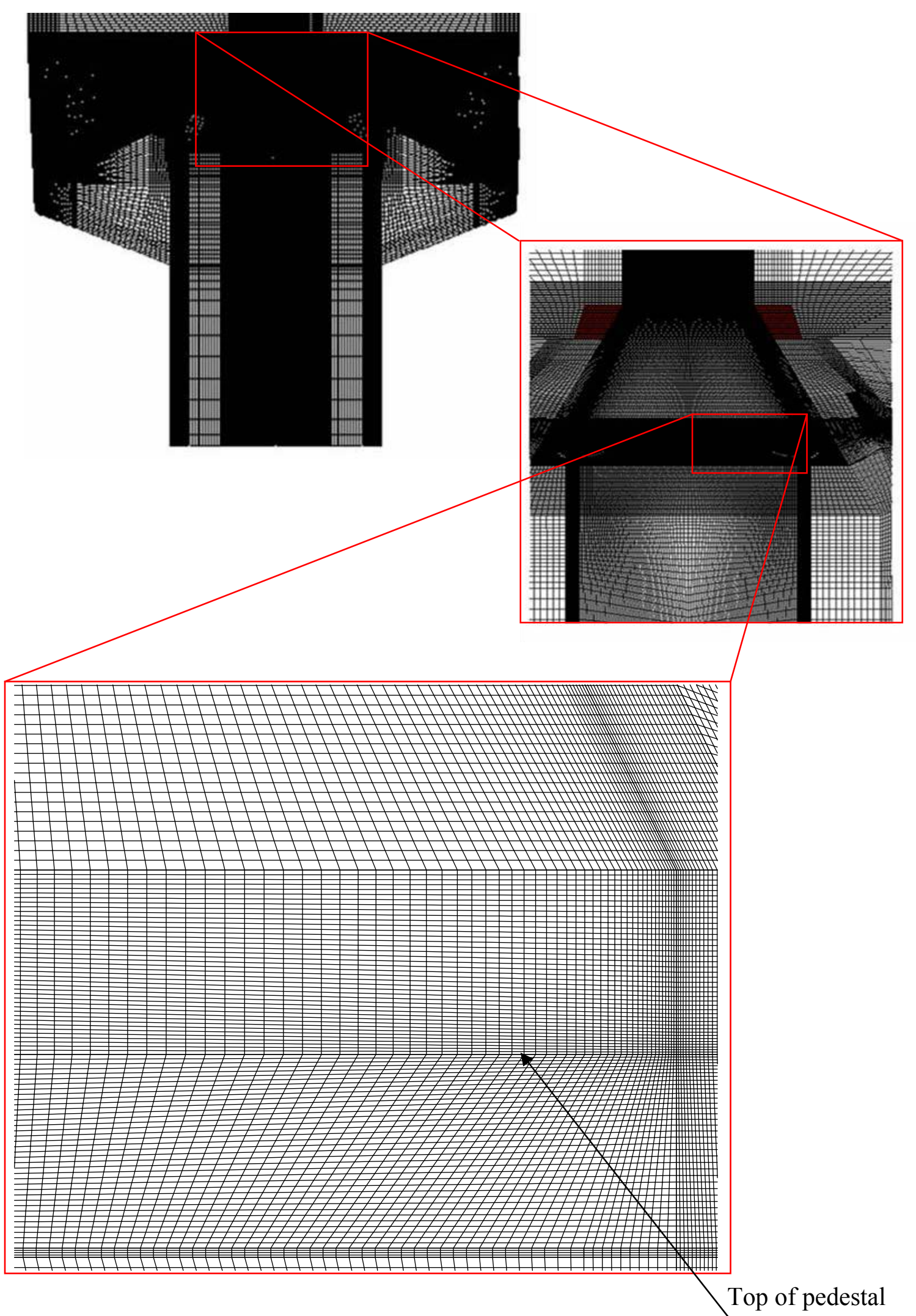

Figure 4.1 Typical grid system used in the simulations (note that the grid is not curved as it may appear). 


\subsection{Case 1 Low Velocity Case with No Gravitational Force and No Kelvin Force}

In this case the velocity of the incoming jet was fixed to be $0.2263 \mathrm{~m} / \mathrm{s}$. The Reynolds number for this case was 2828 and the Weber number was 23.4. This case was similar to Labus' surface tension regime. At $\mathrm{t}=0$, the entire domain was filled with motionless air. After time $t=0$ the fluid HFE 7000 entered into the air filled domain. Figure 4.2 shows the HFE 7000 at $\mathrm{t}=0.0173$ seconds. Figure 4.3 shows the streamlines at the same time. The pressure in front of the tip of the liquid jet is higher thus causing the air around the jet to flow as can be seen in Figure 4.3.

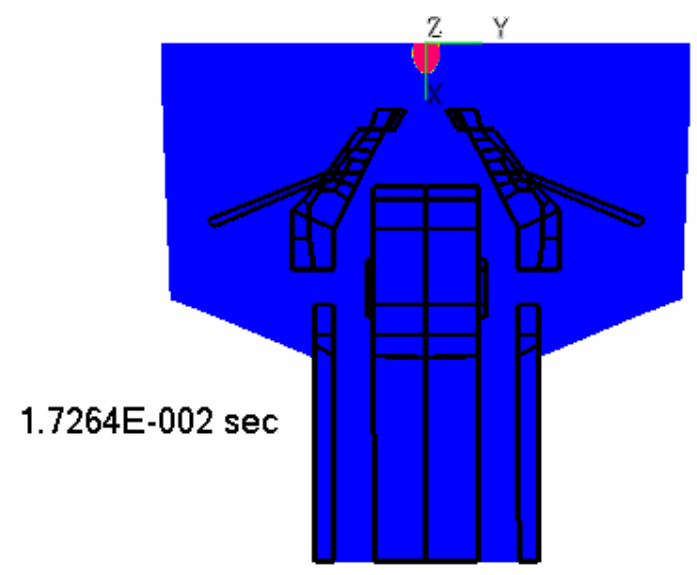

Figure 4.2 Case 1 HFE 7000 at $t=0.0173$ seconds (Red represents HFE 7000 and blue represents air, yellow and green represent a liquid fraction of 0 and 1) 


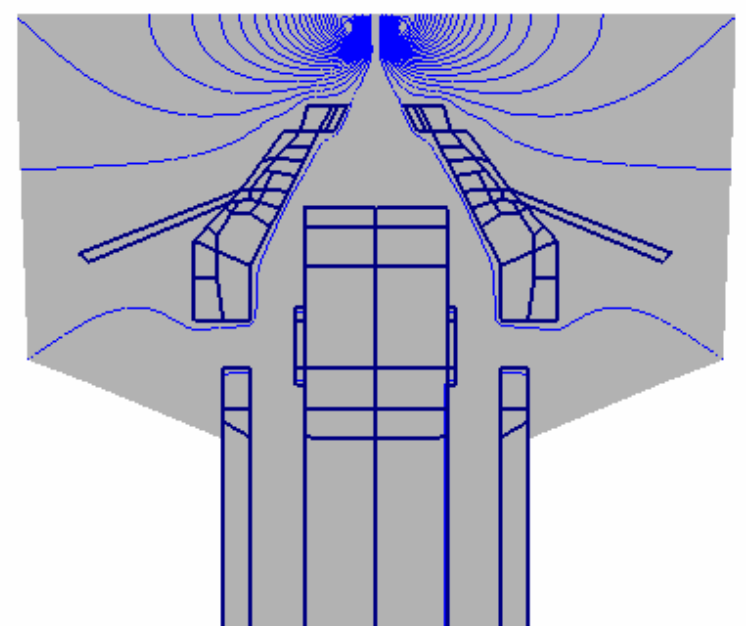

Figure 4.3 Case 1 streamlines at $\mathrm{t}=0.0173$ seconds.

Figure 4.4 shows the location of liquid jet at $t=0.05622$ seconds. The tip of the liquid jet is curved due to surface tension force pulling it inside. The streamlines at the same time are shown in Figure 4.5.

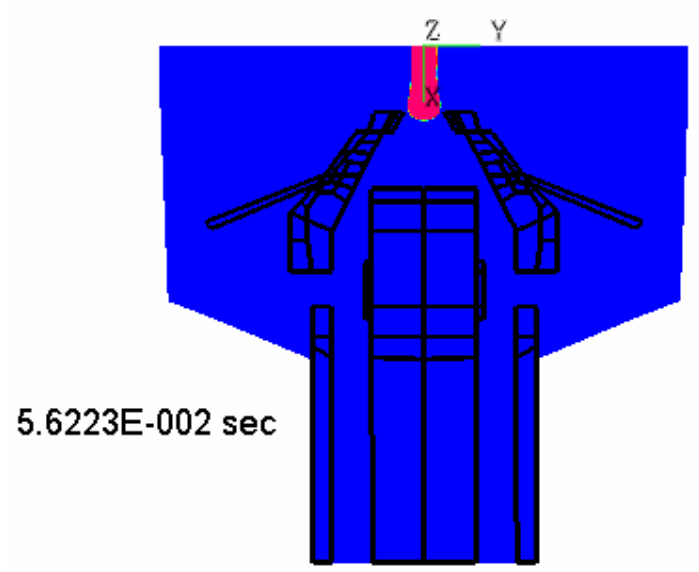

Figure 4.4 Case $1 \mathrm{HFE} 7000$ at $\mathrm{t}=0.05622$ seconds. 


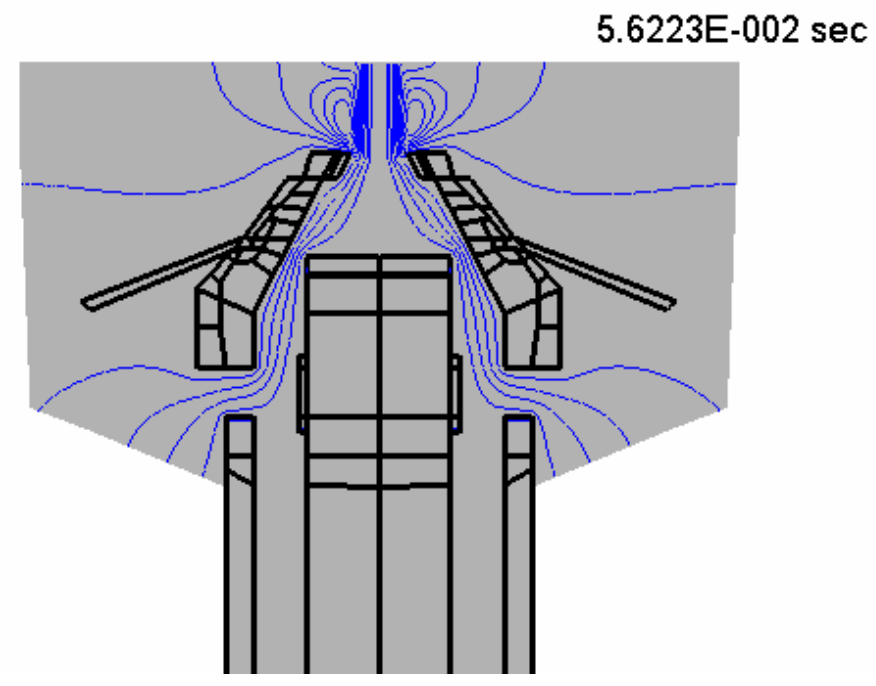

Figure 4.5 Case 1 streamlines at $\mathrm{t}=0.05622$ seconds.

Figure 4.6 shows liquid jet at $\mathrm{t}=0.136$ seconds after the jet has impinged on the pedestal and is moving out radially. Figure 4.7 shows the streamlines at the same time. For the first time a vortex is seen in the air flow in the space between the cap and the top of the pedestal.

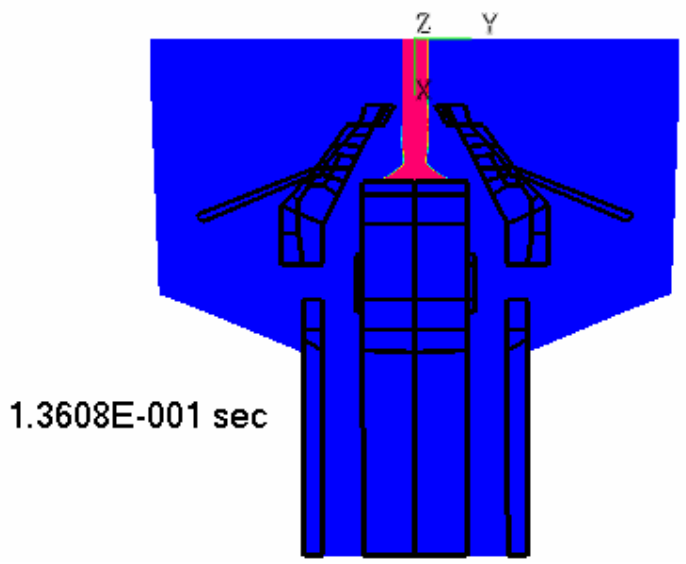

Figure 4.6 Case 1 HFE $7000 \mathrm{t}=0.136$ seconds. 


\section{$1.3088 \mathrm{E}-001 \mathrm{sec}$}

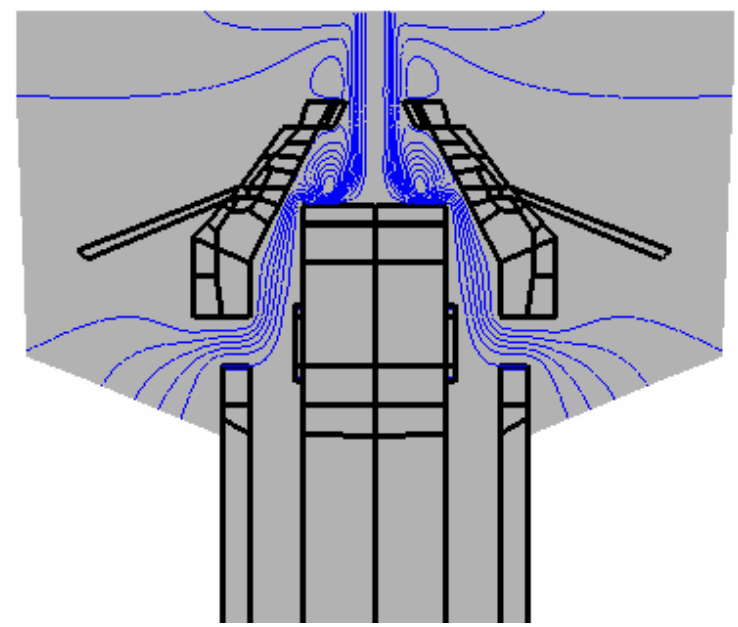

Figure 4.7 Case 1 streamlines $\mathrm{t}=0.136$ seconds.

Figure 4.8 shows the location of liquid jet at $t=0.1442$ seconds. The liquid has turned around the edge of the pedestal and continues its radial and axial movement. Figure 4.9 shows the streamlines at this time. 


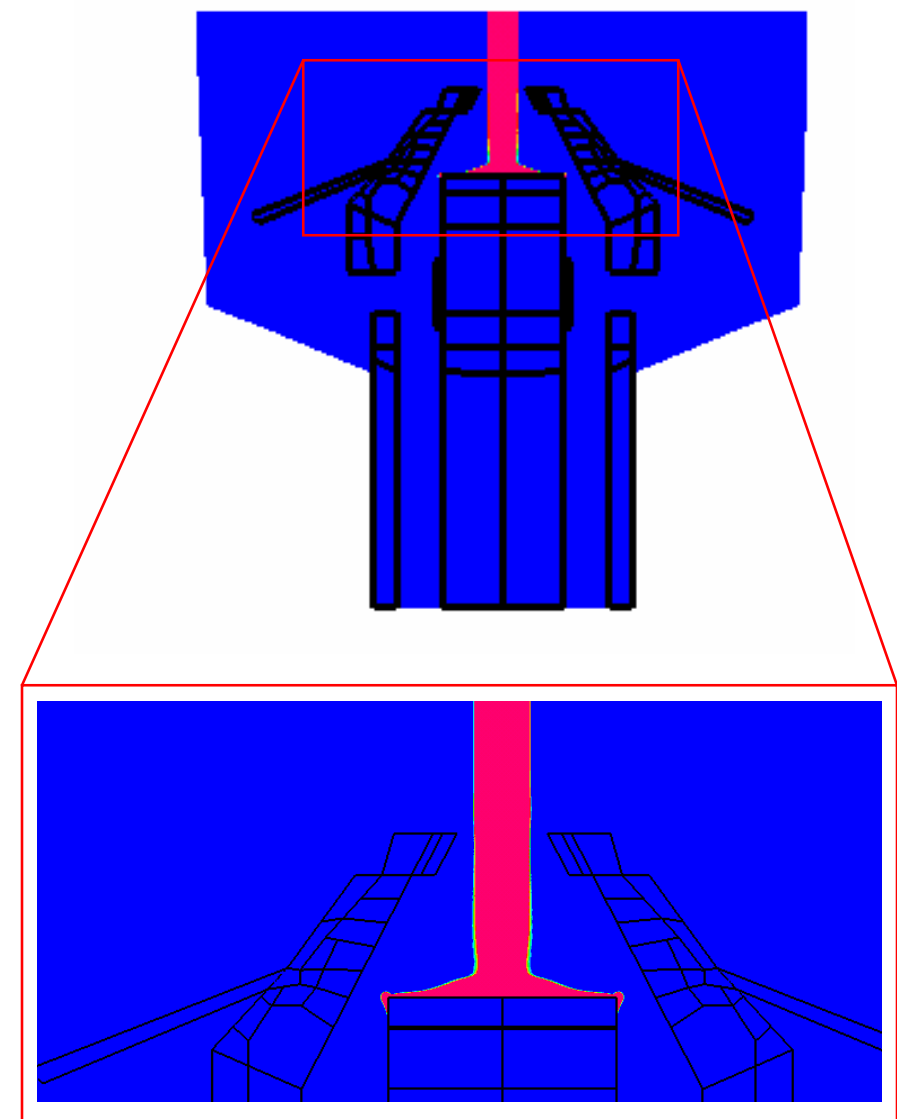

Figure 4.8 Case $1 \mathrm{HFE} 7000$ at $\mathrm{t}=0.1442$ seconds. 
1.4423E-001 sec

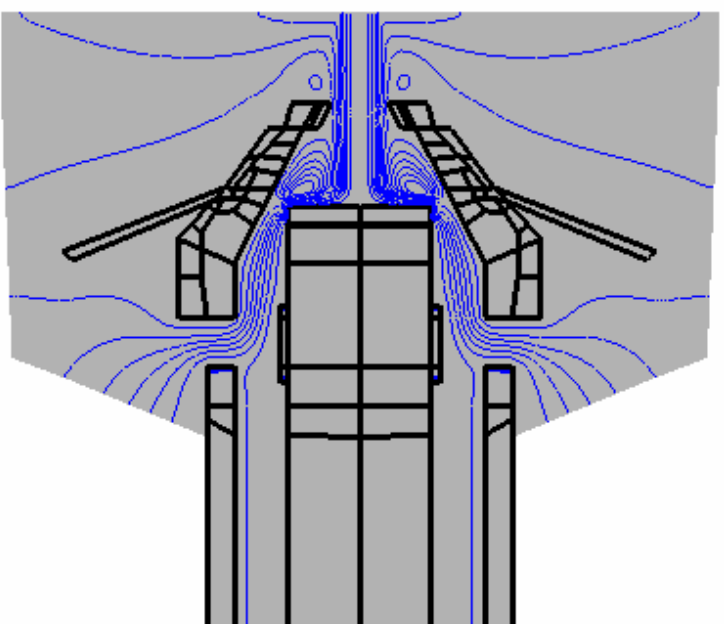

Figure 4.9 Case 1 streamlines at $\mathrm{t}=0.1442$ seconds.

Figure 4.10 shows the location of the liquid jet after 0.1619 seconds, whereas Figure 4.11 shows the streamlines at that instant of time. The liquid jet continues to move down the side of the pedestal. A second vortex has formed in the annular space between the sump and the pedestal. 


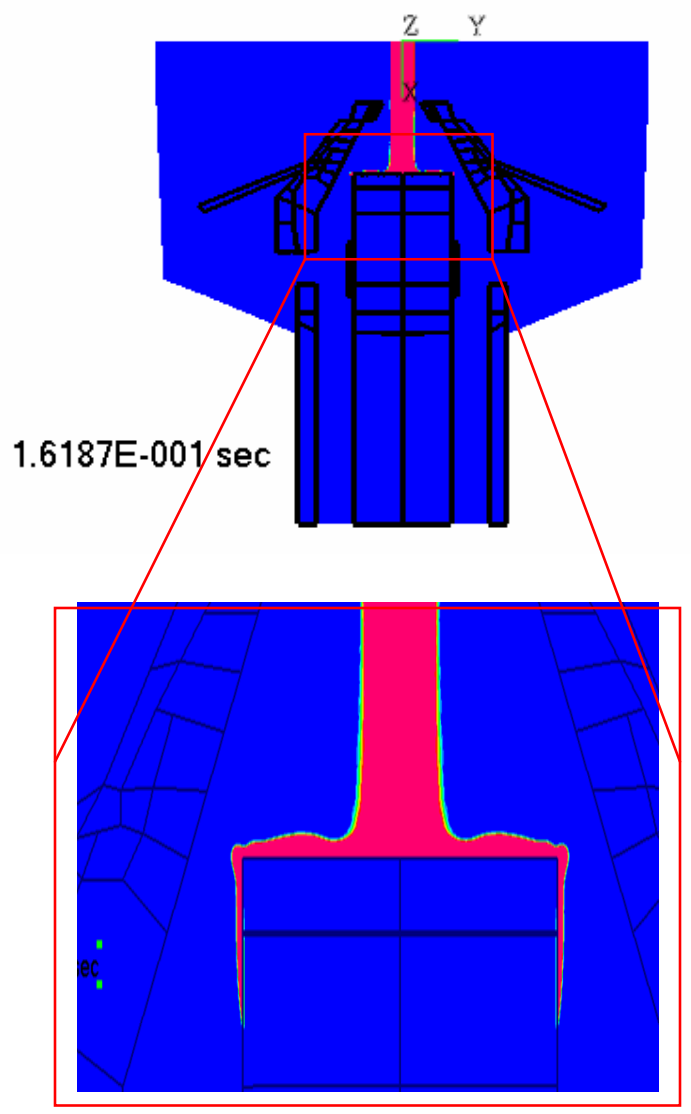

Figure 4.10 Case $1 \mathrm{HFE} 7000$ at $\mathrm{t}=0.1619$ seconds. 


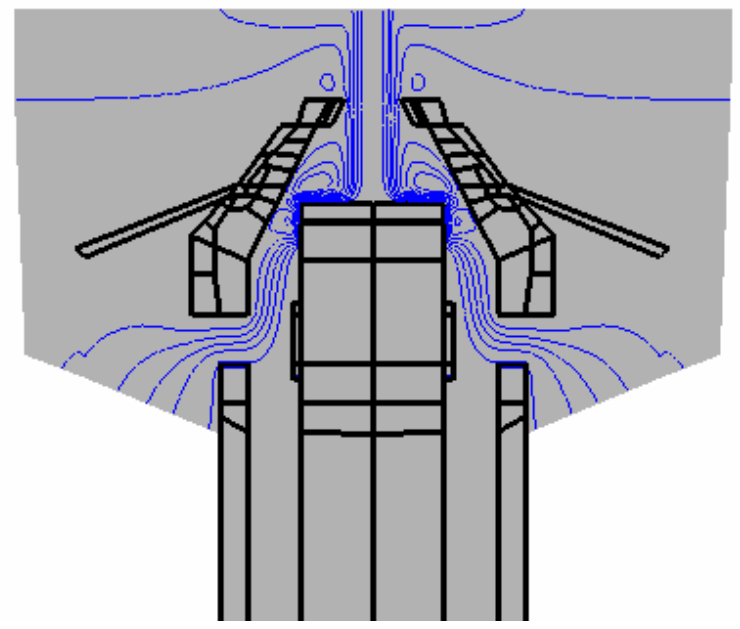

Figure 4.11 Case 1 streamlines after 0.1619 seconds.

The simulation was stopped after 0.1619 seconds because of the excessive computational time. This is not the steady state and the steady state is not expected to occur at least until several seconds. This simulation proves that the liquid jet under similar conditions will continue to climb "up" the pedestal in zero gravity (downwards as shown in the figure). However, note that here the orientation of the jet and impingement plate are such that both gravity and surface tension will tend to cause the jet fluid to turn and flow downwards in the annular region between the pedestal and the sump.

\subsection{Case 2: Low Velocity Case with Gravitational Force and No Kelvin Force}

This case is identical to Case 1 except that Earth's gravity $(1 \mathrm{~g})$ acts in the positive $\mathrm{x}$ direction. Although due to the low velocity of the jet it is expected that the surface 
tension force would dominate the flow, the presence of gravity will accelerate the flow, thus reducing the effects of surface tension compared to Case 1. Figure 4.12 shows the liquid jet at $\mathrm{t}=0.02425$ seconds. Due to the influence of gravity the liquid jet accelerates and thus contracts in diameter as can be seen in Figure 4.12.

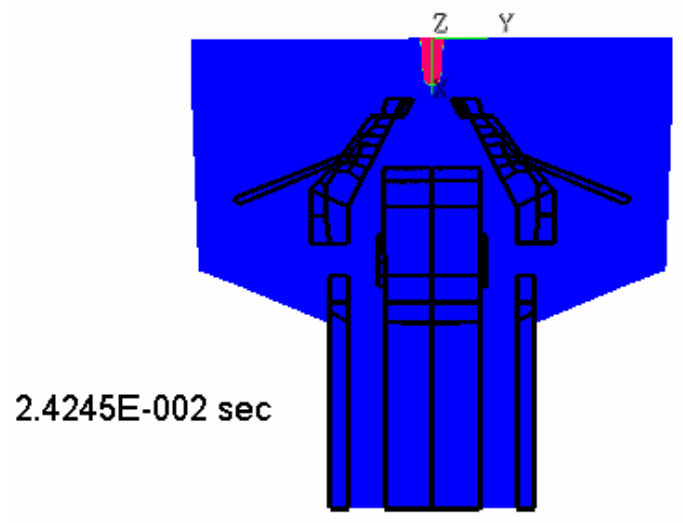

Figure 4.12 Case 2 HFE 7000 at $\mathrm{t}=0.02425$ seconds.

Figure 4.13 shows the liquid jet at $\mathrm{t}=0.032$ seconds.

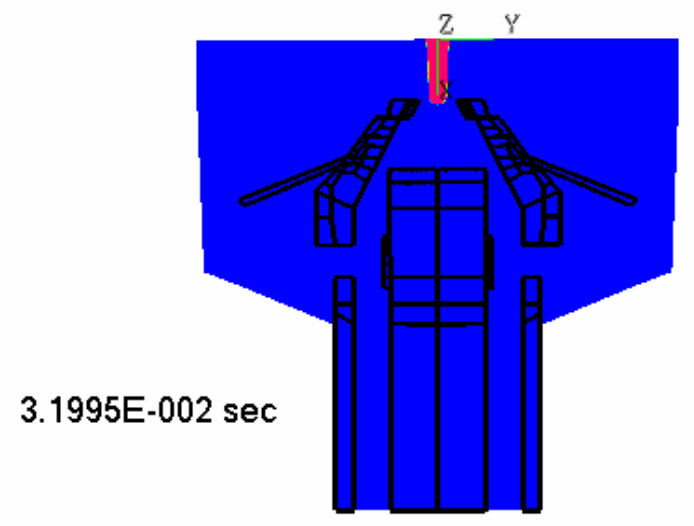

Figure 4.13 Case 2 HFE 7000 at $\mathrm{t}=0.032$ seconds.

Figure 4.14 shows the liquid jet at $t=0.0475$ seconds. From Figure 4.14 it can be seen that the tip of the liquid jet is curved because of the surface tension even though overall 
the jet diameter contracts because of gravity. The acceleration of liquid jet requires this contraction to satisfy the continuity equation.

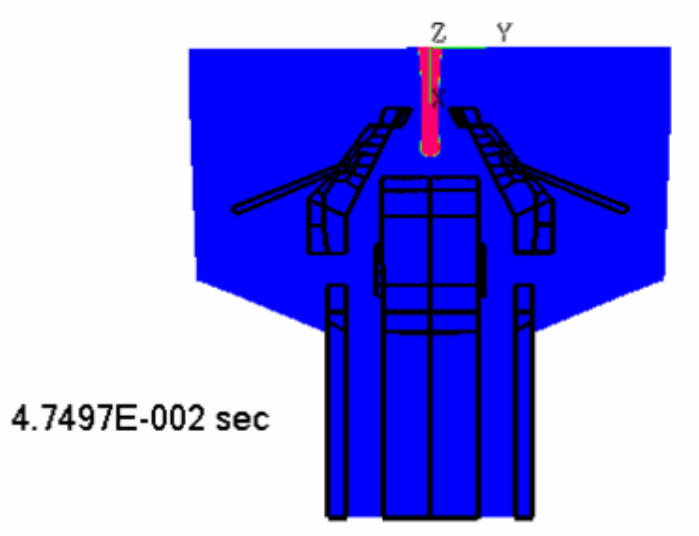

Figure 4.14 Case $2 \mathrm{HFE} 7000$ at $\mathrm{t}=0.0475$ seconds.

Figure 4.15 shows the location of the liquid jet at $t=0.063$ seconds. The liquid layer formed on the pedestal surface after the impingement is thinner than the corresponding layer in the zero gravity case. This is the case even after the jet turns around the pedestal and remains comparatively a thin layer. This is again due to the acceleration of the liquid jet under the influence of gravity. 


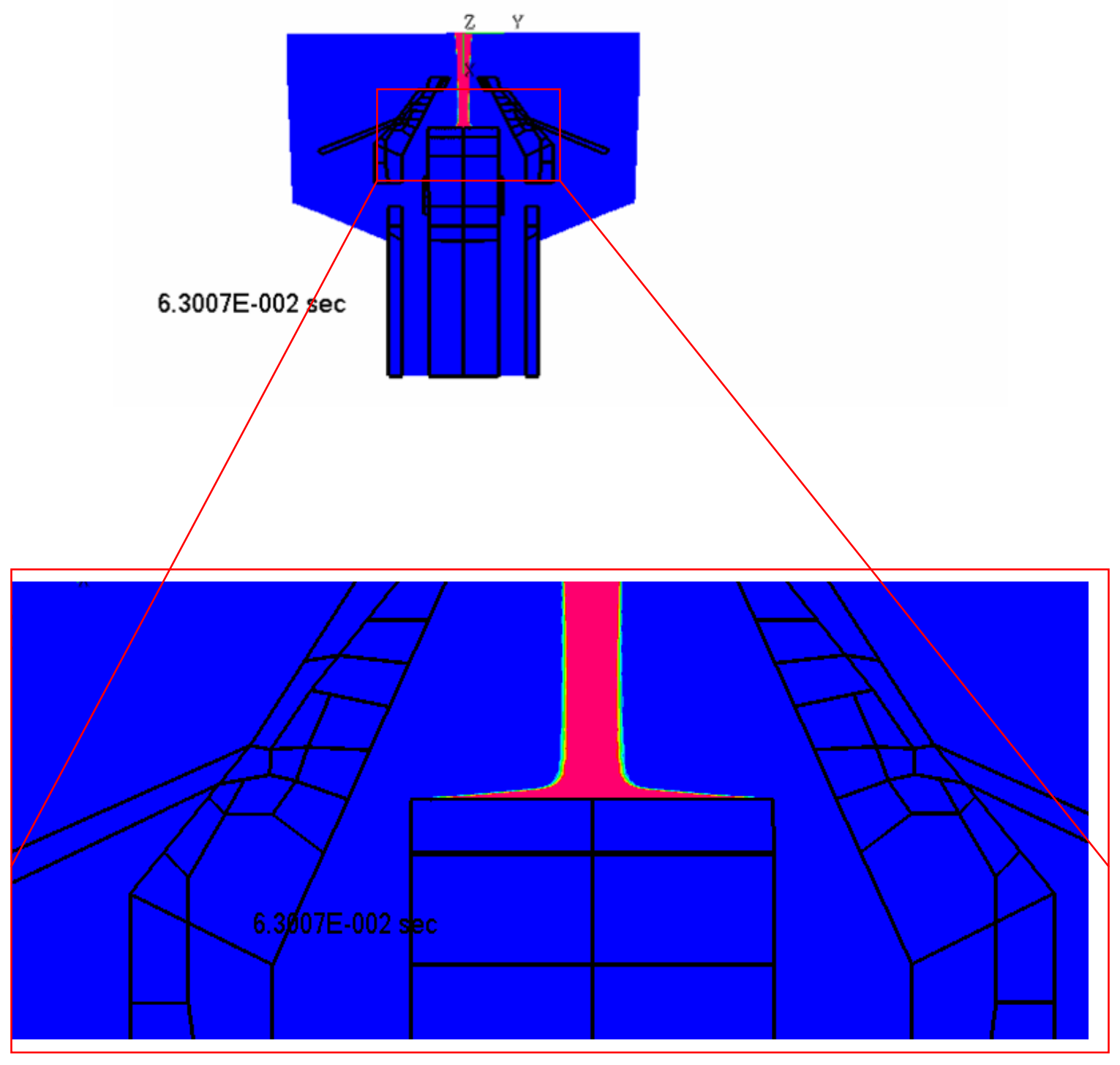

Figure 4.15 Case 2 HFE 7000 at $\mathrm{t}=0.063$ seconds. 


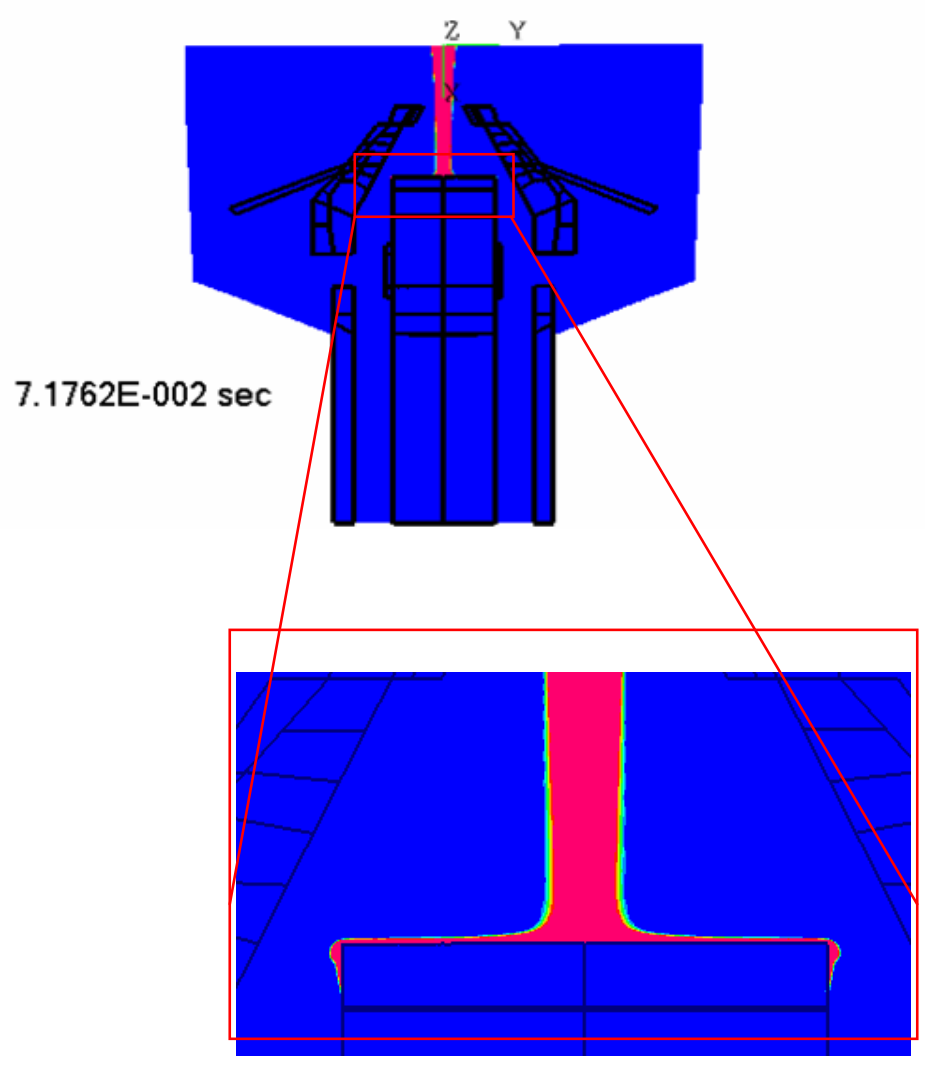

Figure 4.16 HFE 7000 after 0.0718 seconds.

Figure 4.16 shows the liquid jet at $\mathrm{t}=0.0718$ seconds. The liquid has followed the edge of the pedestal and is beginning to flow down the pedestal. 


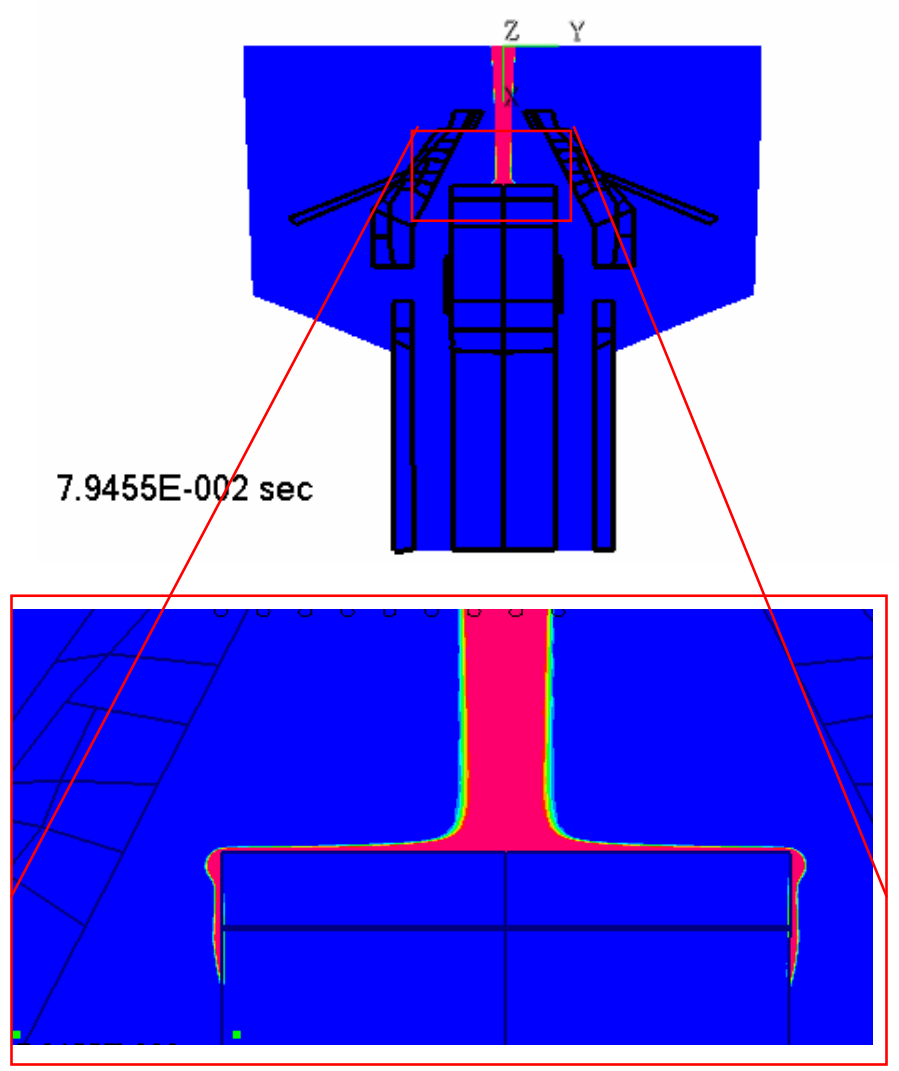

Figure 4.17 Case 2 HFE 7000 at $\mathrm{t}=0.0795$ seconds.

Figure 4.17 shows the liquid jet at $t=0.0795$ seconds. The liquid jet forms a thin layer on the sides of the pedestal and keeps flowing downward. In general the flow in the presence of gravity formed a thinner layer owing primarily to its acceleration under the influence of gravity whereas this layer was thicker in the absence of gravity primarily because the liquid's velocity after impingement did not increase significantly as compared to the case with gravity on.

Note that the cases which were run with gravity had a different pattern of air flow compared to those without gravity apparently because of the non inclusion of the initial 
hydrostatic pressure variation. The resulting air flow patterns are thought to be incorrect and so no plots have been presented. This difference however did not affect the accuracy of the liquid flow in the presence of gravity since a lower velocity case was rerun with the initial hydrostatic variation which gave the correct air flow patterns and did not show any change in the liquid flow when run without hydrostatic variation

\subsection{Case 3: Higher Velocity Case with No Gravitational Force and No Kelvin Force}

In this case the velocity of the incoming jet was increased to $0.5 \mathrm{~m} / \mathrm{s}$. The Reynolds number for this case was 6250 and the Weber number was 114.2. The rest of the model setup is the same as the previous two cases. This case corresponds to the inertial flow regime of Labus' experiments. Figure 4.18 shows the liquid jet at $t=0.00183$ seconds. Figure 4.19 shows the streamlines at that instant of time.

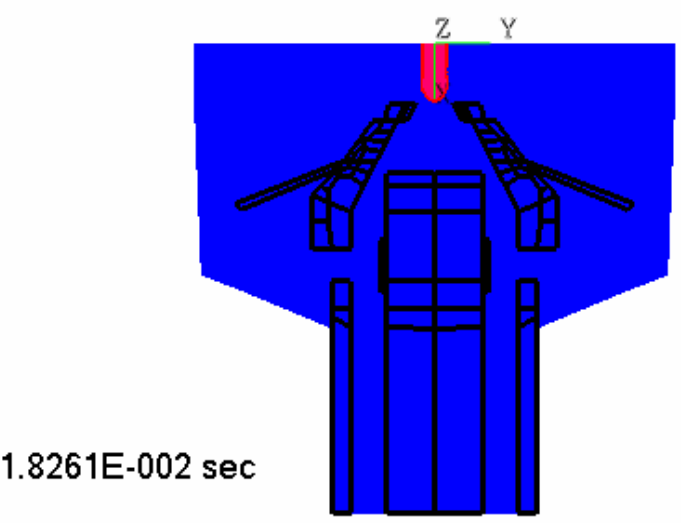

Figure 4.18 Case 3 HFE 7000 at $\mathrm{t}=0.0183$ seconds. 


\subsection{E-002 sec}

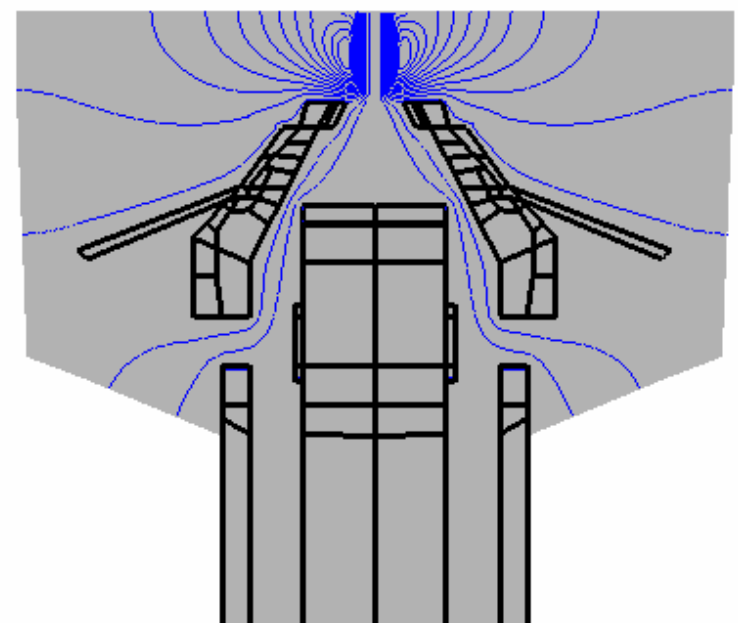

Figure 4.19 Case 3 streamlines at $\mathrm{t}=0.0183$ seconds.

Figure 4.20 shows HFE 7000 at $t=0.0354$ seconds. Figure 4.21 shows the streamlines at $\mathrm{t}=0.0354$ seconds. The jet is thicker at the leading end in this case. The streamlines show that the air flow is recirculating around the liquid jet.

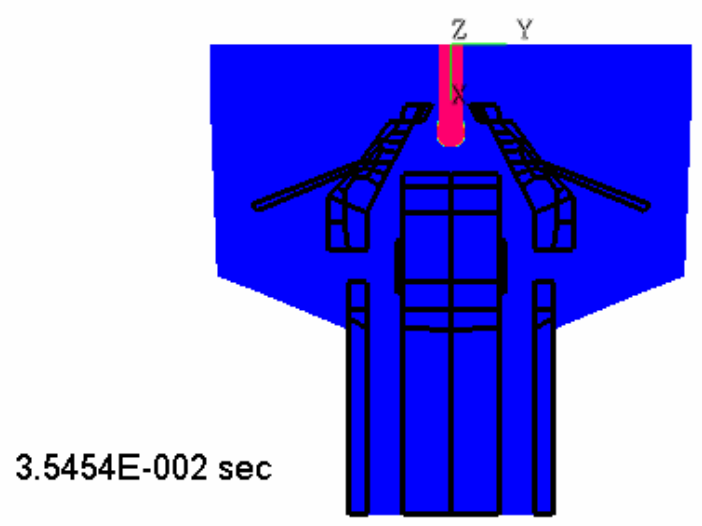

Figure 4.20 Case 3 HFE 7000 at $\mathrm{t}=0.0354$ seconds. 


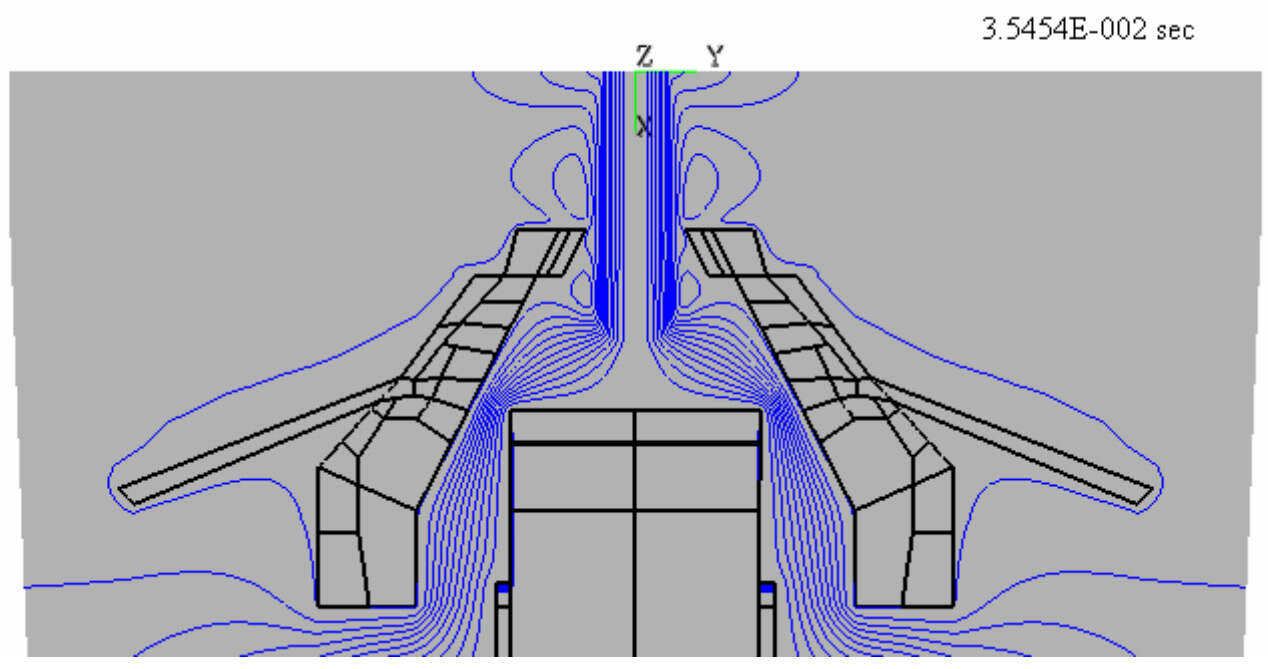

Figure 4.21 Case 3 streamlines at $\mathrm{t}=0.0354$ seconds.

Figure 4.22 shows the liquid jet at $\mathrm{t}=0.0537$ seconds. The liquid jet has impinged on the surface and has started to move radially outwards. Figure 4.23 shows the streamlines at this time. The vortex surrounding the jet above the cap has weakened. 


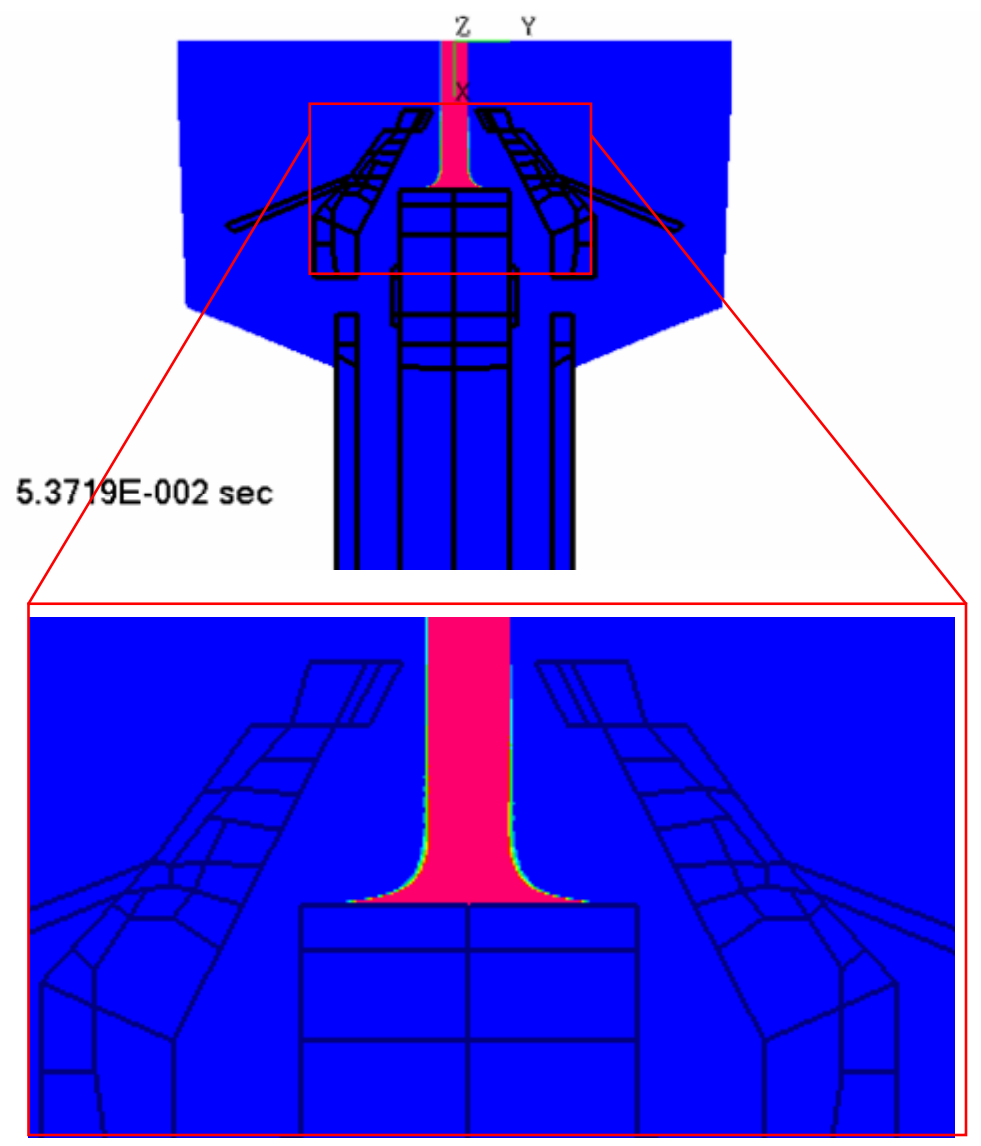

Figure 4.22 Case 3 HFE 7000 at $\mathrm{t}=0.0537$ seconds. 


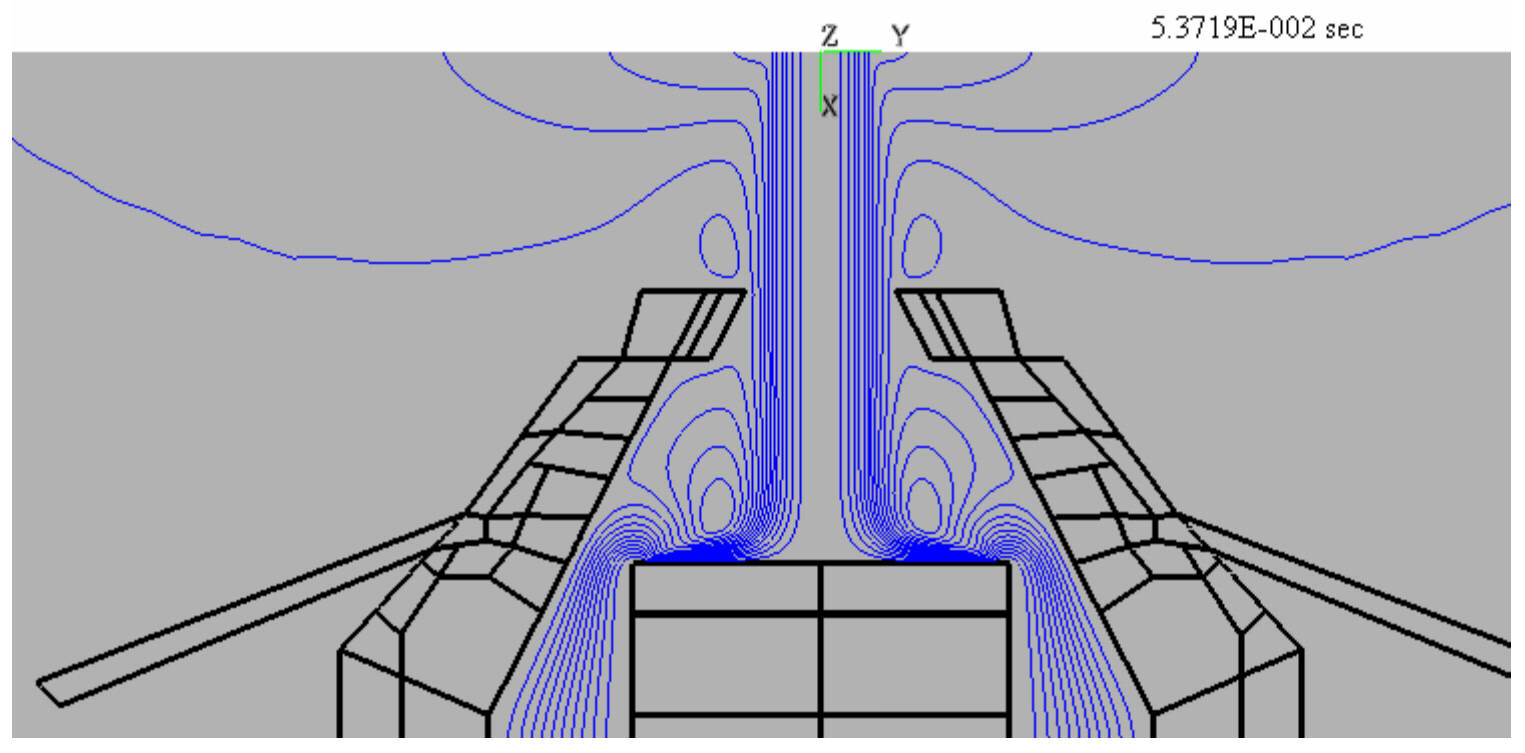

Figure 4.23 Case 3 streamlines at $\mathrm{t}=0.0537$ seconds.

Figure 4.24 shows the HFE 7000 at $\mathrm{t}=0.0599$ seconds. The liquid jet has reached the edge of the pedestal and has started to move around the edge. Figure 4.25 shows the streamlines at $\mathrm{t}=0.0599$ seconds. 


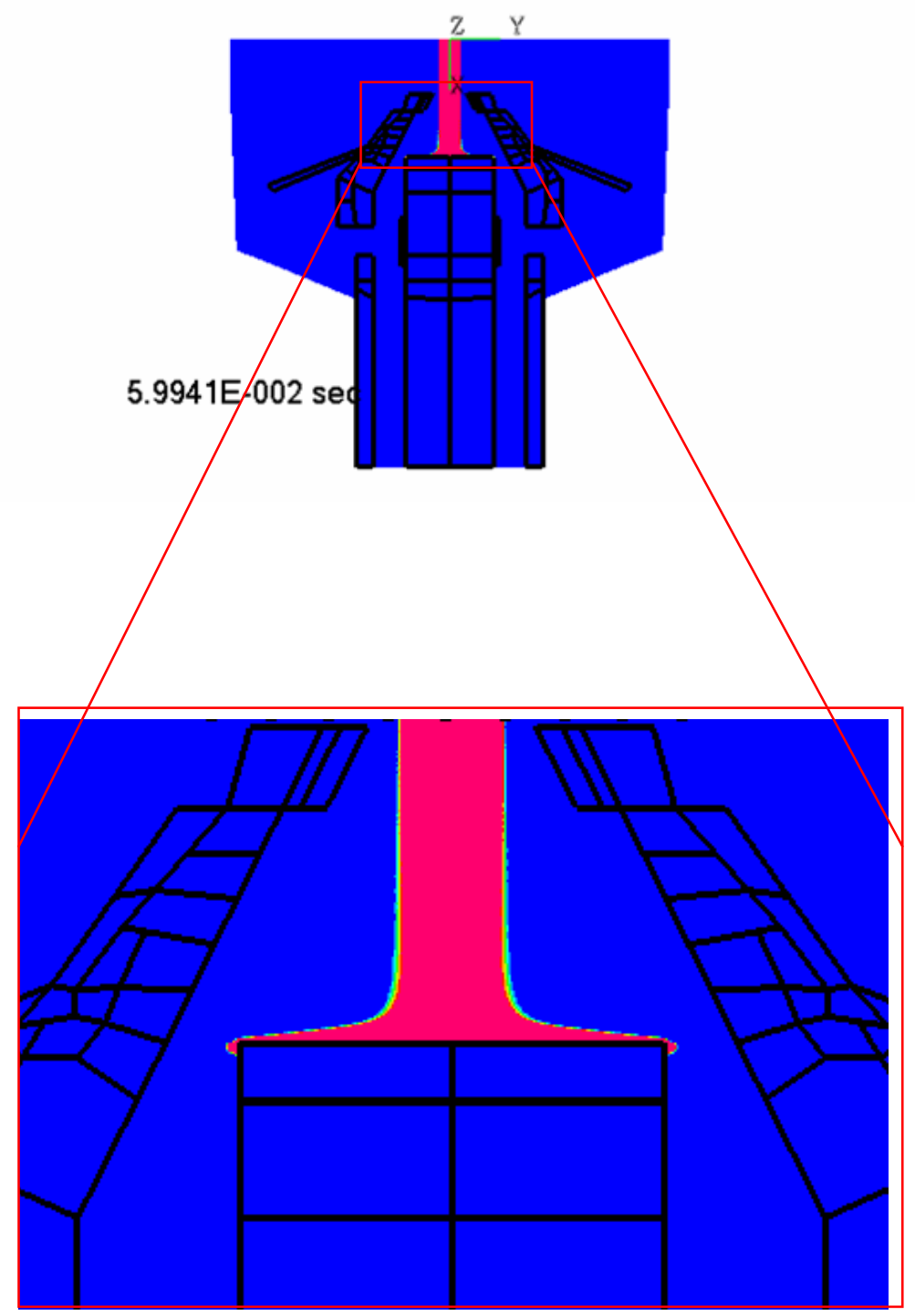

Figure 4.24 Case 3 HFE 7000 at $\mathrm{t}=0.0599$ seconds. 


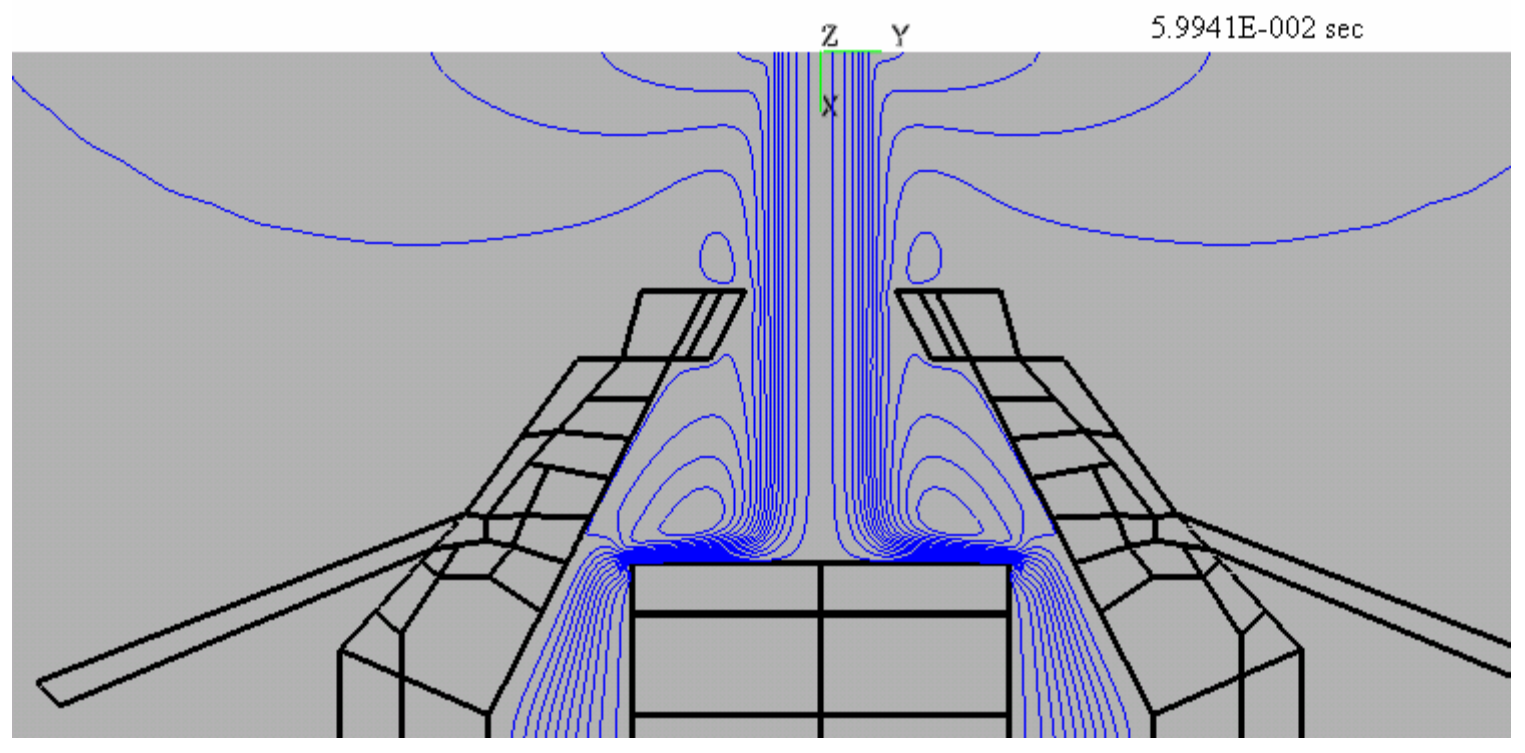

Figure 4.25 Case 3 streamlines at $\mathrm{t}=0.0599$ seconds.

Figure 4.26 shows the HFE 7000 after 0.0818 seconds. The liquid jet in this case is moving along the pedestal and also in the radial direction. Note the large bulge just below the top of the pedestal. In contrast to Labus' results the liquid continues to cling to the pedestal. Figure 4.27 shows the streamlines after 0.0818 seconds. The simulation was stopped at this time. The bulge seen here is apparently an inertial "attempt" of the fluid to continue to flow radially, but it appears that the surface tension causes the liquid to turn back towards the sidewalls of the pedestal. If Reynolds number is much higher than eventually the radial jet would flow outwards and hit the sump. 


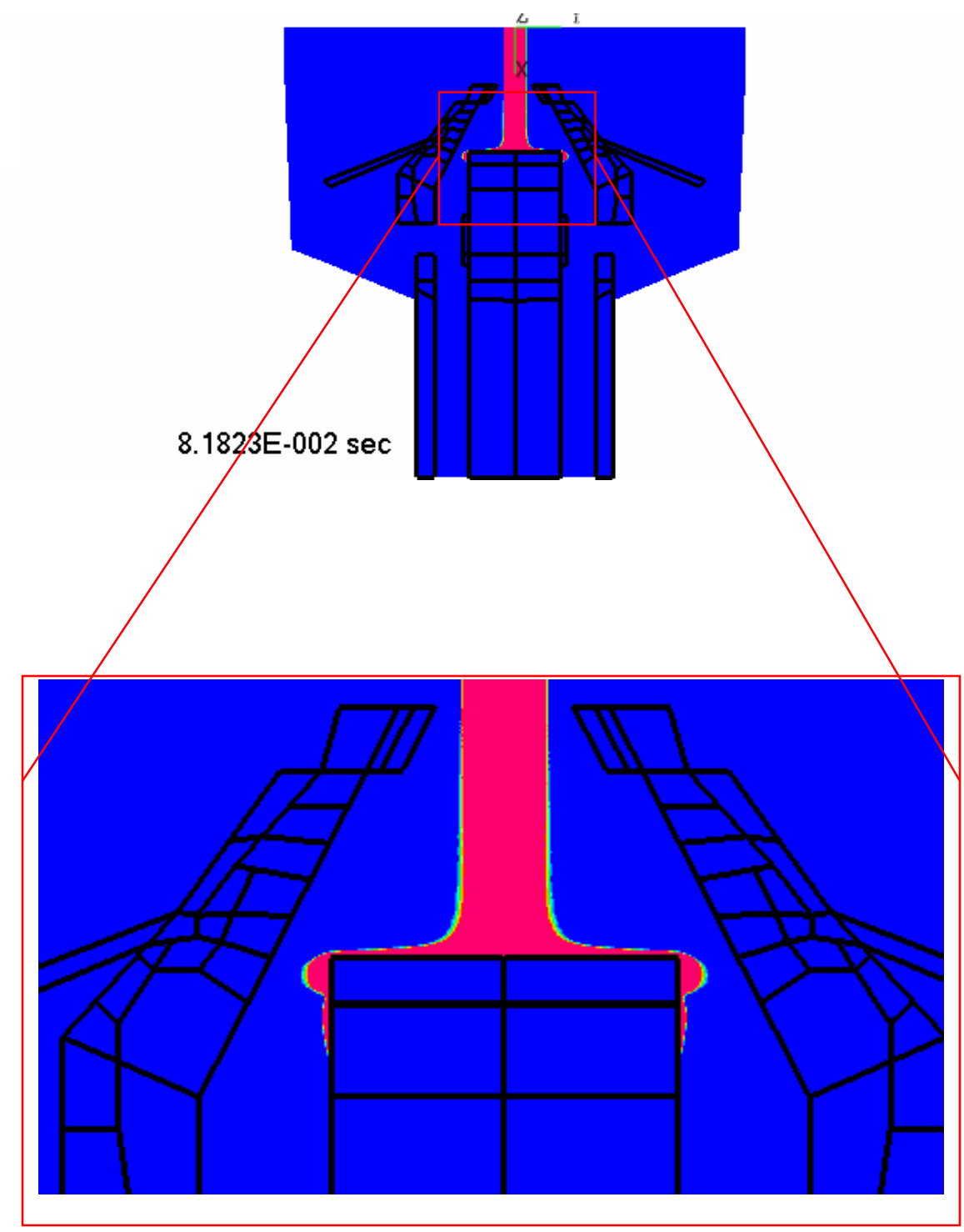

Figure 4.26 Case 3 HFE 7000 at $\mathrm{t}=0.0818$ seconds. 


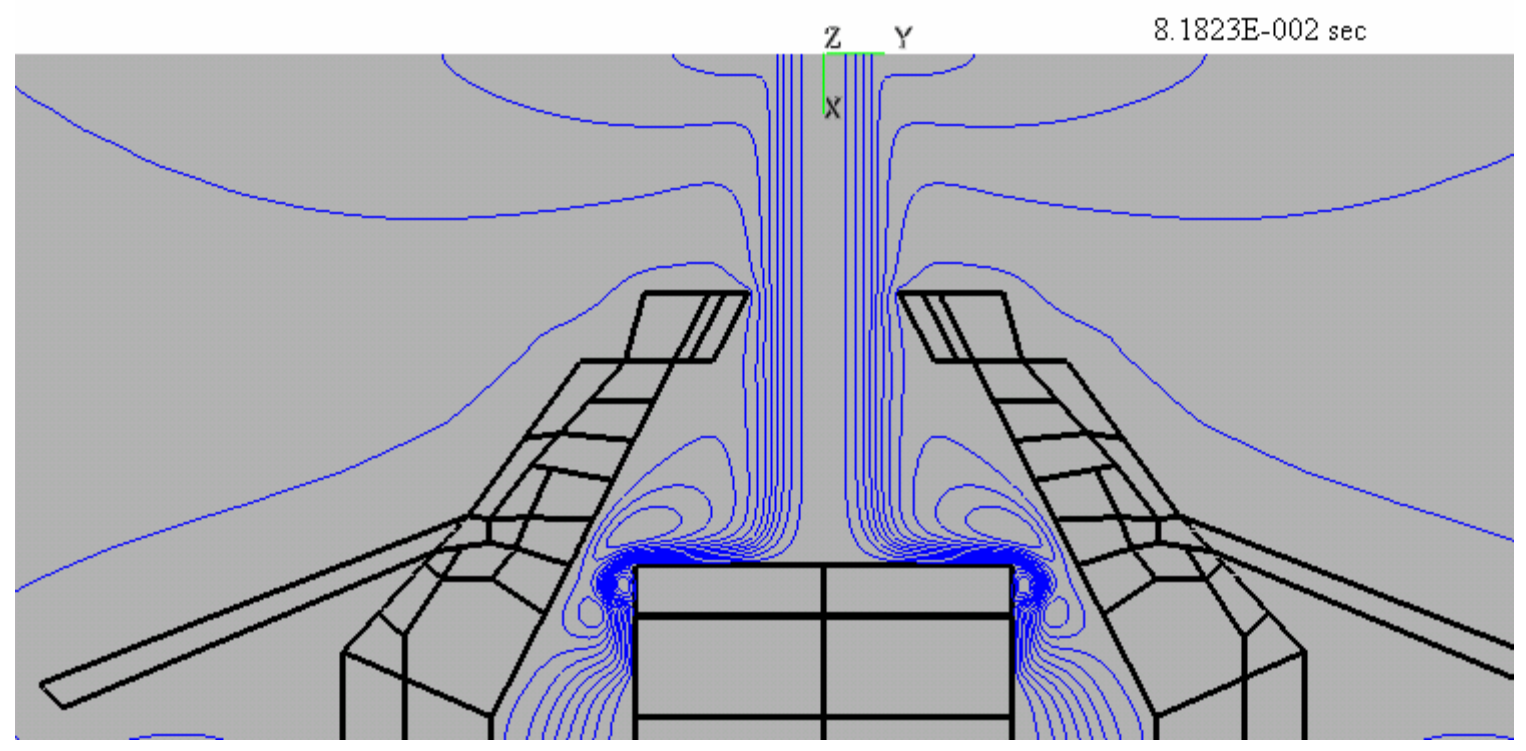

Figure 4.27 Case 3 streamlines after 0.0818 seconds.

\section{5: Case 4 Higher Velocity Case with Gravitational Force and No Kelvin Force}

In this case the velocity of the incoming jet was $0.5 \mathrm{~m} / \mathrm{s}$. The Reynolds number for this case was 6250 and the Weber number was 114.2. The rest of the model and conditions were the same as the previous cases. The presence of gravity accelerates the fluid, thus reducing the liquid jet diameter at the farthest end of the jet to preserve the continuity equation. Figure 4.28 shows the liquid jet at $\mathrm{t}=0.0126$ seconds. 


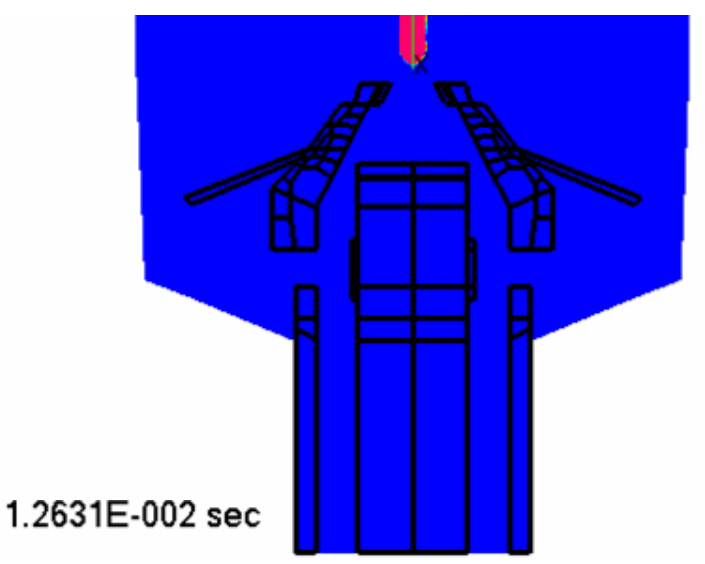

Figure 4.28 Case 4 HFE 7000 at $\mathrm{t}=0.0126$ seconds.

Figure 4.29 shows the liquid jet at $t=0.0255$ seconds. It can be seen that the liquid has contracted slightly to maintain conservation of mass in the presence of gravity. 


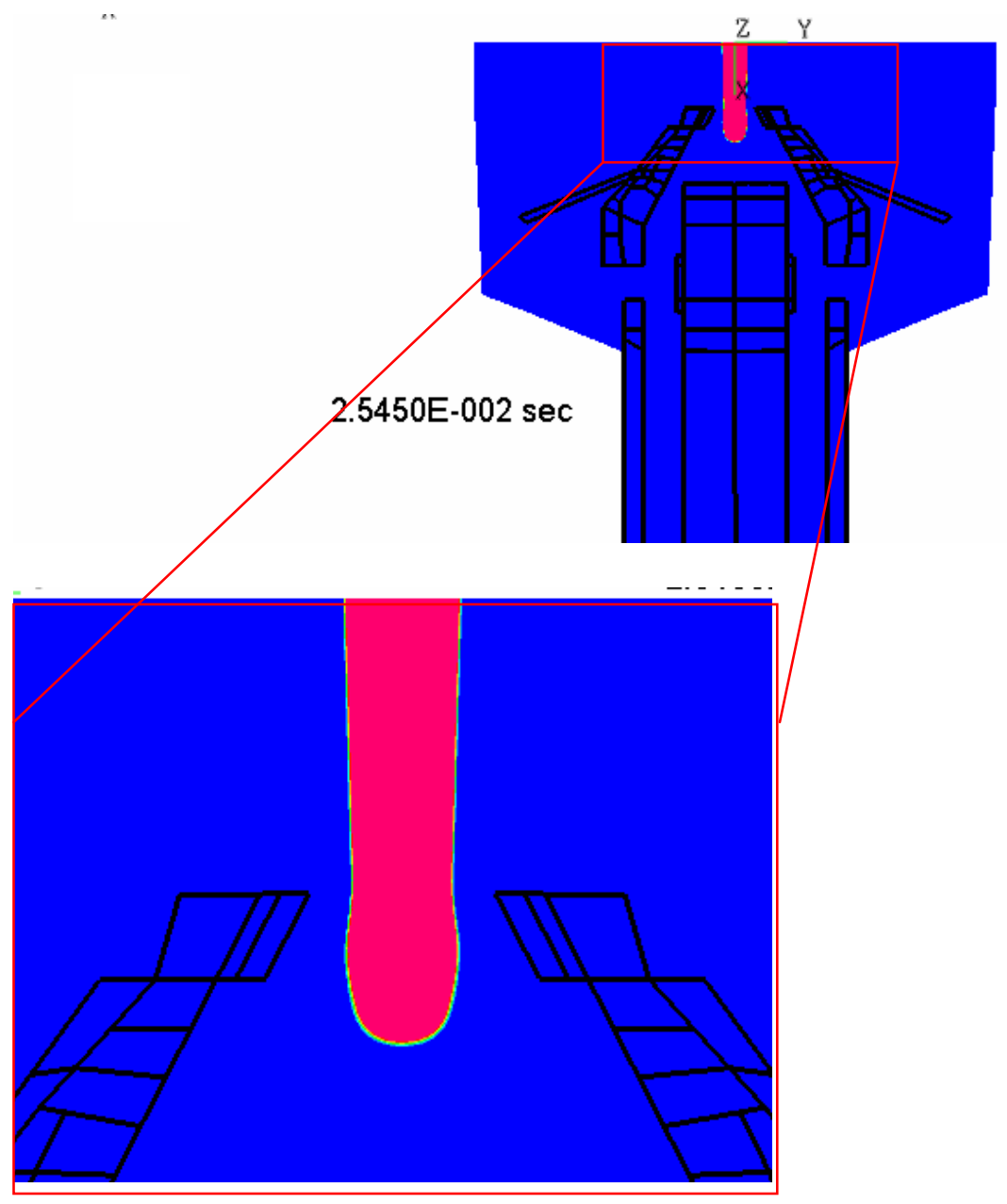

Figure 4.29 Case $4 \mathrm{HFE} 7000$ at $\mathrm{t}=0.0255$ seconds.

Figure 4.30 shows the liquid jet at $\mathrm{t}=0.0424$ seconds. The liquid jet, after hitting the pedestal surface, moves radially outwards as a thin layer of liquid. 


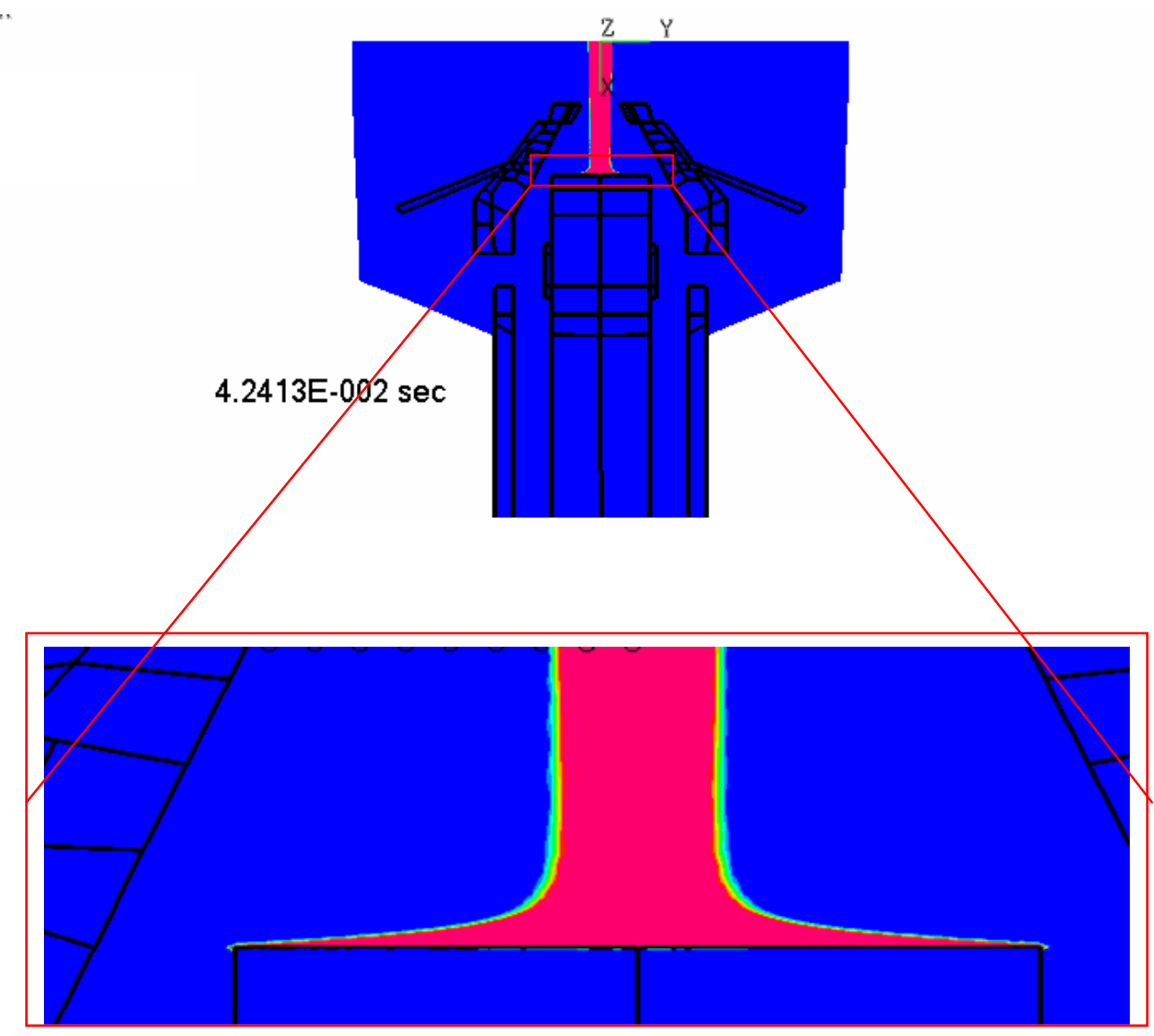

Figure 4.30 Case 4 HFE 7000 at $\mathrm{t}=0.0424$ seconds.

Figure 4.31 shows the liquid jet after 0.0479 seconds. The liquid has flowed onto the cylindrical surface of the pedestal. The simulation was stopped at this point. 


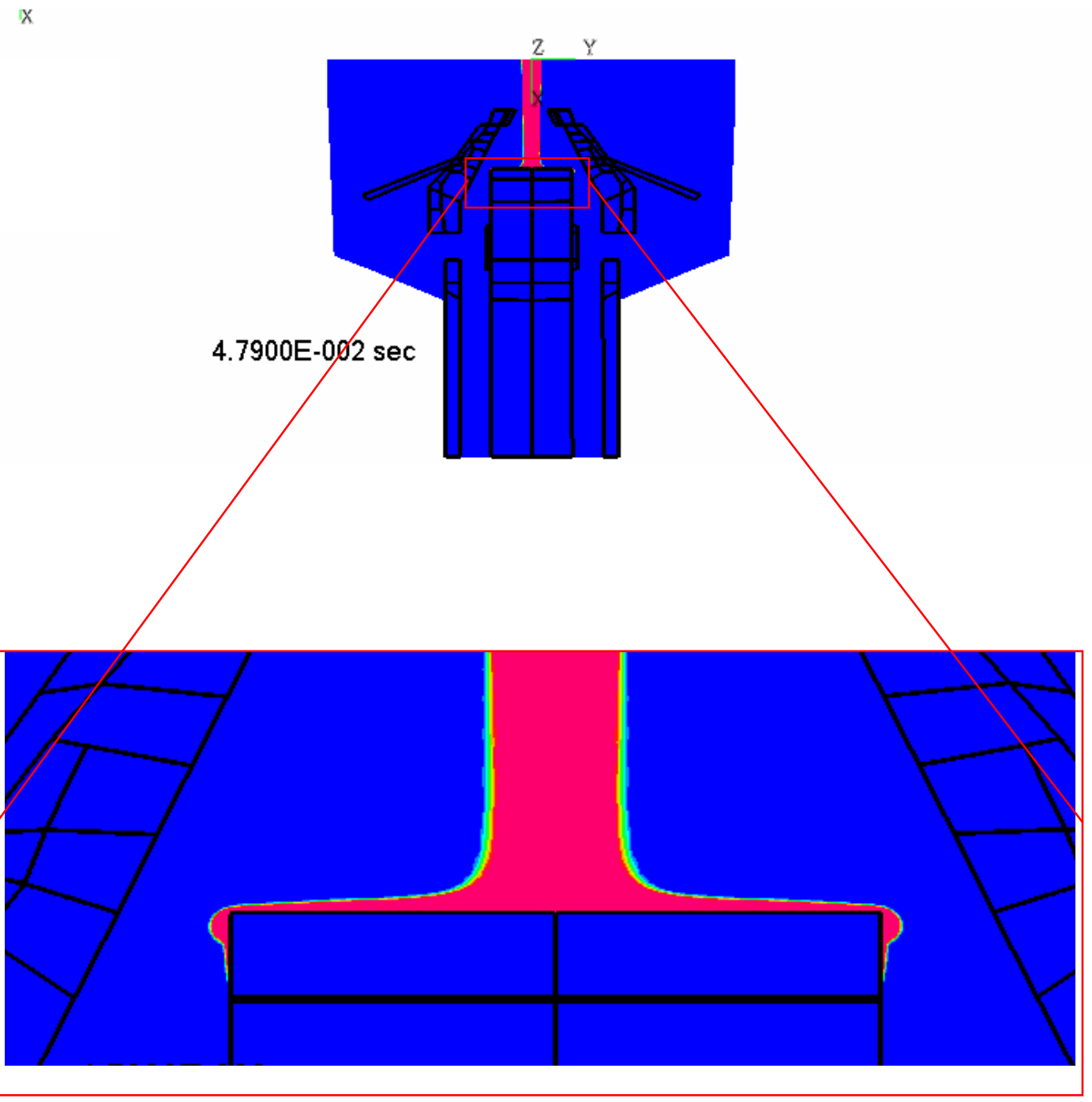

Figure 4.31 Case $4 \mathrm{HFE} 7000$ at $\mathrm{t}=0.0479$ seconds.

In general the liquid layer was thinner in the case with gravity on compared to the case with no gravity. However, this difference was not as apparent as in the low velocity regime cases. 


\section{6: Case 5 Low Velocity Case with Gravitational Force Opposed by Kelvin Force}

In this case the velocity of the incoming jet was $0.2263 \mathrm{~m} / \mathrm{s}$. Voltages of $24 \mathrm{kV}$ and $0 \mathrm{kV}$ were applied to the electrodes and $12 \mathrm{~V}$ was applied to the heater. The electric field created by this voltage creates an electric Kelvin body force which was described in Chapter 3. The electric Kelvin body force was added to the momentum equation as a source term in this case. The rest of the model and the conditions were the same as the previous cases. Figure 4.32 shows the liquid jet at $\mathrm{t}=0.0344 \mathrm{~s}$.

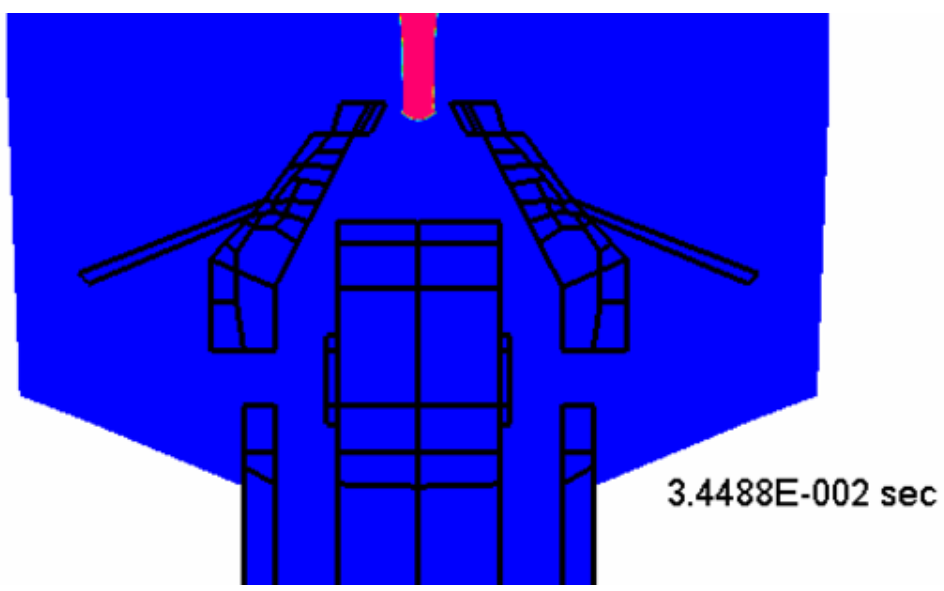

Figure 4.32 Case 5 liquid jet at $\mathrm{t}=0.0344 \mathrm{~s}$.

Figure 4.33 shows the jet at $t=0.0421 \mathrm{~s}$. The liquid jet near the electrode is pulled towards the grounded electrode because the gradient of electric field squared points towards the electrode in that region. 

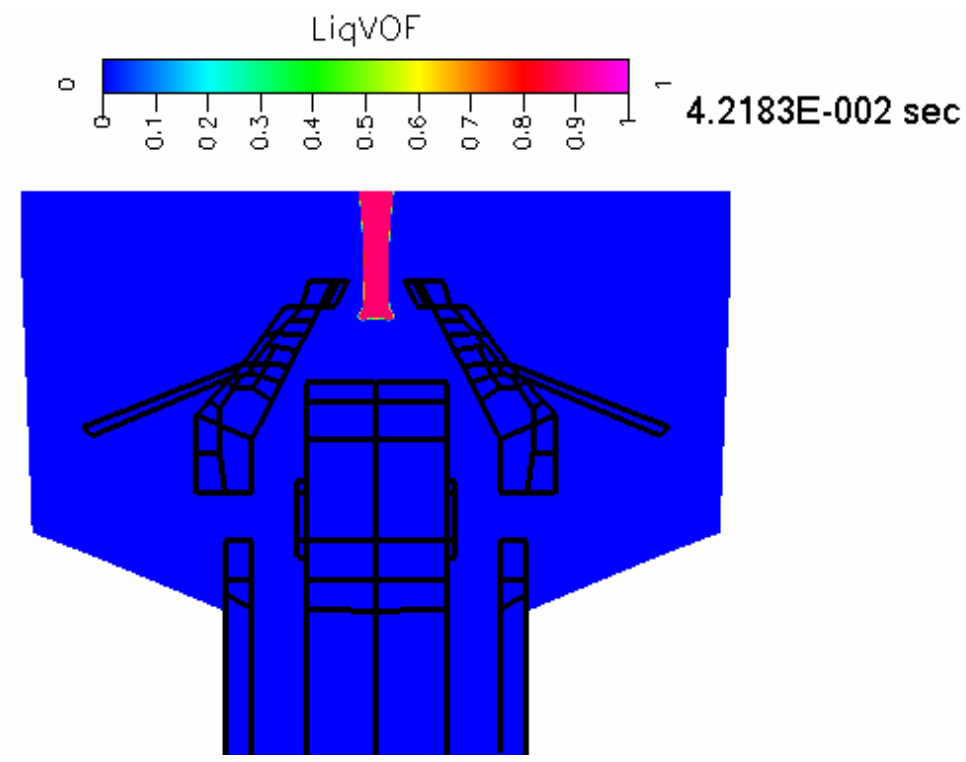

Figure 4.33 Case 5 liquid jet at $\mathrm{t}=0.042 \mathrm{~s}$.

Figure 4.34 shows the liquid jet after $0.0496 \mathrm{~ms}$. The bulge in the liquid formed near the electrode has moved downwards.
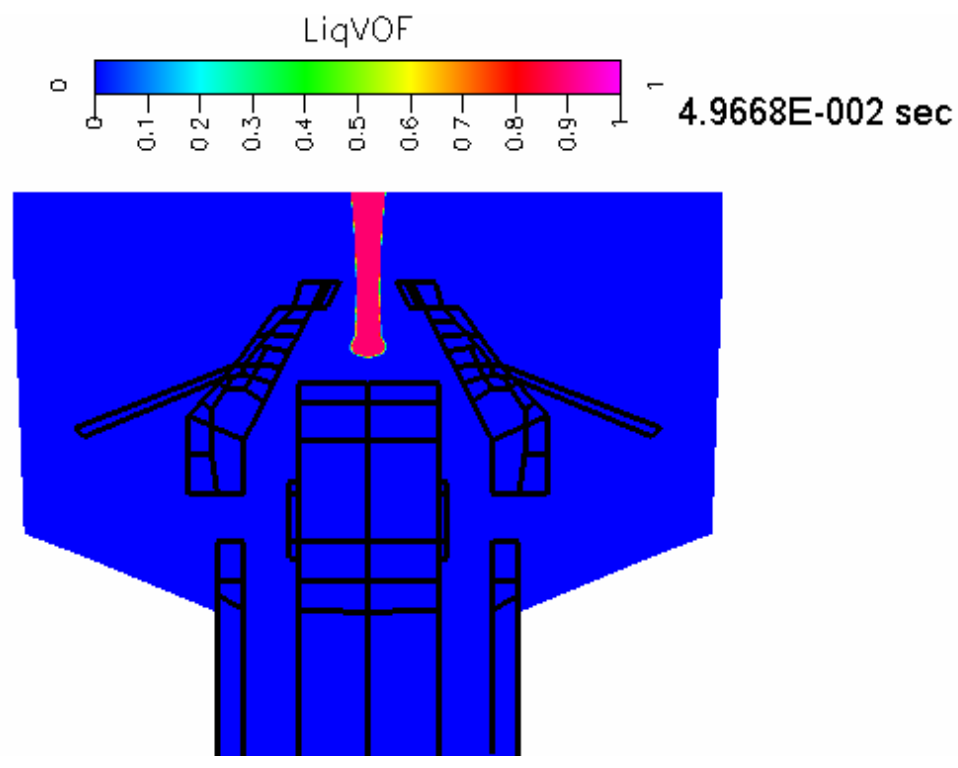

Figure 4.34 Case 5 liquid jet at $\mathrm{t}=0.0496 \mathrm{~s}$. 
Figure 4.35 shows the liquid jet after $0.0586 \mathrm{~s}$. Figure 4.35 shows that the liquid jet has impinged on the surface and is moving radially outwards. The surface of the liquid looks disturbed, probably because of surface waves formed near the electrode where there was significant electric Kelvin force pulling the liquid away from the jet and towards the electrode. Some effect however could be attributed to the coarseness of the grid around that region although refining the grid does not mean this disturbance will not be present in the physical flow.

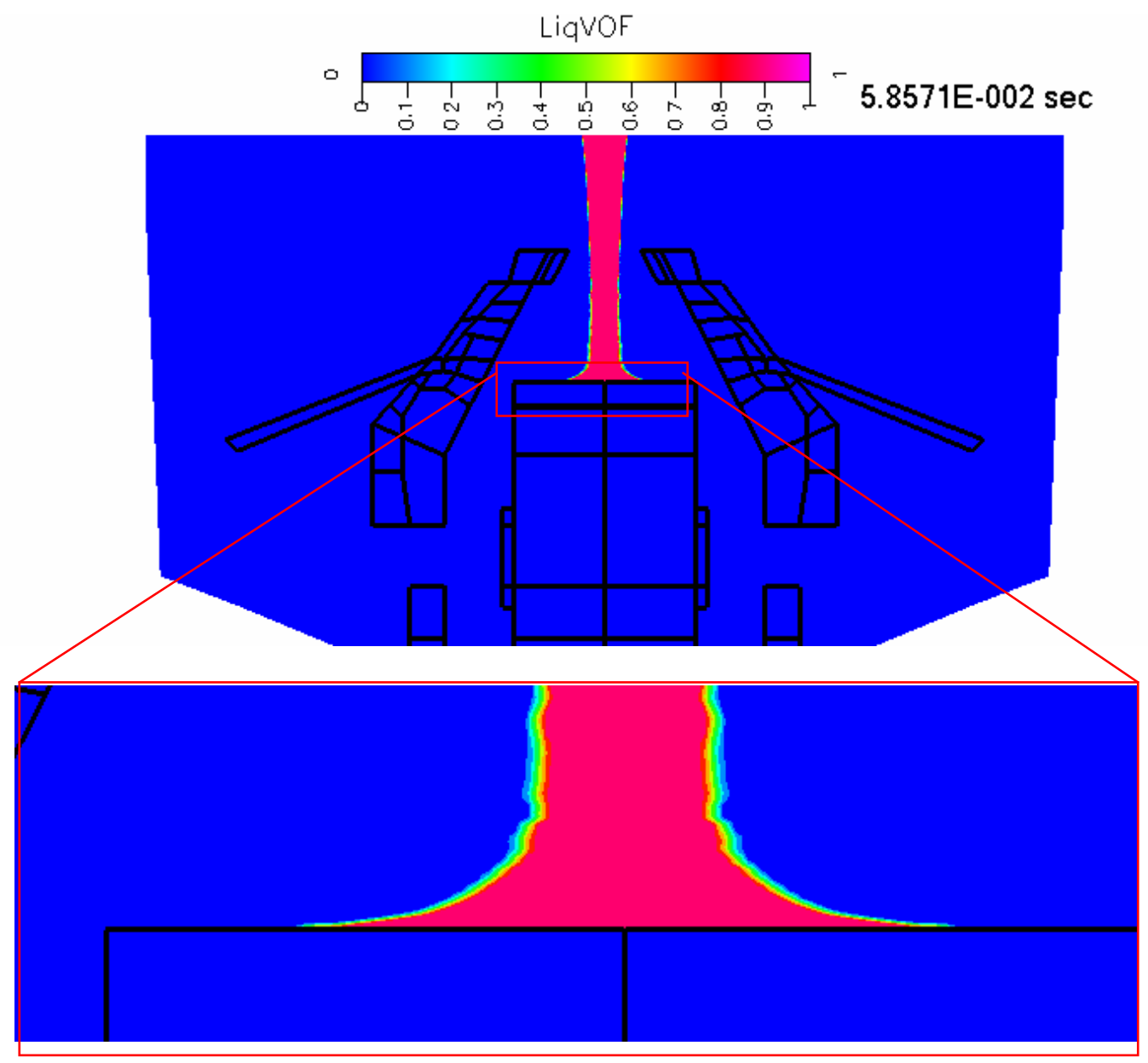

Figure 4.35 Case 5 liquid jet at $\mathrm{t}=0.0586 \mathrm{~s}$. 
Figure 4.36 shows the liquid jet at $t=0.064 \mathrm{~s}$.

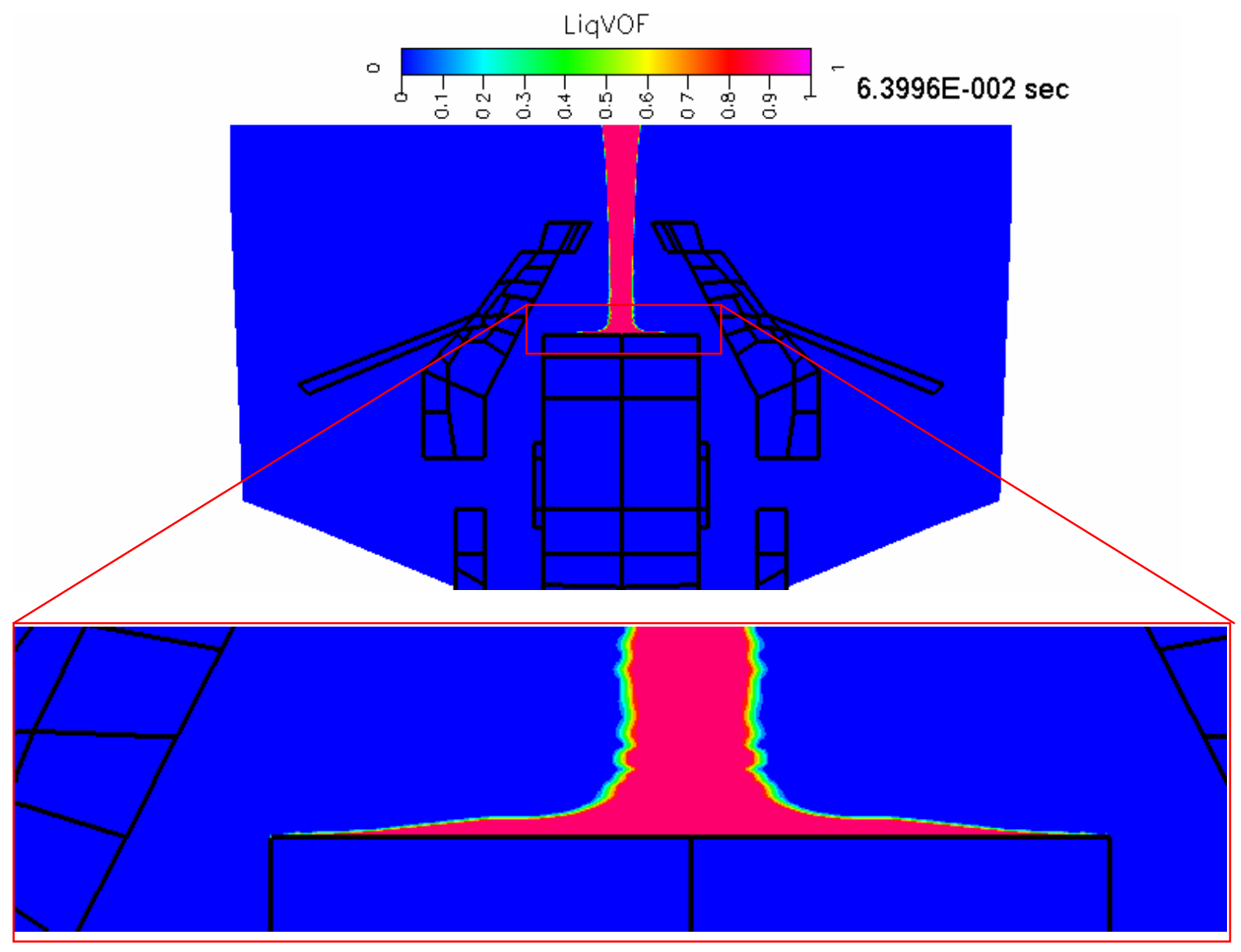

Figure 4.36 Case 5 liquid jet after $0.064 \mathrm{~s}$.

Figure 4.37 shows the liquid jet at $t=0.069 \mathrm{~s}$, and it shows that the liquid has reached the edge of the pedestal and has started to flow down the pedestal. 


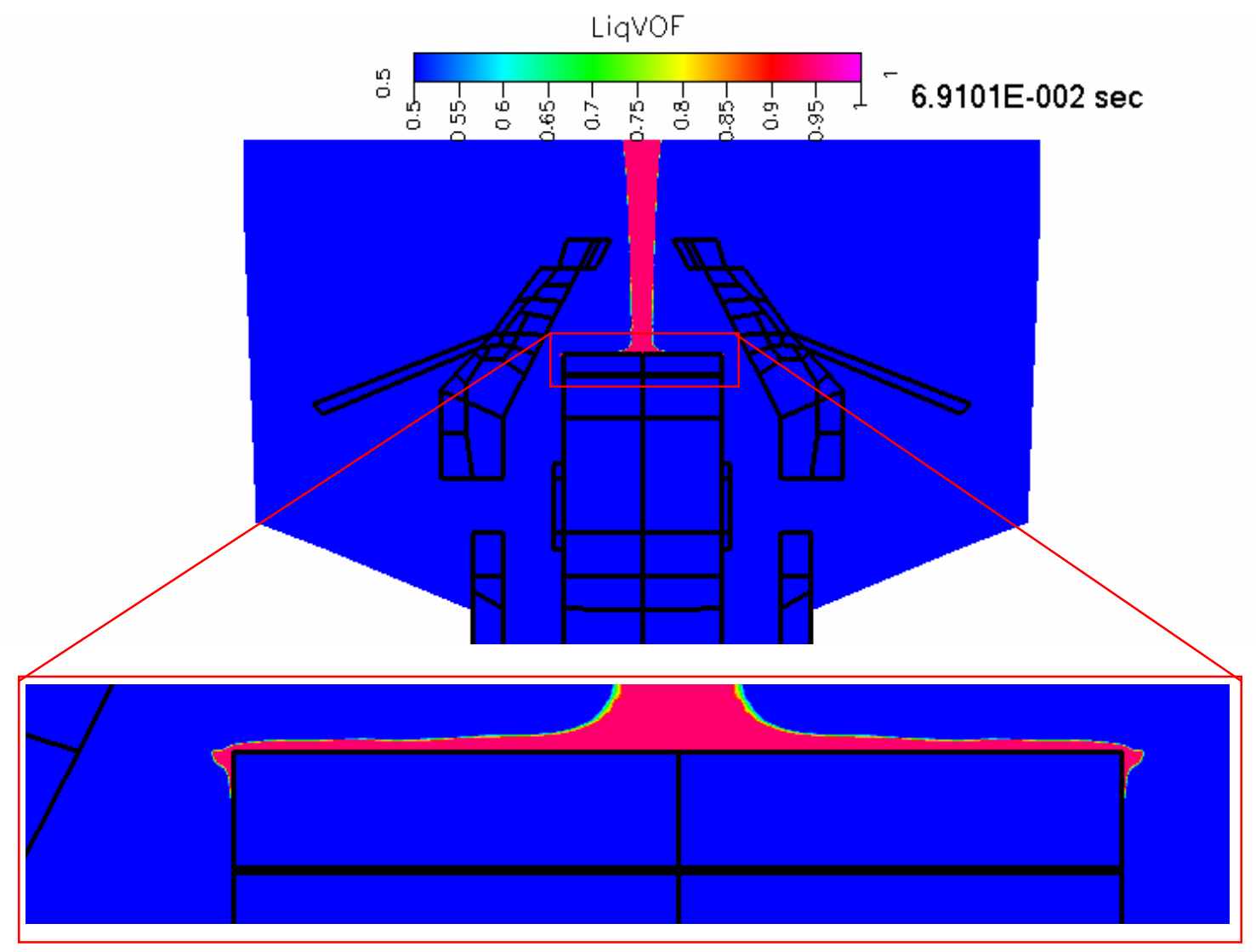

Figure 4.37 Case 5 liquid jet at $\mathrm{t}=0.0691 \mathrm{~s}$.

Figure 4.38 shows the electric potential at $0 \mathrm{~s}$ and at $\mathrm{t}=0.0691 \mathrm{~s}$, when the liquid starts flowing down the pedestal. The electric potential gets modified slightly under the presence of the liquid because of the liquid's permittivity differs that of the air. 

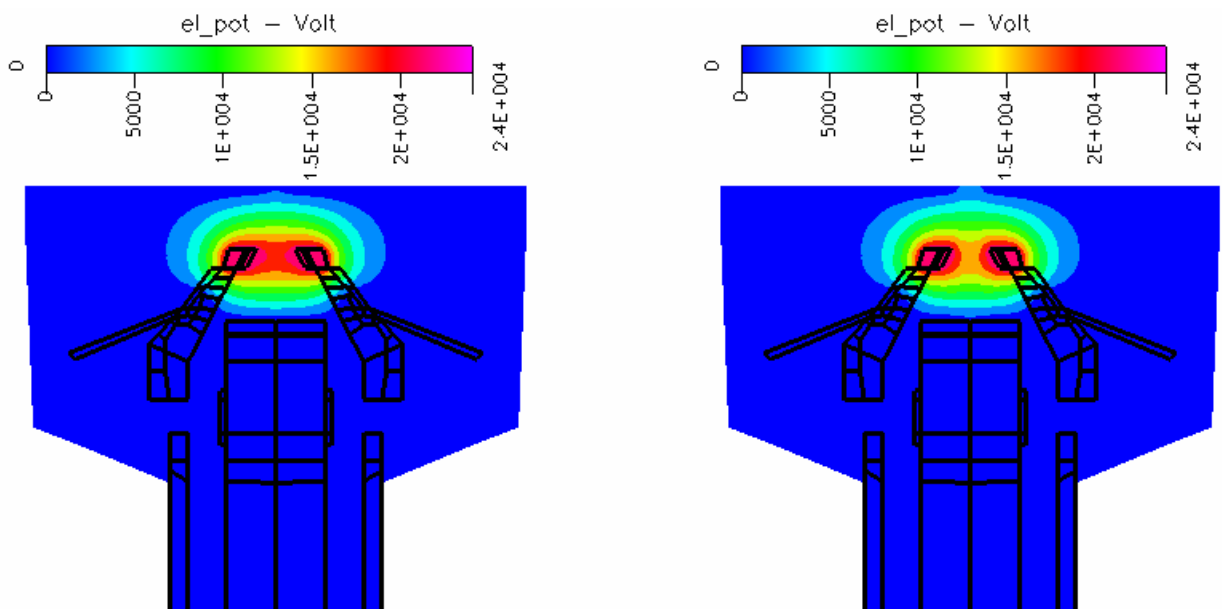

Figure 4.38 Case 5 electric potential at $0 \mathrm{~s}$ and at $0.0691 \mathrm{~s}$.

Figure 4.39 shows the centerline velocity variation from the inlet to $0.1 \mathrm{~mm}$ before the surface. Figure 4.40 shows this plot after the jet impinges on the pedestal. The axial velocity is affected only slightly by the presence of the electric Kelvin force when compared to $1 \mathrm{~g}$ case. This is apparent from both the plots of before and after the jet impingement on the surface. This difference is small since the volume over which the electric Kelvin force reduces the gravitational force is about $1 \mathrm{~mm}$ thick and the liquid jet needs to travel for a significant distance (order of $1 \mathrm{~cm}$ in this case) in the uniform gravitational force to have a large impact on the final flow configuration. 


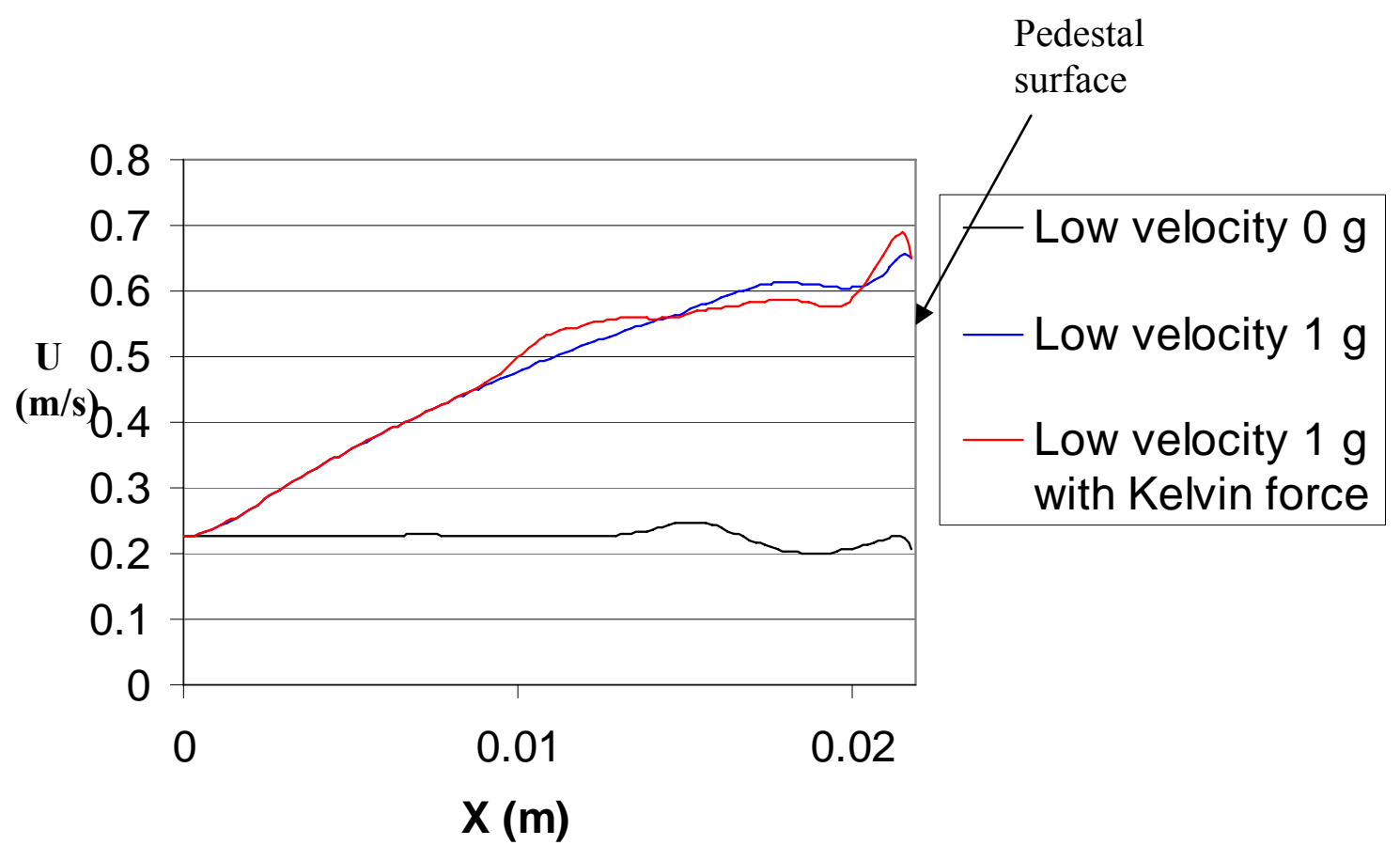

Figure 4.39 Centerline velocity measured from the inlet before the jet impingement for the low velocity cases. 


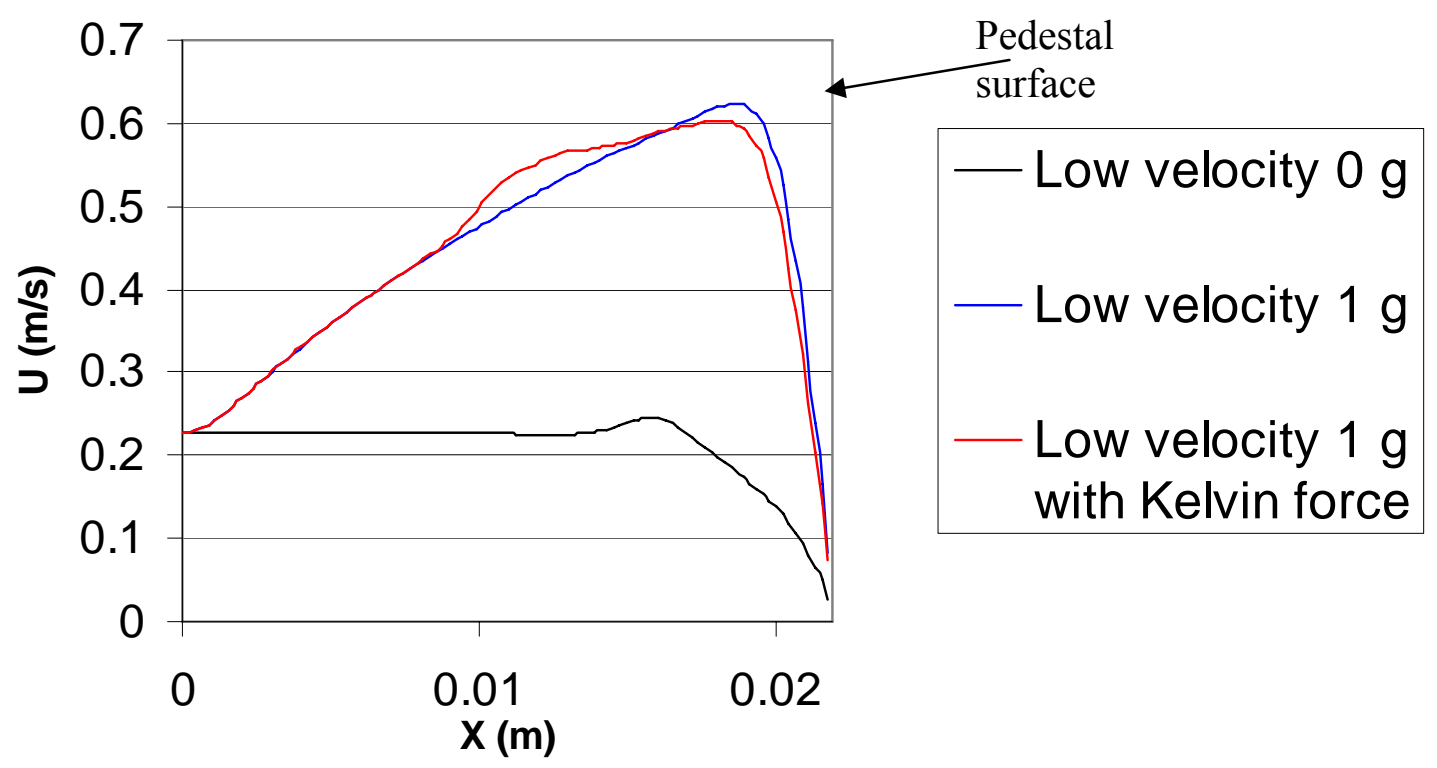

Figure 4.40 Centerline axial velocity measured from the inlet after the jet impingement for the low velocity cases.

\subsection{Case 6: Higher Velocity Case with Gravitational Force Opposed by Kelvin Force}

In this case the velocity of the incoming jet was fixed to be $0.5 \mathrm{~m} / \mathrm{s}$. The gravity was in the direction of the jet and the electric Kelvin force was also activated in this case before the fluid enters the domain. The rest of the model is the same as the previous cases. Figure 4.41 shows the liquid jet at $\mathrm{t}=0.0133 \mathrm{~s}$. 


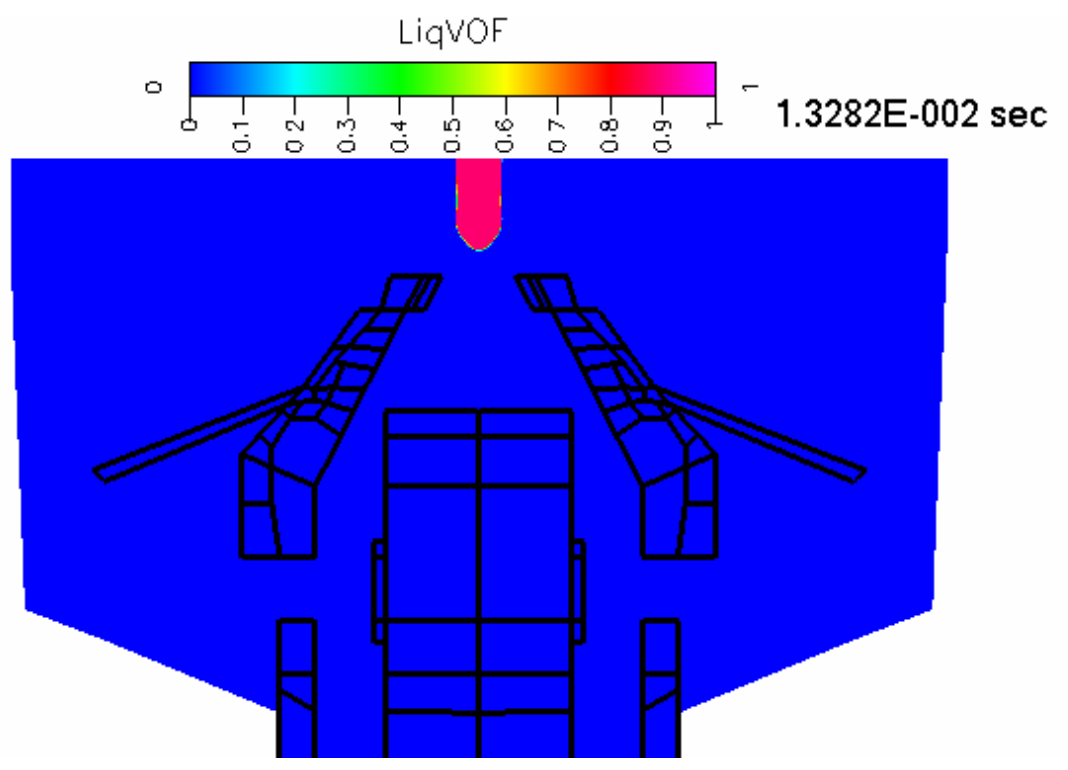

Figure 4.41 Case 6 liquid jet after $0.0133 \mathrm{~s}$.

Figure 4.42 shows the location of the liquid jet at $t=0.0258 \mathrm{~s}$. Figure 4.43 shows the liquid jet at $\mathrm{t}=0.0351 \mathrm{~s}$

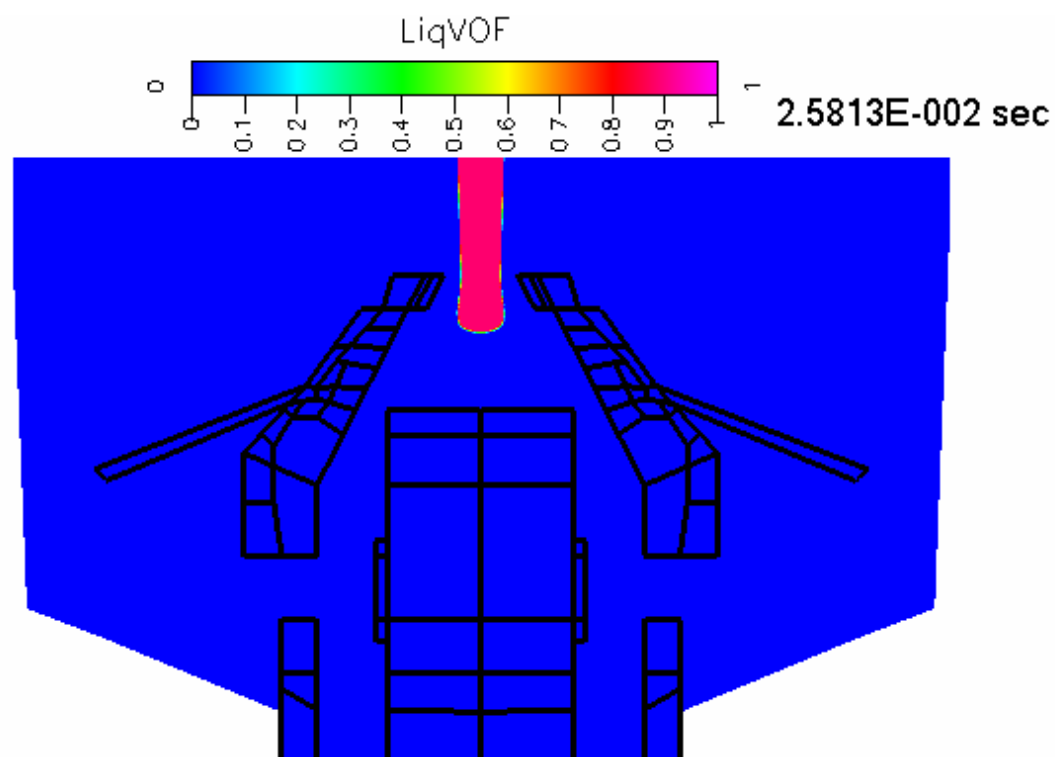

Figure 4.42 Case 6 liquid jet at $\mathrm{t}=0.0258 \mathrm{~s}$. 


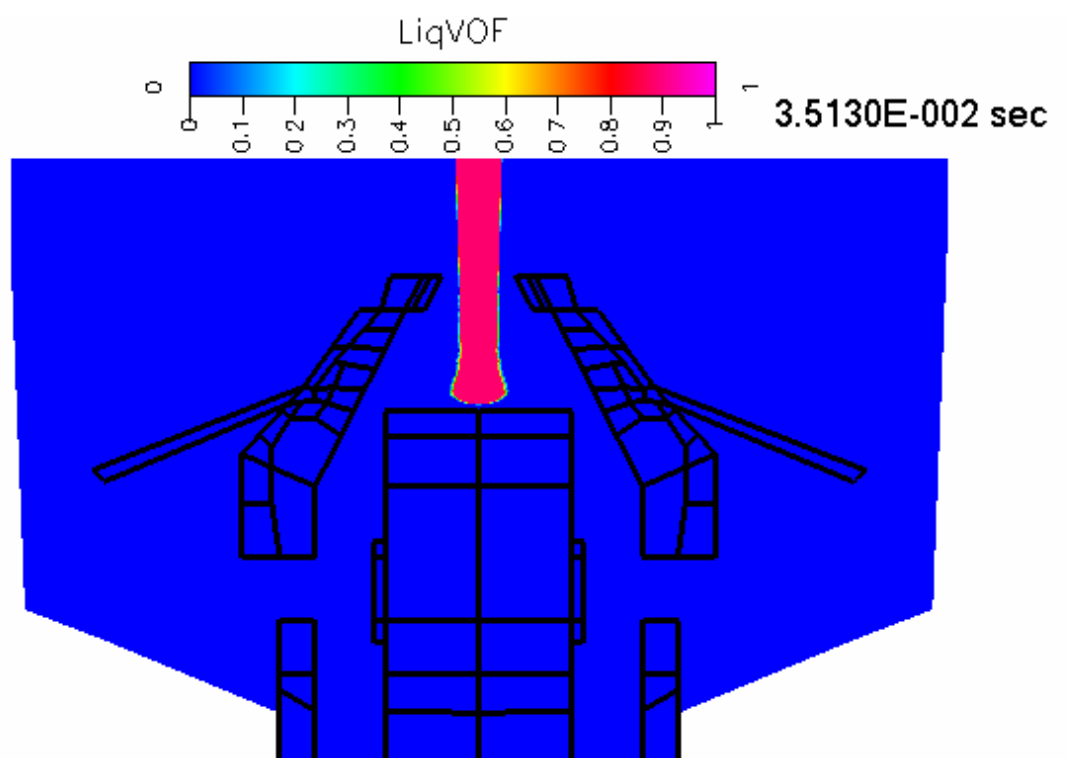

Figure 4.43 Case 6 liquid jet at $\mathrm{t}=0.0351 \mathrm{~s}$.

Figure 4.44 depicts the liquid jet at $t=0.041 \mathrm{~s}$. The liquid jet has impinged on the surface and has started flowing radially outwards on the pedestal. Figure 4.45 shows the electric potential solution before the fluid has entered the domain and after the liquid jet has impinged on the pedestal surface. Figure 4.46 shows the plot of centerline velocity of the jet before the jet impinges on the surface $(0.1 \mathrm{~mm}$ before the surface). Figure 4.47 shows the same plot after the jet impinges on the surface. It may be inferred from these graphs that the electric Kelvin force does influence the axial velocity of the liquid jet when the electric field is activated. This difference is small owing to the reasons discussed in Case 5. 


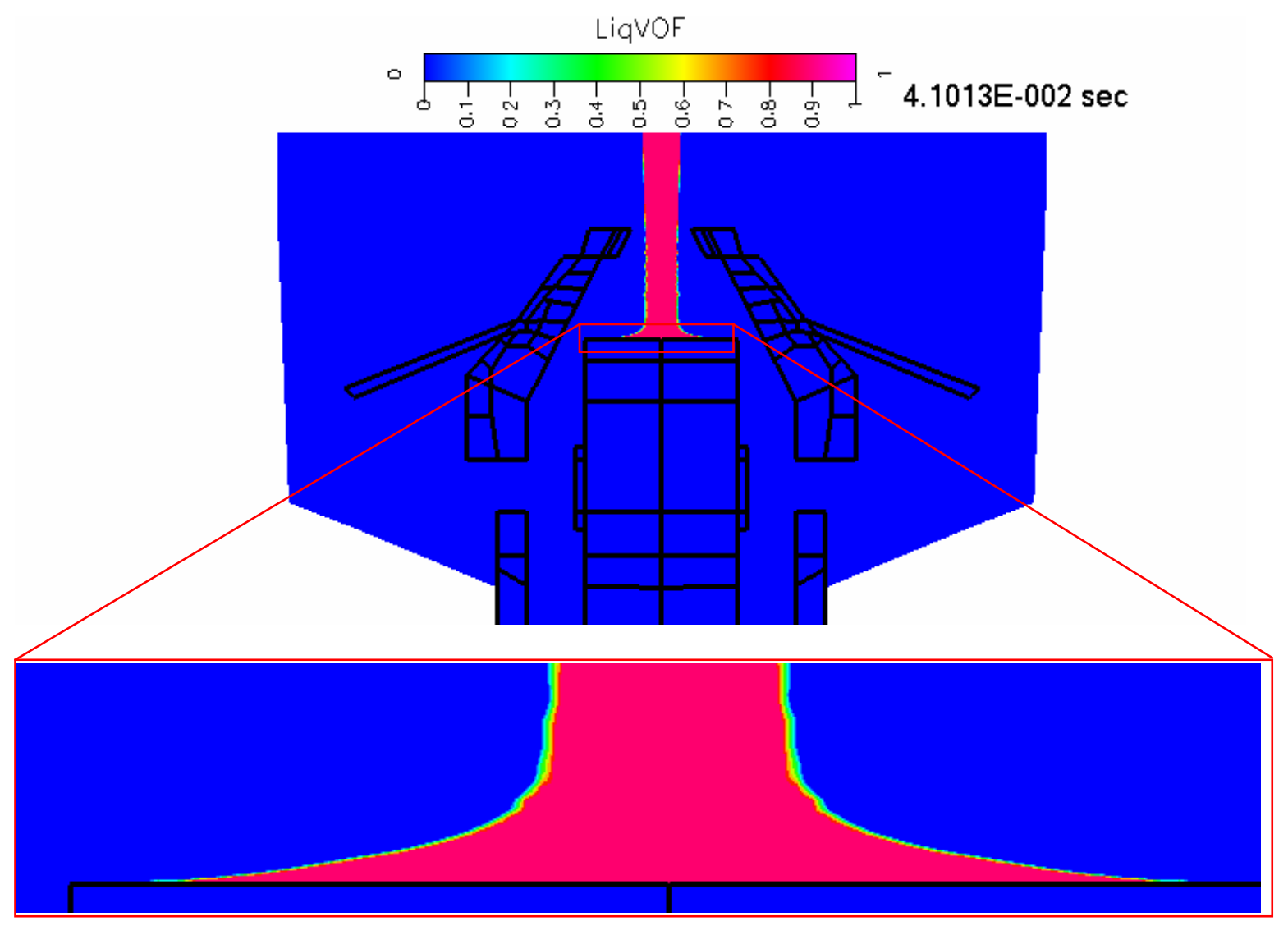

Figure 4.44 Case 6 liquid jet after $0.041 \mathrm{~s}$. 

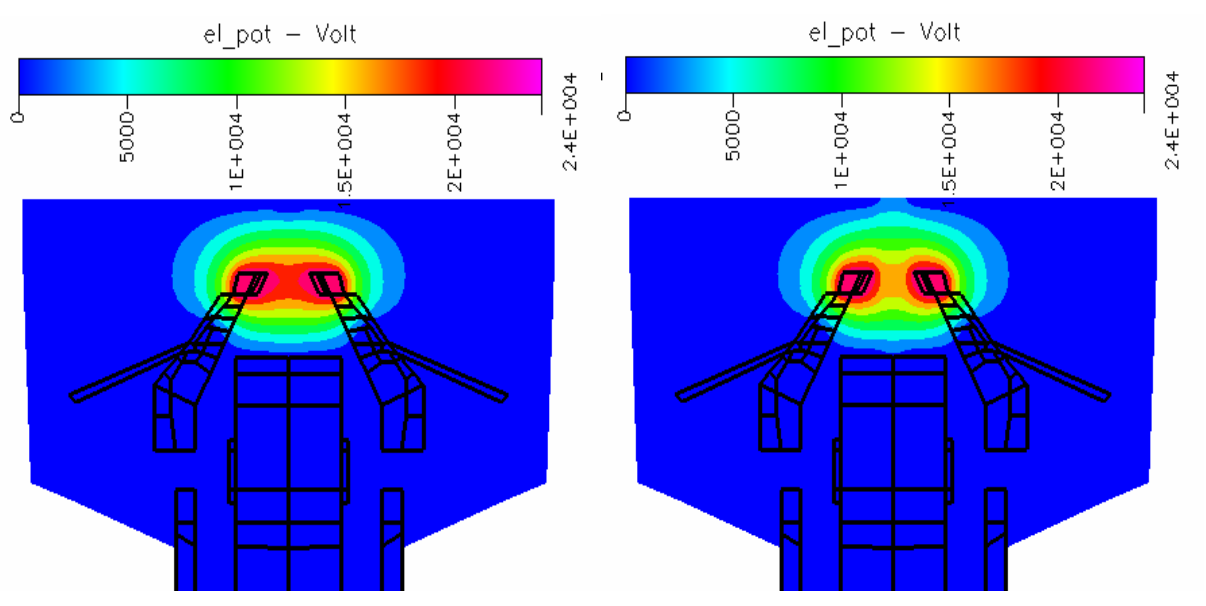

$$
\mathrm{t}=0 \mathrm{~s} \quad \mathrm{t}=0.04 \mathrm{~s}
$$

Figure 4.45 Case 6 electric potential before the jet enters the domain and after the liquid impinges on the pedestal.

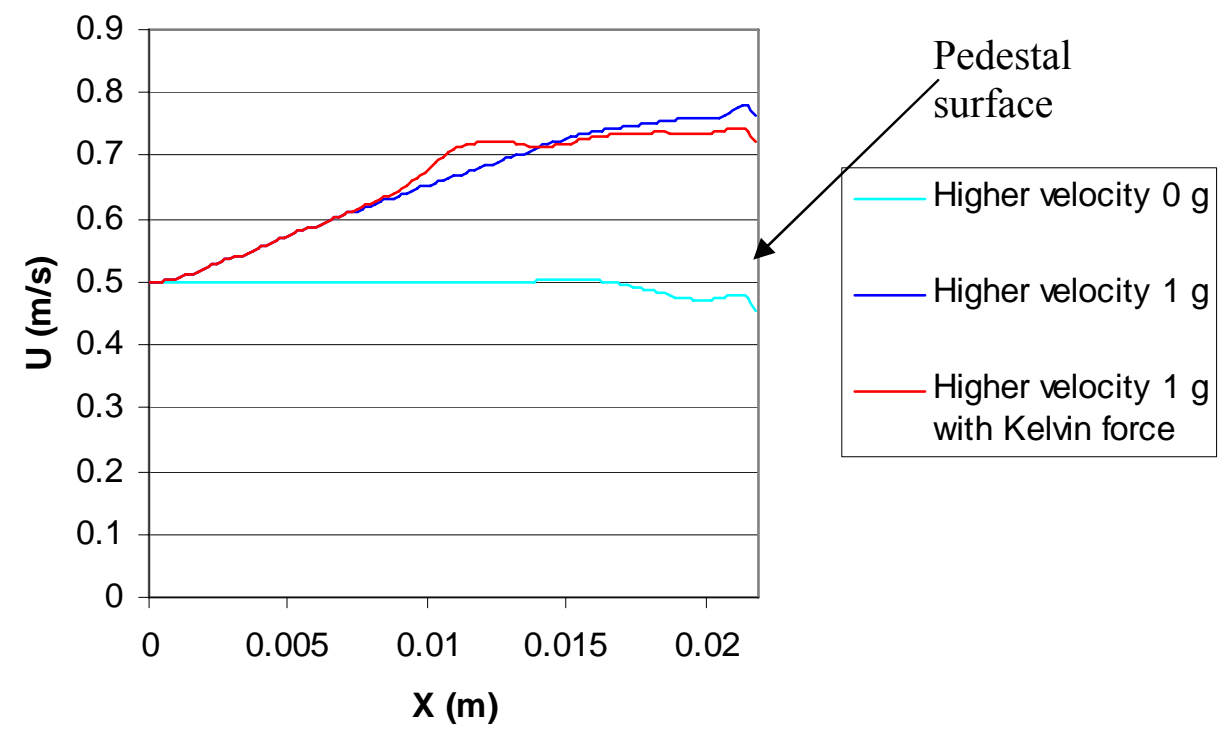

Figure 4.46 Centerline velocity measured from the inlet before the jet impingement for the higher velocity cases. 


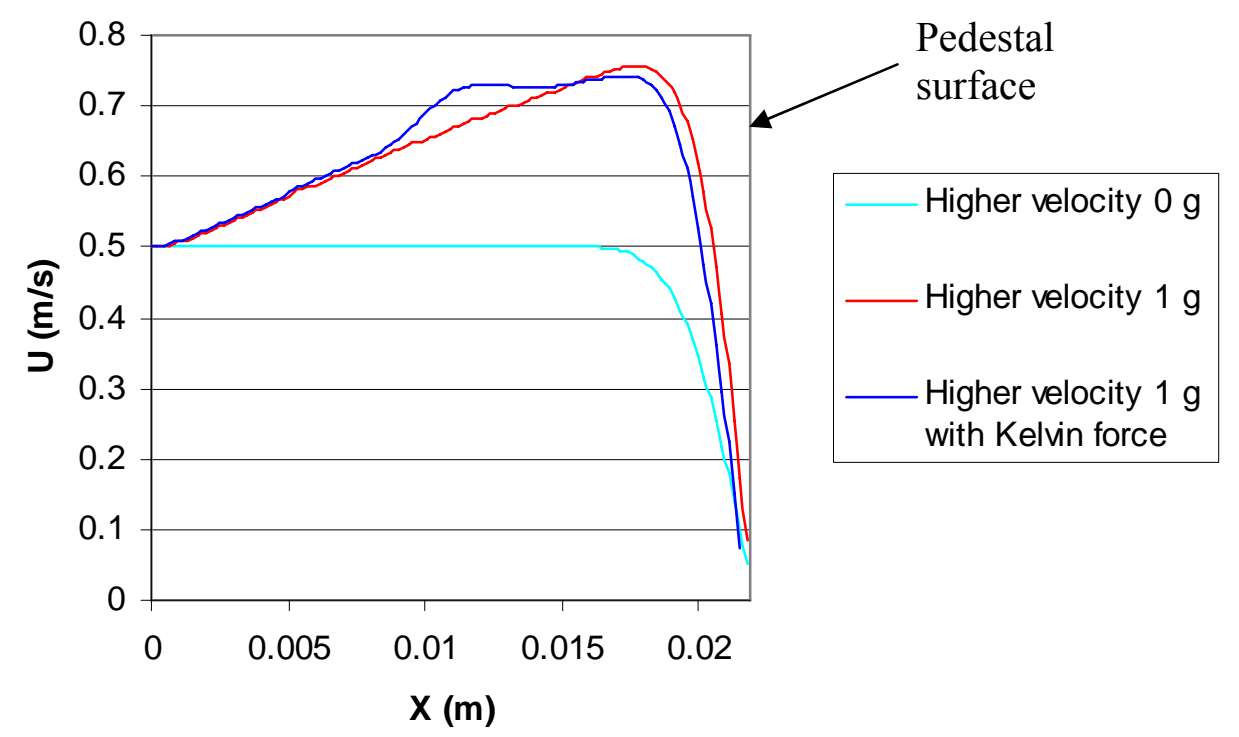

Figure 4.47 Centerline velocity measured from the inlet after the jet impingement for the higher velocity cases.

The cases from 1 to 6 described in this chapter suggest that electric Kelvin force to mass ratio will make a "large" effect on the isothermal flow if the region over which this ratio is uniform is large (of the order of $1 \mathrm{~cm}$ ) and liquid jet actually flows through the region. Also, these effects are larger at lower jet velocity (Re), and would be increased for higher voltages. 


\section{Chapter 5}

\section{Heat Transfer with Variable Gravitational Accelerations}

\subsection{Introduction and Setup}

This chapter presents simulations of heat transfer cases with different values of gravity. The purpose of these simulations was to find how the heat transfer from the liquid jet impingement is affected as the gravity is varied. This is important since we are living in an era of space exploration which involves use of micro and macro electronic equipment. Many of the micro electronic devices heat up very rapidly and need efficient mechanisms to cool down. One such mechanism is liquid jet impingement where the liquid is impinged upon a heated surface and carries the heat with the flow. These simulations suggest how the heat transfer is affected as the gravitational body force is varied. Also the electric Kelvin force per unit mass can mimic the gravitational body force per unit mass on Earth. These simulations also suggest what kind of electric Kelvin force per unit mass would be required to significantly enhance the heat transfer under terrestrial gravity conditions.

All the cases were again modeled as two dimensional axi-symmetric flows using CFDACE+. The domain in this case was $1.3 \mathrm{~cm} \times 0.8 \mathrm{~cm}$. The larger length was the axial direction which was also the direction of the jet and gravity. This model is shown in Figure 5.1. The jet diameter was equal to $4 \mathrm{~mm}$. The liquid used was HFE 7000, whose properties have been listed in Table 3.1. The density of the fluid was modeled as constant 
because for the small temperature differences and higher Reynolds numbers in these simulations, buoyancy is not expected to make a significant difference in the solution. The other properties of the liquid including the viscosity, thermal conductivity and specific heat were also assumed constant. The thickness of the heated plate on which the liquid jet impinged was $0.1 \mathrm{~mm}$ and the properties of stainless steel were assigned to it. The density of this plate was thus $8000 \mathrm{~kg} / \mathrm{m}^{3}$, the specific heat was $500 \mathrm{~J} / \mathrm{kg} \cdot \mathrm{K}$ and the thermal conductivity was $14 \mathrm{~W} / \mathrm{m} \cdot \mathrm{K}$.

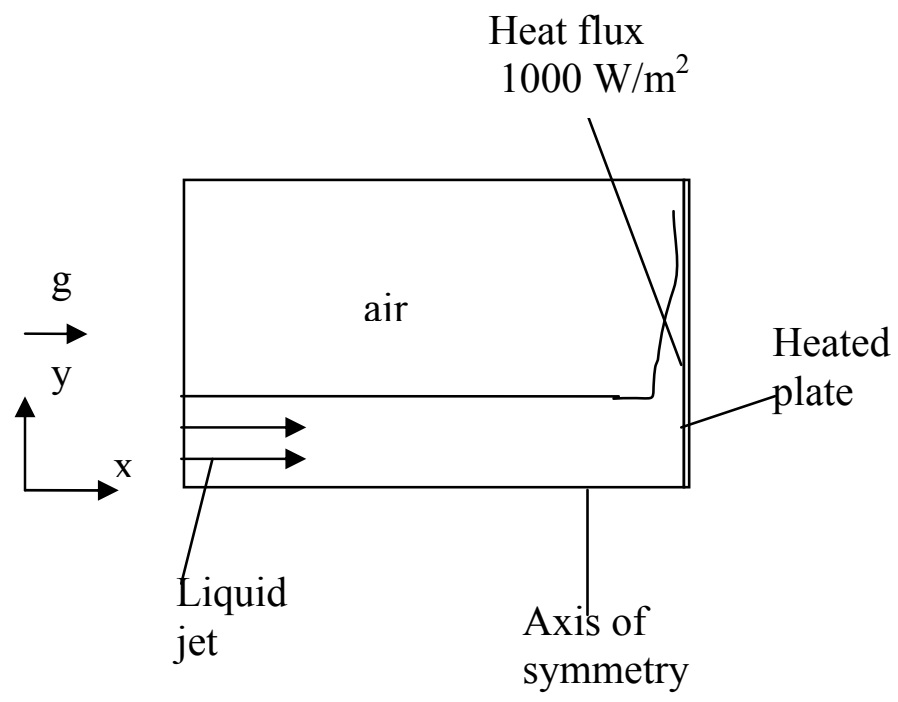

Figure 5.1 An axi-symmetric model for liquid jet impingement with heat transfer.

The inlet boundary condition was a fixed uniform velocity as specified in Table 5.1. The boundary where the liquid was flowing out of the domain was specified to be a zero pressure gradient boundary. The contact angle on the solid wall was specified to be fully wetting or $0^{\circ}$. All other boundaries were specified have a constant atmospheric pressure. The heat flux used in all the cases was equal to $1000 \mathrm{~W} / \mathrm{m}^{2}$. This low value was used because of the low boiling point $\left(34{ }^{\circ} \mathrm{C}\right)$ of the liquid used in the simulations, HFE 7000. 
Since this study did not include phase change it was prudent to use a low power which would not cause boiling. The heat flux was specified on the upper boundary of the plate which can physically mean the heat coming from a very thin metal through which current is passed and heat is generated because of the resistance. The lower boundary was given an adiabatic boundary condition which means heat loss from this boundary was ignored and all the heat was expected to flow through the moving liquid layer from the jet. .

The sets of Re and We numbers based on the jet exit velocity were the same as those used in Cases 1 to 6 in Chapter 4. Figure 5.2 shows the grid used to obtain a steady state solution with this model. Evaporation was not modeled, but energy exchange could take place between the liquid and air. The conduction in the plate was modeled and was part of the actual solution in each case. As can be seen in Figure 5.2 the grid was refined in the layer adjacent to the heated plate. This grid had a total of 1410 cells.

The steady state conditions were reached when it was found that the temperature stopped varying with time after running for several seconds. This physical time varied for different simulations from 2 to 8 seconds. The grid was then refined to 2760 cells check for grid independent solution and this did not have any effect on the final steady state temperature distribution. It may be noted that the circumferential surface tension is also taken into account through radial pressure gradients.

The test matrix for the cases involving heat transfer includes eight different simulations as shown in Table 5.1. In four of these cases a low velocity $0.2263 \mathrm{~m} / \mathrm{s}$ was used and the uniform body force was varied in the increments of $0.5 \mathrm{~g}$, from 0 to $1.5 \mathrm{~g}$. Similarly, four 
cases were simulated in which the velocity was higher, $0.5 \mathrm{~m} / \mathrm{s}$. The two different velocities were selected so as to find out how heat transfer is affected as the velocity of the liquid jet varies.

The Stokes number is a measure of the ratio of viscous to gravitational forces and is defined by

$$
\mathrm{St}=\frac{v \mathrm{U}_{\mathrm{e}}}{\mathrm{g} \mathrm{L}^{2}}
$$

where $v$ is the kinematic viscosity

$\mathrm{U}_{\mathrm{e}}$ is the jet exit velocity at the nozzle, $\mathrm{g}$ is the acceleration due to gravity, and $\mathrm{L}=0.0129 \mathrm{~m}$ is the distance between the jet inlet plane and the impingement plane. Jet impingement velocity is given by

$$
\mathrm{U}_{\mathrm{i}}=\left(\mathrm{U}_{\mathrm{e}}^{2}+2 \mathrm{gL}\right)^{0.5}
$$


Table 5.1 Simulated heat transfer cases with variable gravity.

\begin{tabular}{|l|l|l|l|l|l|l|l|l|}
\hline Case & H1 & H2 & H 3 & H 4 & H 5 & H 6 & H 7 & H8 \\
\hline $\begin{array}{l}\text { Gravity } \\
\left(\mathrm{m} / \mathrm{s}^{2}\right)\end{array}$ & 0 & 4.9 & 9.8 & 14.7 & 0 & 4.9 & 9.8 & 14.7 \\
\hline $\begin{array}{l}\mathbf{U}_{\mathbf{e}} \\
(\mathrm{m} / \mathrm{s})\end{array}$ & 0.2263 & 0.2263 & 0.2263 & 0.2263 & 0.5 & 0.5 & 0.5 & 0.5 \\
\hline $\begin{array}{l}\mathbf{U}_{\mathbf{i}}(\mathrm{m} / \mathrm{s}) \\
\mathbf{W e}\end{array}$ & 0.2263 & 0.4215 & 0.5514 & 0.6561 & 0.5 & 0.6135 & 0.709 & 0.793 \\
\hline $\mathbf{R e}$ & 23.4 & 23.4 & 23.4 & 23.4 & 114.2 & 114.2 & 114.2 & 114.2 \\
\hline $\mathbf{1 / S t}$ & 0 & 11260 & 22520 & 33780 & 0 & 5096 & 10193 & 15289 \\
\hline
\end{tabular}

\subsection{Simulation Results and Discussion}

Figure 5.3 shows the steady state flow conditions for the low velocity regime with no gravity, Case H1. Figure 5.4 shows the steady state temperature distribution for Case H1. The scale deltaT_dim is the temperature difference made dimensionless by the maximum temperature difference.

deltaT_dim $=\frac{T-288}{T_{\max }-288}$

where $\mathrm{T}$ is the local temperature in Kelvin 
Figure 5.4 shows that the temperature increases radially outwards as the thermal boundary layer and the viscous layer boundary layer increase in height. The temperature also increases away from the centerline, suggesting less heat transfer to the moving layer. The plot shows lines of constant temperature in the solid plate as well as in the liquid layer. 


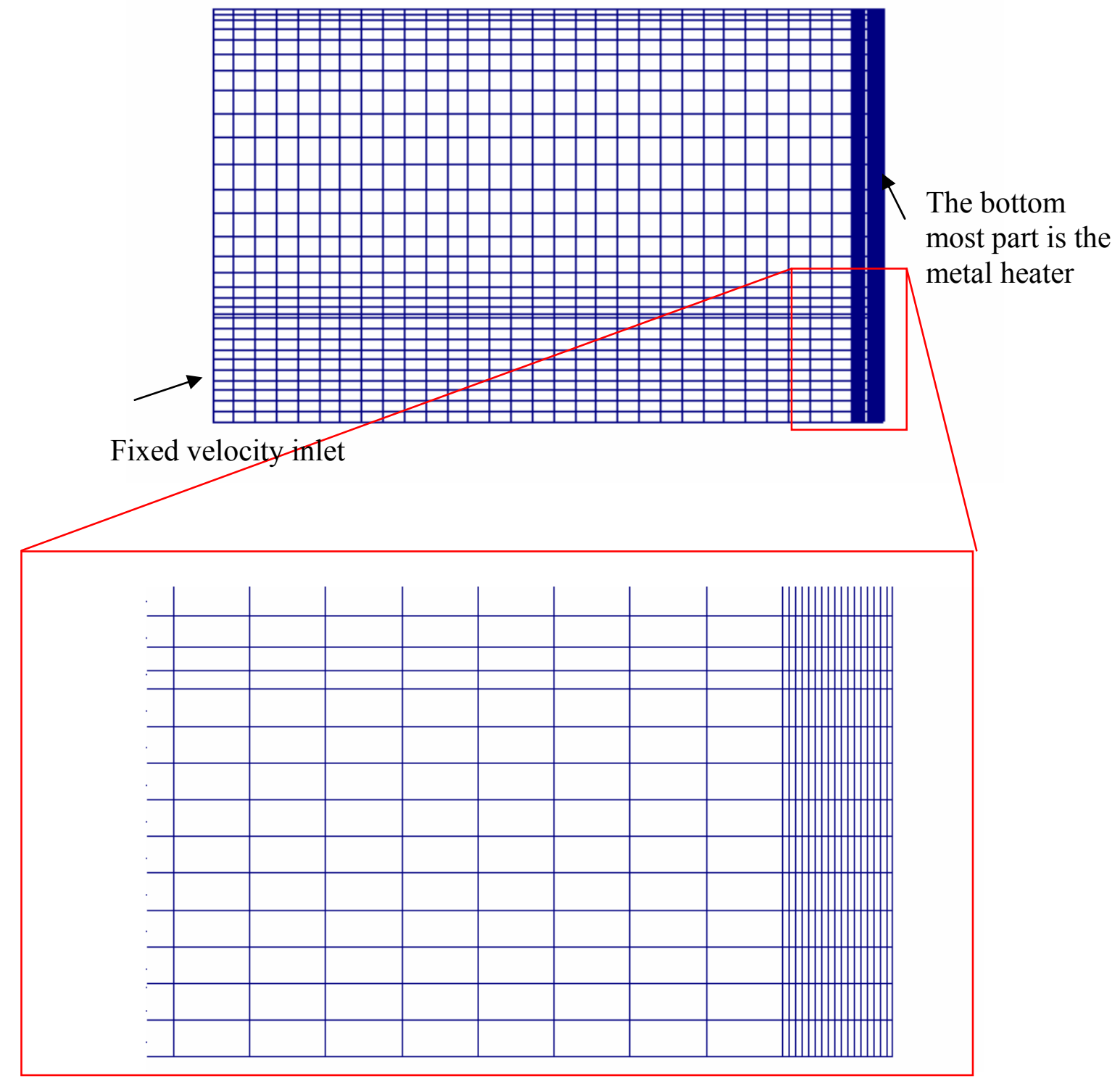

Figure 5.2 Grid for the low and high velocity heat transfer cases. 


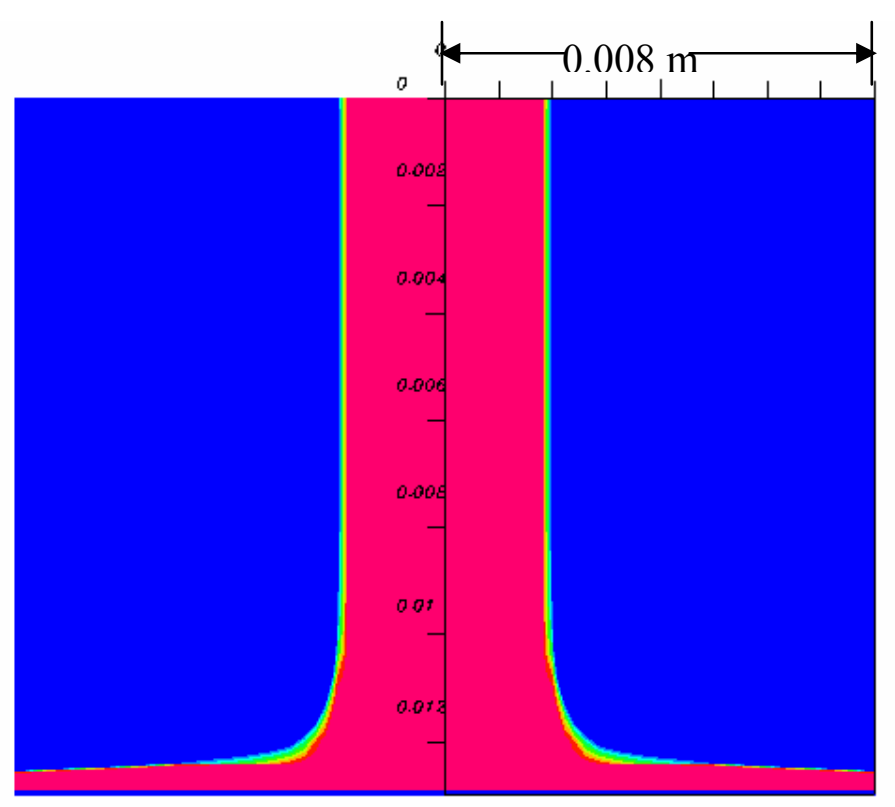

Figure 5.3 Case H1 steady state flow conditions.

(Red represents HFE 7000 and blue represents air, yellow and green represent a liquid fraction of 0 and 1 )
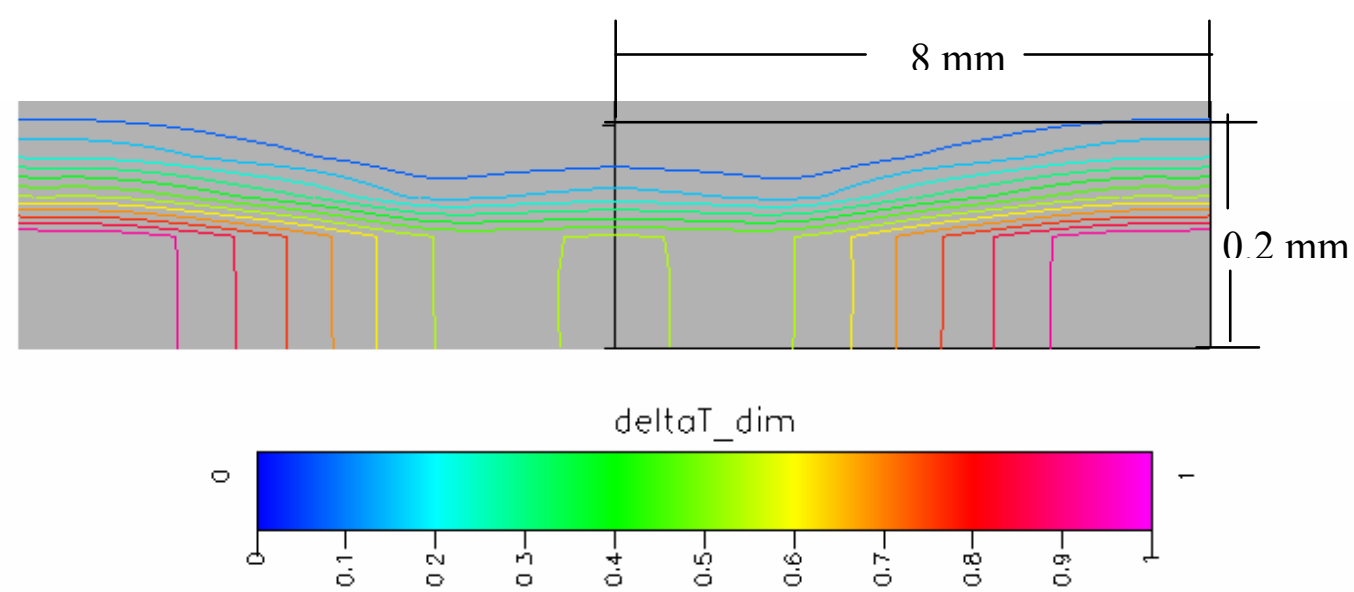

Figure 5.4 Case H1 steady state temperature distribution (the heater surface is $0.1 \mathrm{~mm}$ from the bottom of the figure) 
Figure 5.5 shows the steady state flow conditions for the low velocity regime with $0.5 \mathrm{~g}$, Case H2. Figure 5.6 shows the corresponding temperature distribution. As can be seen in Figure 5.5, even half the Earth's gravity causes the fluid to accelerate and contract to conserve mass before hitting the heated plate. Due to this increase in velocity the heat transfer is enhanced as suggested by the temperature contours of Figure 5.6 compared to Figure 5.4. 


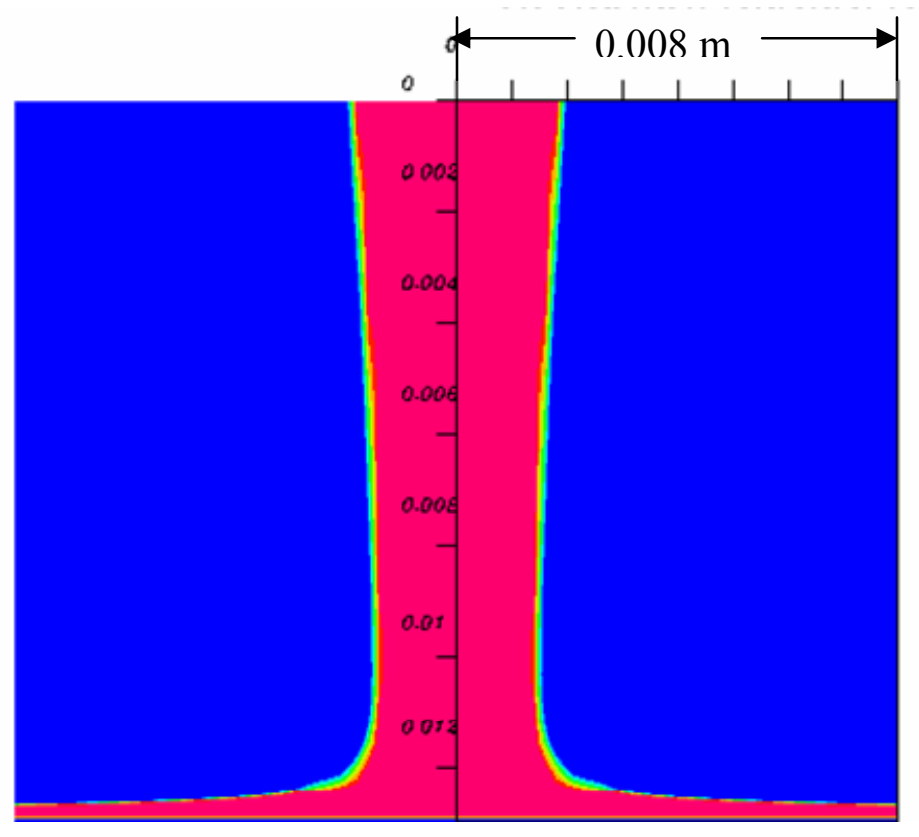

Figure 5.5 Case H2 steady state flow conditions.

(Red represents HFE 7000 and blue represents air)
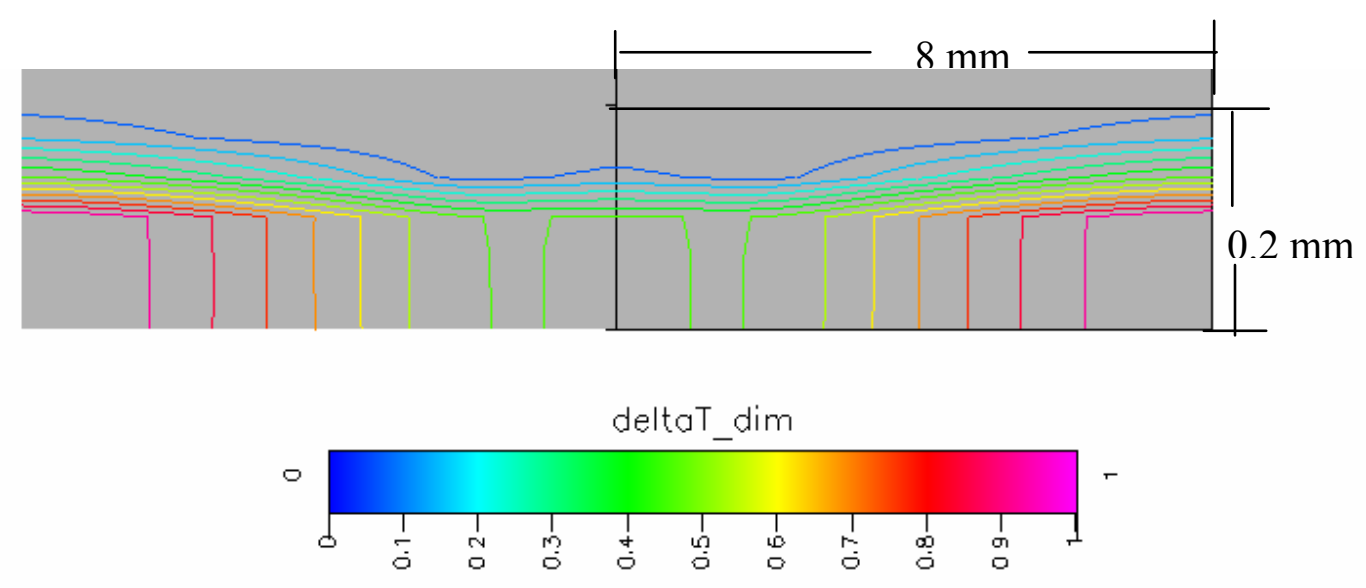

Figure 5.6 Case H2 steady state temperature distribution. 
Figure 5.7 shows the steady state flow conditions for $1 \mathrm{~g}$ Case $\mathrm{H} 3$ whereas Figure 5.8 shows the steady state temperature distribution for the same Case H3. Figure 5.8 also suggests that the temperature increase with radial distance and away from the plate is not as much as in cases $\mathrm{H} 1$ and $\mathrm{H} 2$. 


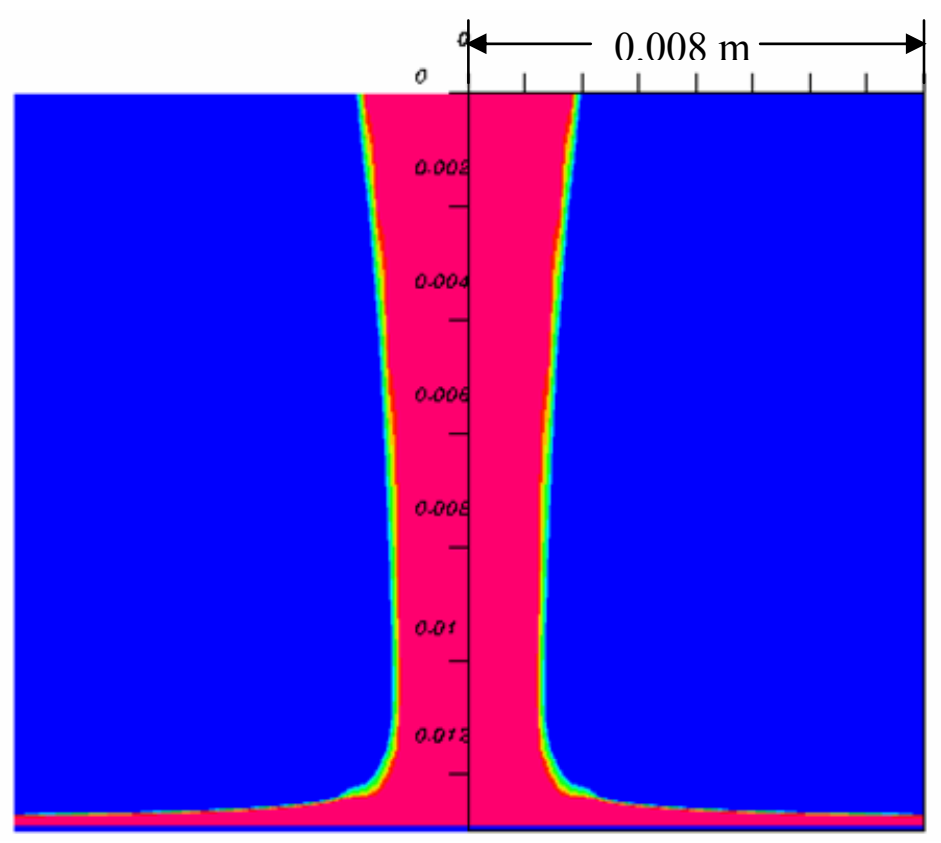

Figure 5.7 Case H3 steady state flow conditions.

(Red represents HFE 7000 and blue represents air)

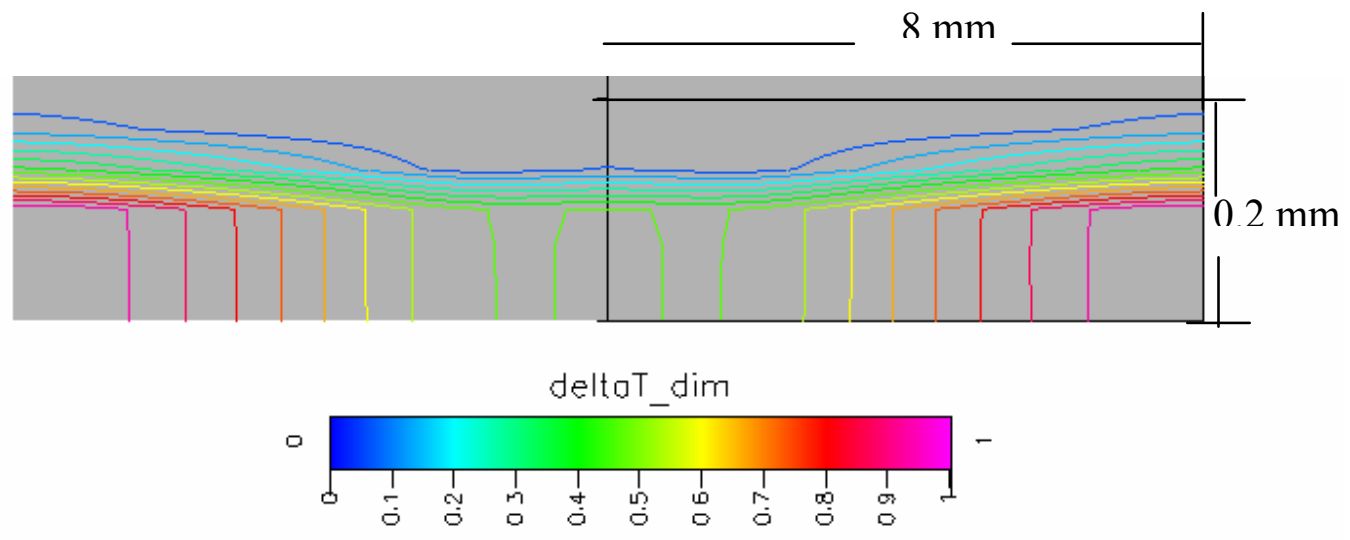

Figure 5.8 Case H3 steady state temperature distribution. 
Figure 5.9 shows the steady state flow conditions for $1.5 \mathrm{~g}$, Case H4. Figure 5.10, shows the steady state temperature distribution for this case. The temperature increase away from the plate as the radial distance is increased is lowest of all three cases $\mathrm{H} 1, \mathrm{H} 2$, and $\mathrm{H} 3$. Note that the acceleration of the flow from $0 \mathrm{~g}$ to $0.5 \mathrm{~g}$ is less than that from $0 \mathrm{~g}$ to 1 $\mathrm{g}$ which in turn is less than the acceleration from $0 \mathrm{~g}$ to $1.5 \mathrm{~g}$. Thus the liquid jet contracts to the lowest radius in the case of $1.5 \mathrm{~g}$ since the acceleration is higher compared to the other cases and the liquid jet contracts more to account for this increase in velocity. 


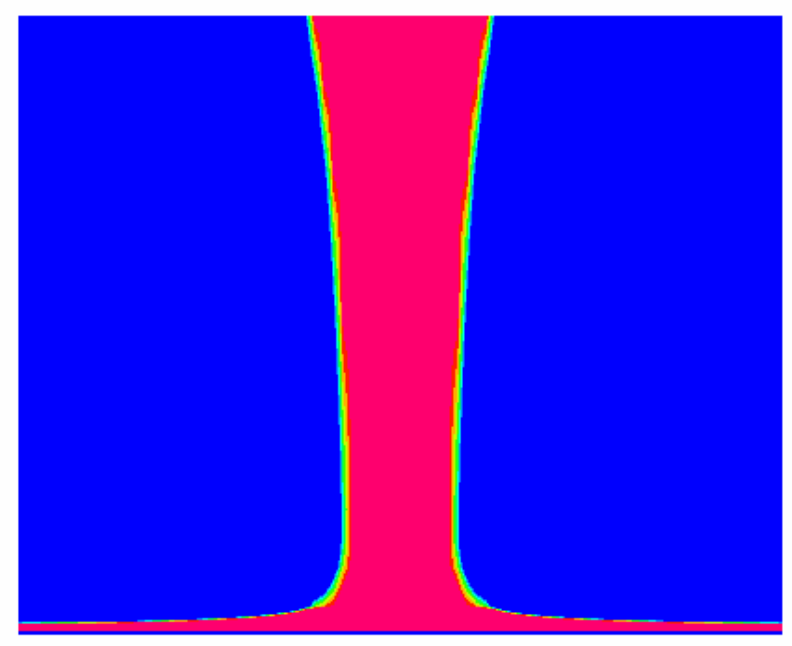

Figure 5.9 Case H4 steady state flow conditions.

(Red represents HFE 7000 and blue represents air)

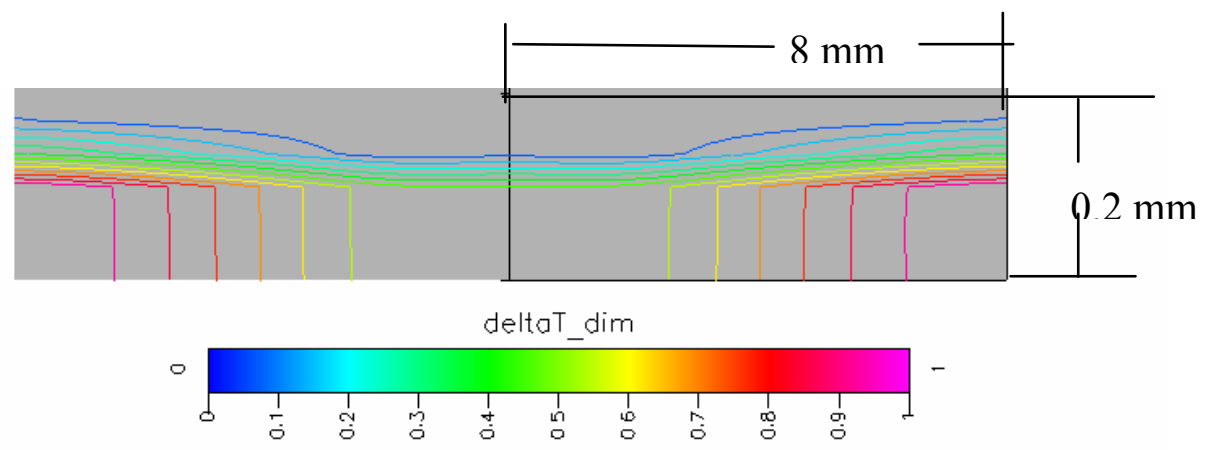

Figure 5.10 Case H4 steady state temperature distribution .

Figure 5.11 shows the computed free surface of the liquid jets as the gravity is varied in each case. The zero gravity case does not show any contraction at all whereas the case with $1.5 \mathrm{~g}$ shows the highest contraction for the reasons discussed earlier. There are 10 cells from the center of the jet to the outer radius of the jet. 


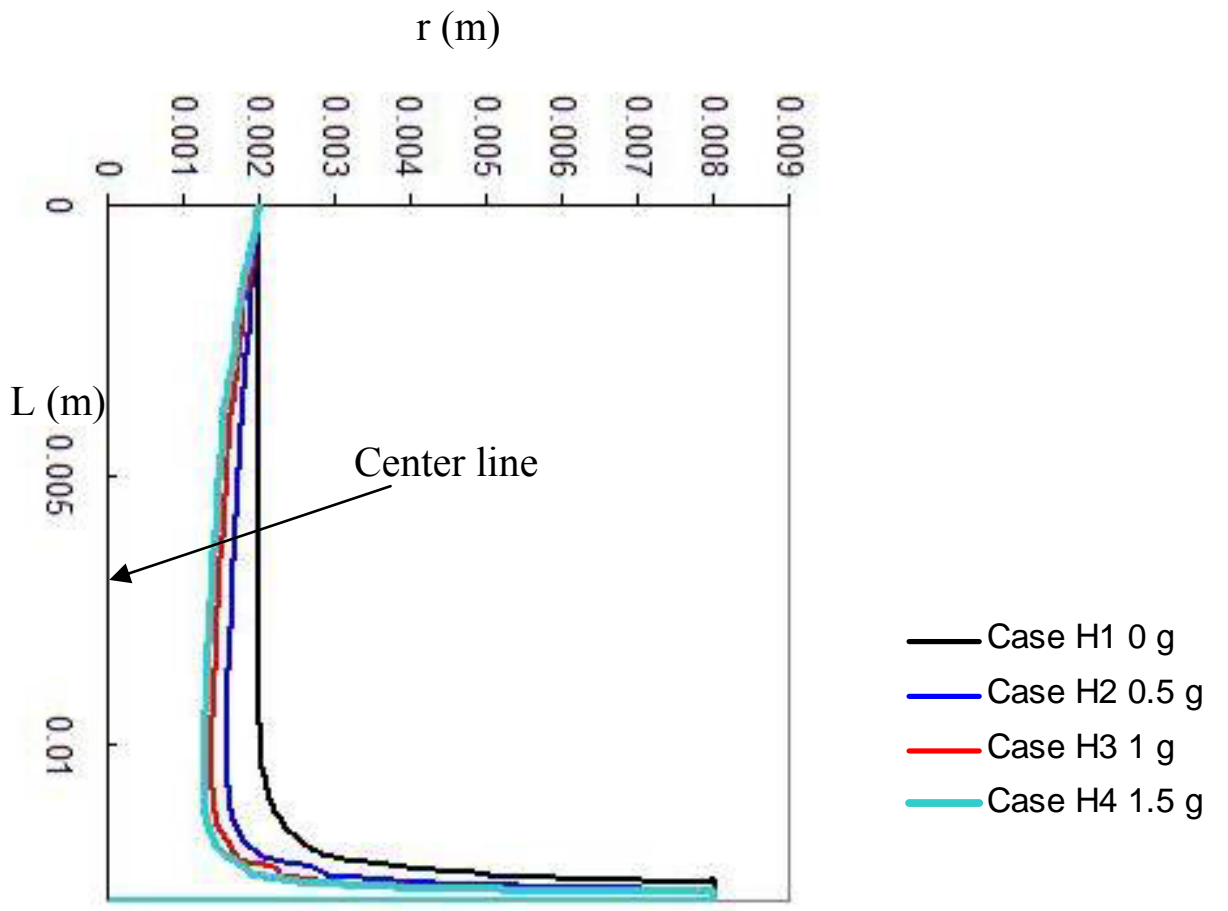

Figure 5.11 Free surfaces of liquid jets with varying gravity.

The local Nusselt number $\mathrm{Nu}$ is defined as

$$
\mathrm{Nu}=\frac{\mathrm{Q}^{\prime \prime} \mathrm{r}_{\mathrm{j}}}{\mathrm{k}\left(\mathrm{T}_{\mathrm{w}}-\mathrm{T}_{\mathrm{f}}\right)}
$$

where $\mathrm{Q}^{\prime}$ is the heat flux $\left(\mathrm{W} / \mathrm{m}^{2}\right)$

$r_{j}$ is the jet radius (m)

$\mathrm{k}$ is the thermal conductivity of the liquid $(\mathrm{W} / \mathrm{m} \cdot \mathrm{K})$

$\mathrm{T}_{\mathrm{w}}$ is the wall temperature $(\mathrm{K})$

$\mathrm{T}_{\mathrm{f}}$ is the initial fluid temperature, $288 \mathrm{~K}$

The computed Nusselt number plotted versus the radius is shown in Figure 5.12.

When gravity is added in the direction of the flow, the flow accelerates. When gravity is increased then the flow accelerates more than before. This higher acceleration translates 
into higher velocity at impact. Thus every time gravity is increased in the direction of the liquid jet impinging on a heated surface, the heat transfer increases owing to the higher velocities. This trend can be seen in Figure 5.12 where the Nusselt number is increased each time the gravitational force is increased. The curves appear to shift vertically as the gravity is increased with a "parallel" shift outside the stagnation zone whereas in the stagnation zone the curve shape also changes along with this shift of Nusselt number.

$r^{\prime}=\frac{r}{r_{o}}$, where $r_{o}=0.008 \mathrm{~m}$

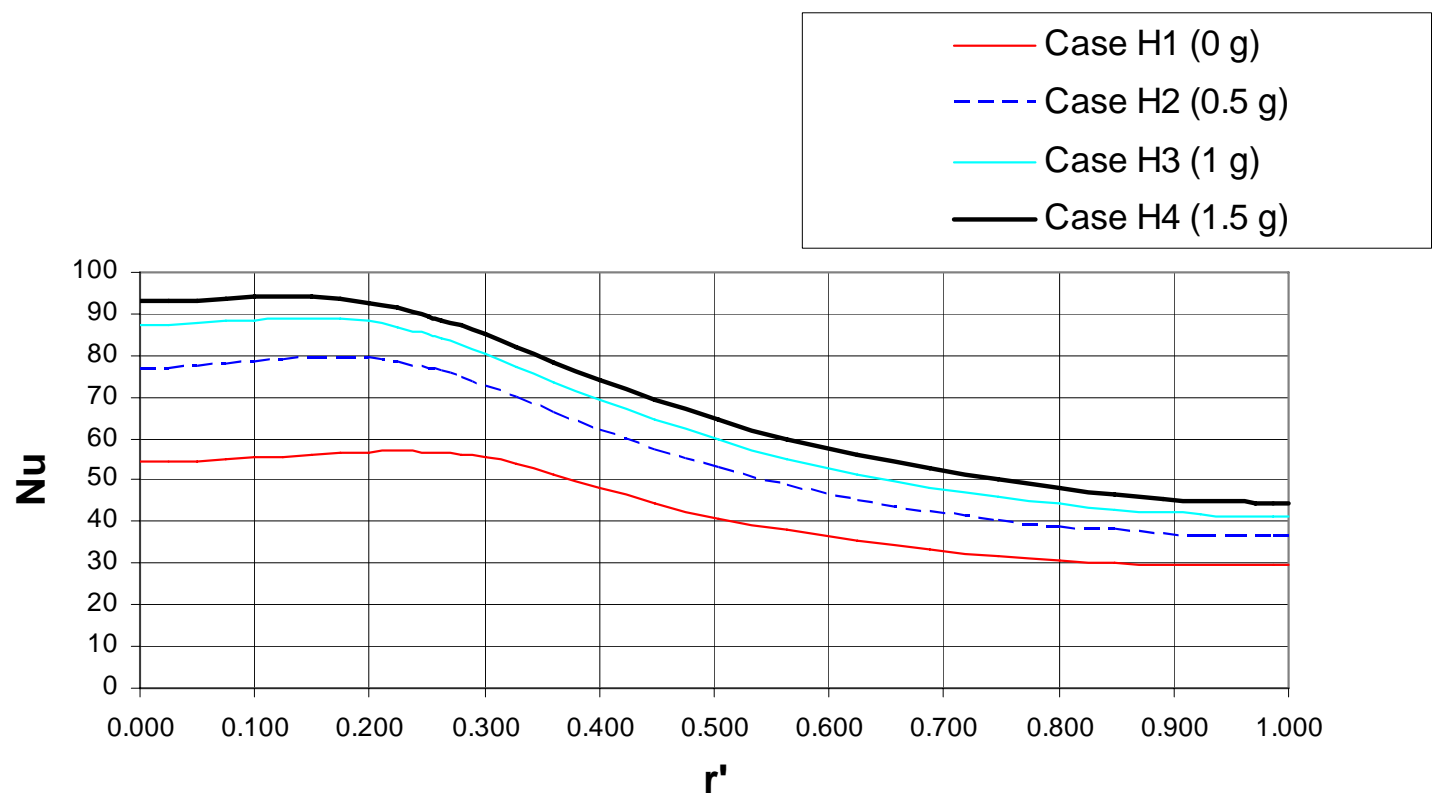

Figure 5.12 Nusselt number variation with the dimensionless radius.

Figure 5.13 shows the percentage increase in Nusselt numbers when the body forces are varied. This figure shows the increase in Nusselt numbers from, 0 to $0.5 \mathrm{~g}, 0.5 \mathrm{~g}$ to $1 \mathrm{~g}$ and $1 \mathrm{~g}$ to $1.5 \mathrm{~g}$. This trend shows there is a non linear increase in the heat transfer with magnitude of the gravitational body force. The highest percentage change in Nusselt 
number occurs when the gravity is varied from 0 to $0.5 \mathrm{~g}$. whereas this change becomes less and less as the gravity is increased in equal increments.

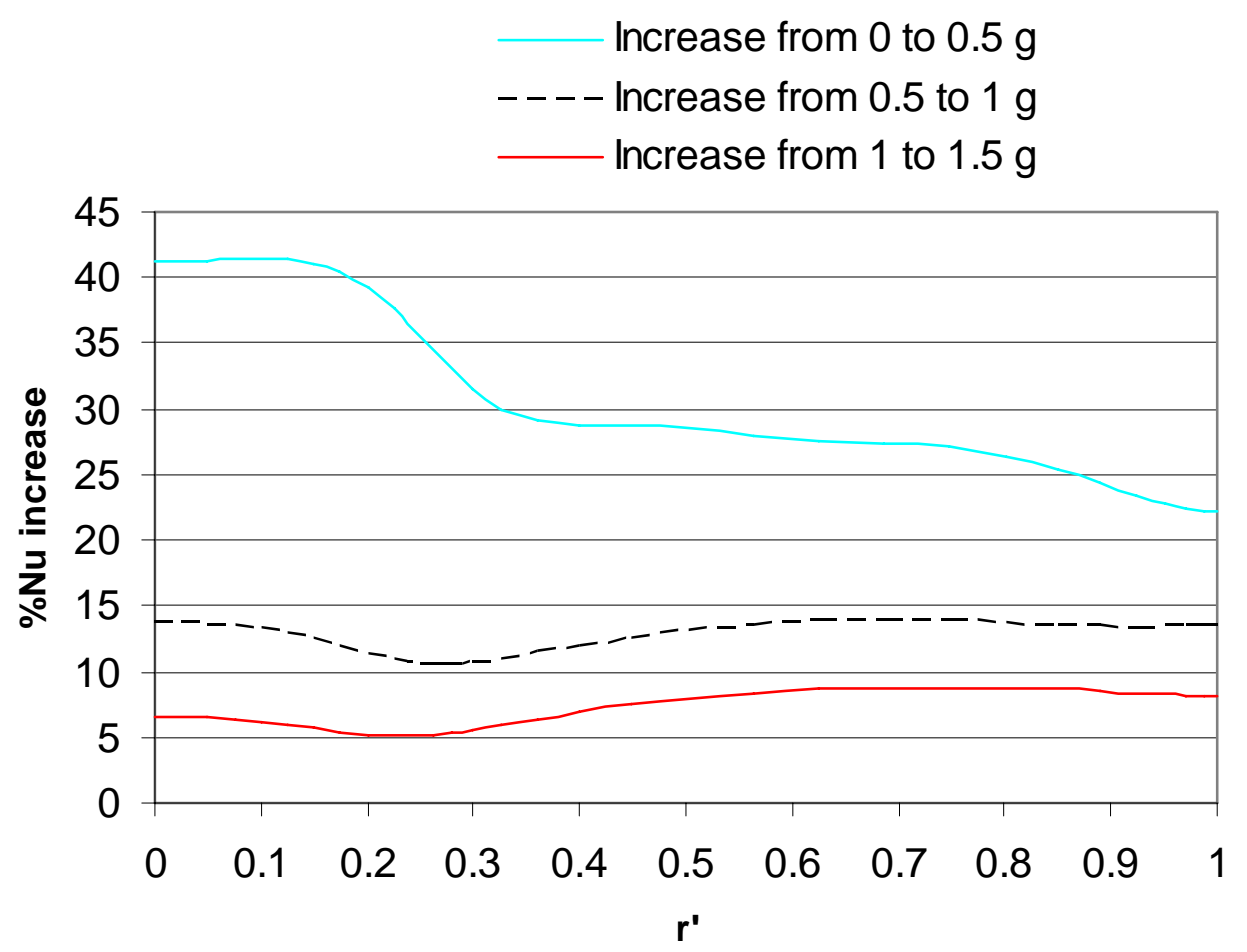

Figure 5.13 Percentage increase in Nusselt numbers with varying body forces.

The average Nusselt number was found using the local temperature averaged over the area.

$$
\mathrm{Nu}=\frac{\mathrm{Q}^{\prime \prime} \mathrm{r}_{\mathrm{j}}}{\mathrm{k}\left(\overline{\mathrm{T}}-\mathrm{T}_{\mathrm{f}}\right)}
$$

where $\overline{\mathrm{T}}=\frac{2 \pi \int_{0}^{\mathrm{r}_{0}} \mathrm{~T}(\mathrm{r}) \mathrm{rdr}}{\pi \mathrm{r}_{\mathrm{o}}^{2}}$ 
The average Nusselt number as a function of the reciprocal of the Stokes number is shown in Figure 5.14. Upon fitting a curve to this data the following equation was obtained

$$
\overline{\mathrm{Nu}}=-10^{-8} \mathrm{St}^{-2}+0.009 \mathrm{St}^{-1}+34.818 \text { and } \mathrm{R}^{2}=0.9994
$$

where St is the Stokes number, and

$\overline{\mathrm{Nu}}$ is the average Nusselt number

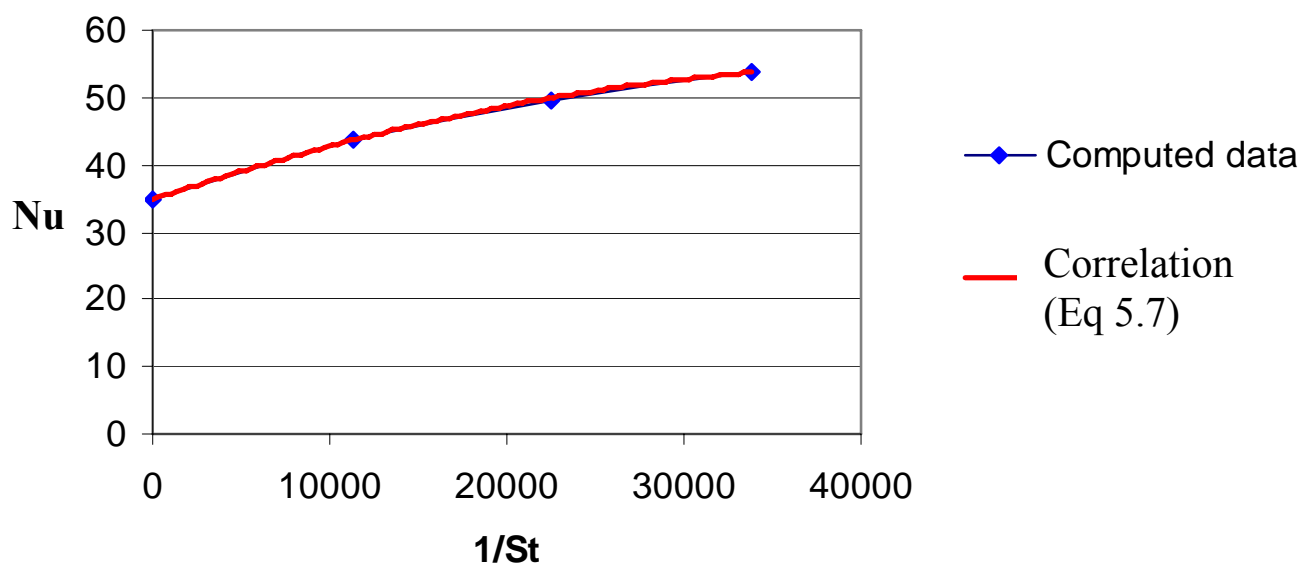

Figure 5.14 Average Nusselt number increase with the reciprocal of Stokes number for low velocity cases.

Womac et al. (1990) in their 1993 paper described the correlation for the Nusselt number on the basis of jet impingement velocity instead of the jet exit velocity at the nozzle. Thus Womac et al. (1993) incorporated the direct effect of gravity in their correlation instead of the nozzle to heater separation distance. Their complex correlation was 


$$
\begin{aligned}
& \frac{\overline{\mathrm{Nu}} \mathrm{u}_{1}}{\operatorname{Pr}^{0.4}}=0.516 \operatorname{Re}_{\mathrm{d}_{\mathrm{i}}}^{0.5} \frac{1}{\mathrm{~d}_{\mathrm{i}}} \mathrm{A}_{\mathrm{r}}+0.491 \mathrm{Re}_{\mathrm{L}}^{0.532} \frac{1}{\mathrm{~L}}\left(1-\mathrm{A}_{\mathrm{r}}\right) \\
& \overline{\mathrm{N}} \mathrm{u}_{1}=\frac{\mathrm{qS}_{1}}{\mathrm{kA}\left(\overline{\mathrm{T}}_{\mathrm{S}}-\mathrm{T}_{\mathrm{up}}\right)}
\end{aligned}
$$

$\mathrm{S}_{1}$ is the side length of the square heater

$\mathrm{A}$ is the area of the heater

$\mathrm{k}$ is the thermal conductivity of the fluid

$\overline{\mathrm{T}_{\mathrm{s}}}$ is the average surface temperature at the wall

$\mathrm{T}_{\text {up }}$ is the upstream temperature at the nozzle

$\mathrm{Re}_{\mathrm{d}_{\mathrm{i}}}$ is the Reynolds number based on the impingement velocity $U_{\mathrm{i}}$ and the impingement diameter $\mathrm{d}_{\mathrm{i}}$

where $\mathrm{U}_{\mathrm{i}}=\left(\mathrm{U}_{\mathrm{e}}^{2}+2 \mathrm{gs}\right)^{0.5}$

$\mathrm{U}_{\mathrm{e}}$ is the jet exit velocity at the nozzle, $\mathrm{g}$ is the acceleration due to gravity, and $\mathrm{s}$ is the distance between the nozzle exit and the heater surface

$$
\mathrm{d}_{\mathrm{i}}=\left(\frac{\mathrm{U}_{\mathrm{e}}}{\mathrm{U}_{\mathrm{i}}}\right)^{0.5} \mathrm{~d}
$$

where $d$ is the nozzle diameter

$$
\begin{aligned}
& \mathrm{A}_{\mathrm{r}}=\frac{\pi \mathrm{d}_{\mathrm{i}}^{2}}{41^{2}} \\
& \mathrm{~L}=0.5\left(\mathrm{D}-\mathrm{d}_{\mathrm{i}}\right)=\frac{0.5\left(\sqrt{2} \mathrm{~S}_{1}-\mathrm{d}_{\mathrm{i}}\right)+0.5\left(\mathrm{~S}_{1}-\mathrm{d}_{\mathrm{i}}\right)}{2}
\end{aligned}
$$

where $\mathrm{D}$ is the heater diameter 


$$
\operatorname{Re}_{\mathrm{L}}=\frac{\mathrm{U}_{\mathrm{i}} \mathrm{L}}{v}
$$

The two different formulas of $\mathrm{L}$ were used by Womac et al. when comparing between a circular heater and a square heater. In the current research used a circular heater was used and therefore the formula containing the heater diameter was used to calculate L. The table 5.2 shows the comparison between the $\mathrm{Nu}$ numbers computed from Womac et al. correlations and from the heat transfer results from the current simulations. The percentage discrepancy is between 1.2 and 9 for all the four cases simulated in low velocity regime. The maximum discrepancy of 4 percent occurs for Case 1 which is the zero gravity case.

Table 5.2 Comparison of computed $\mathrm{Nu}$ number with available correlations for Cases $\mathrm{H} 1$ to H4.

\begin{tabular}{|l|l|l|l|}
\hline Case number & $\begin{array}{l}\text { Nu from Womac et } \\
\text { al. correlations }\end{array}$ & $\begin{array}{l}\overline{\mathbf{N}} \mathbf{u}_{1} \text { computed } \\
\text { from current } \\
\text { simulations }\end{array}$ & $\begin{array}{l}\text { Percentage } \\
\text { discrepancy }\end{array}$ \\
\hline H1 & 255 & 278 & 9 \\
\hline H2 & 343 & 351 & 2.4 \\
\hline H3 & 391 & 398 & 1.8 \\
\hline H4 & 425 & 431 & 1.2 \\
\hline
\end{tabular}

Figure 5.15 shows the variation of heat transfer coefficient of all four low velocity cases as a function of non dimensional radius. The heat transfer coefficient is the highest for Case H4 . It can be seen that the increase in local heat transfer coefficient from the gravitational force of $0 \mathrm{~g}$ to $0.5 \mathrm{~g}$ is higher than the corresponding increase from $0.5 \mathrm{~g}$ to $1 \mathrm{~g}$. 


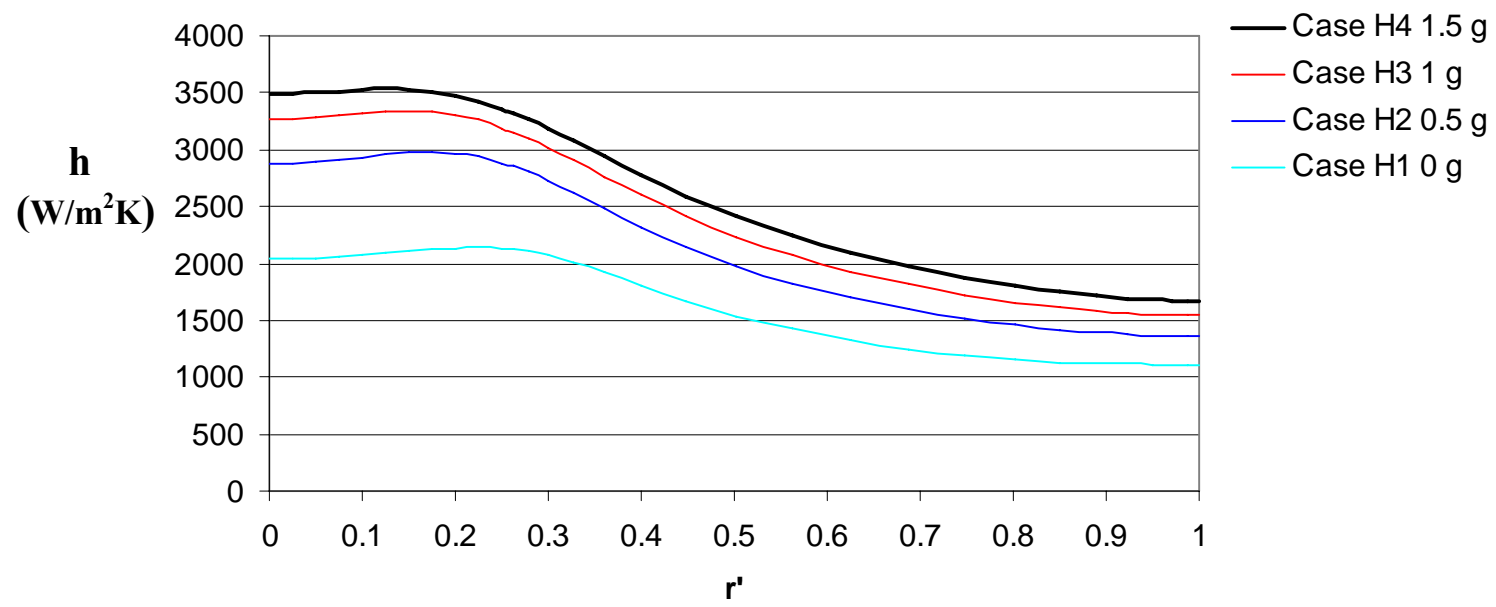

Figure 5.15 Heat transfer coefficient as a function of dimensionless radius.

The high velocity regime also consisted of four cases each with different values of $\mathrm{g}$. Gravity was varied in the increments of $0.5 \mathrm{~g}$, from 0 to $1.5 \mathrm{~g}$. Figure 5.16 shows the steady state flow conditions for $0 \mathrm{~g}$, Case H5. The jet does not contract in the absence of any gravitational force. Figure 5.17 shows the steady state temperature distribution for the Case H5. The temperature increases away from the centerline as the radial velocity of the jet decreases. Figure 5.18 shows the steady state flow for $0.5 \mathrm{~g}$ high velocity regime Case H6. The jet contracts slightly in the presence of gravitational force, but this is not apparent in the figure. Figure 5.19 shows the steady state temperature distribution for the same Case H6. The temperature increases away from the centerline but is less than the temperature in the Case H5. Similarly Figures 5.20 and 5.21 show the steady state flow and temperature distribution respectively for $1 \mathrm{~g}$ high velocity regime Case H7. Figure 5.20 shows clearly that the jet is contracted to conserve continuity in the presence of the gravitational force. The temperature, like all other cases, increases away from the 
centerline. Steady state flow and temperature distribution for the $1.5 \mathrm{~g}$ Case $\mathrm{H} 8$ for high velocity flow regime are shown in Figures 5.22 and 5.23 respectively. The jet can be seen contracted before the impingement plane under the influence of gravity. The temperature also increases away from the center line in Case H8. 


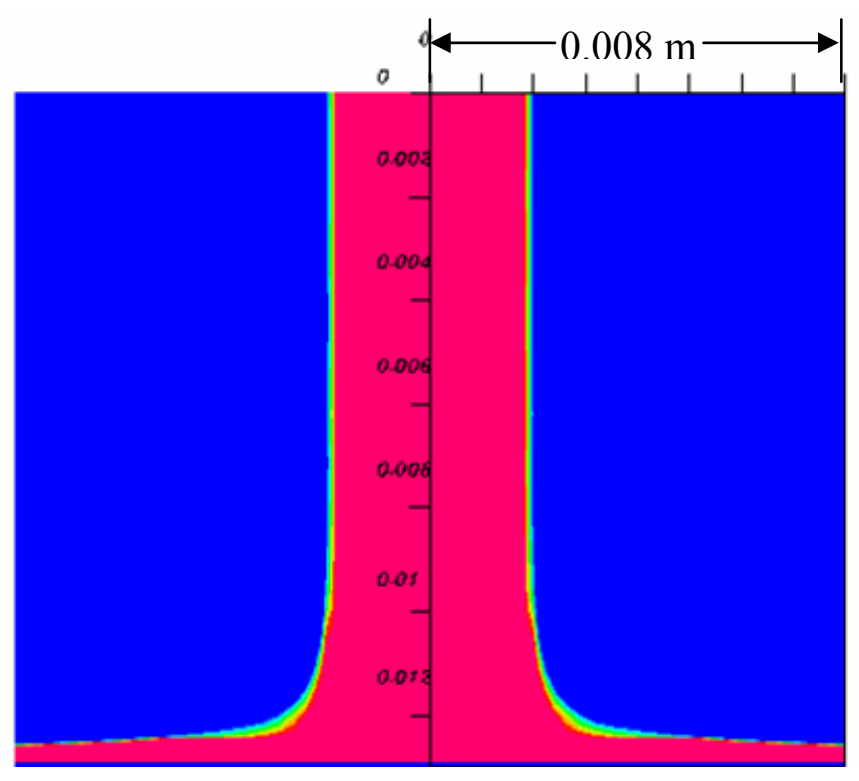

Figure 5.16 Case H5 steady state flow conditions for $0 \mathrm{~g}$ high velocity regime. (Red represents HFE 7000 and blue represents air)

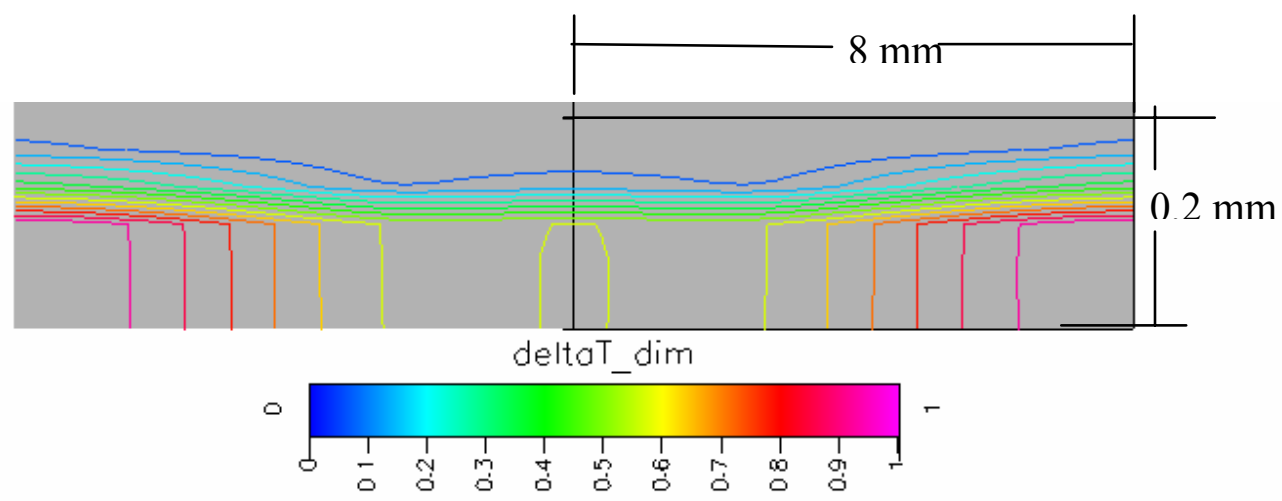

Figure 5.17 Case H5 steady state temperature distribution for $0 \mathrm{~g}$ high velocity regime. 


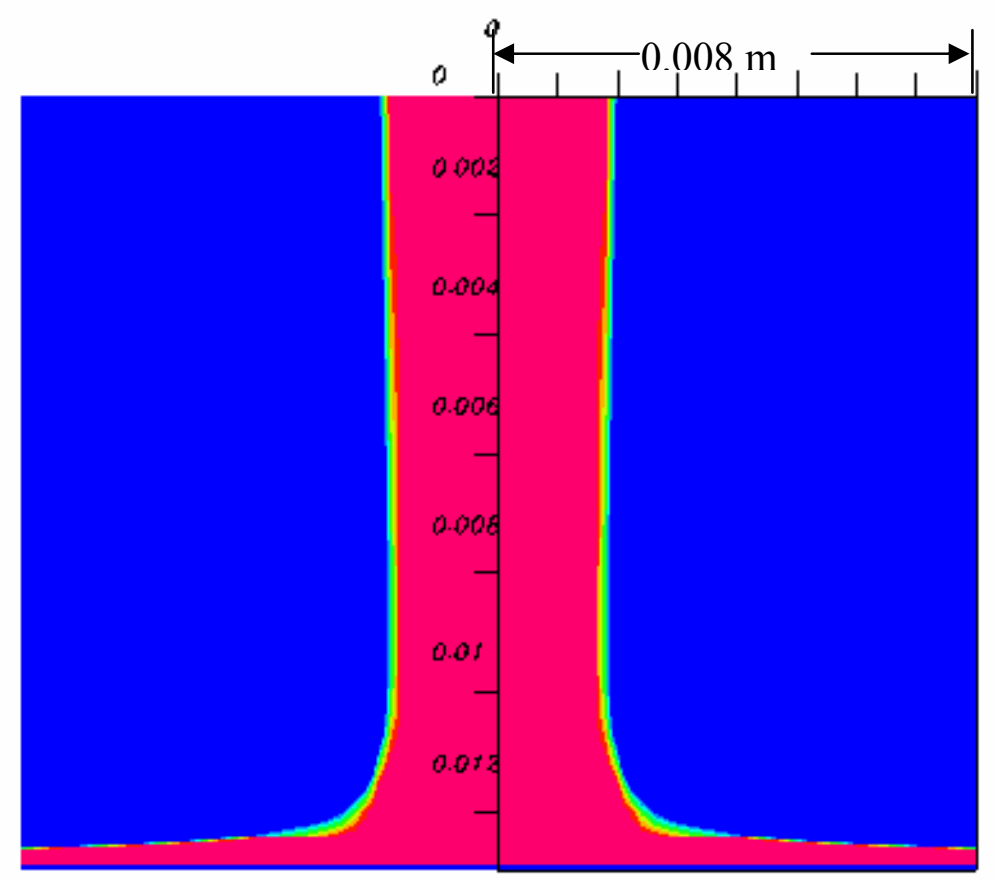

Figure 5.18 Case H6 steady state flow conditions for $0.5 \mathrm{~g}$ high velocity regime. (Red represents HFE 7000 and blue represents air)

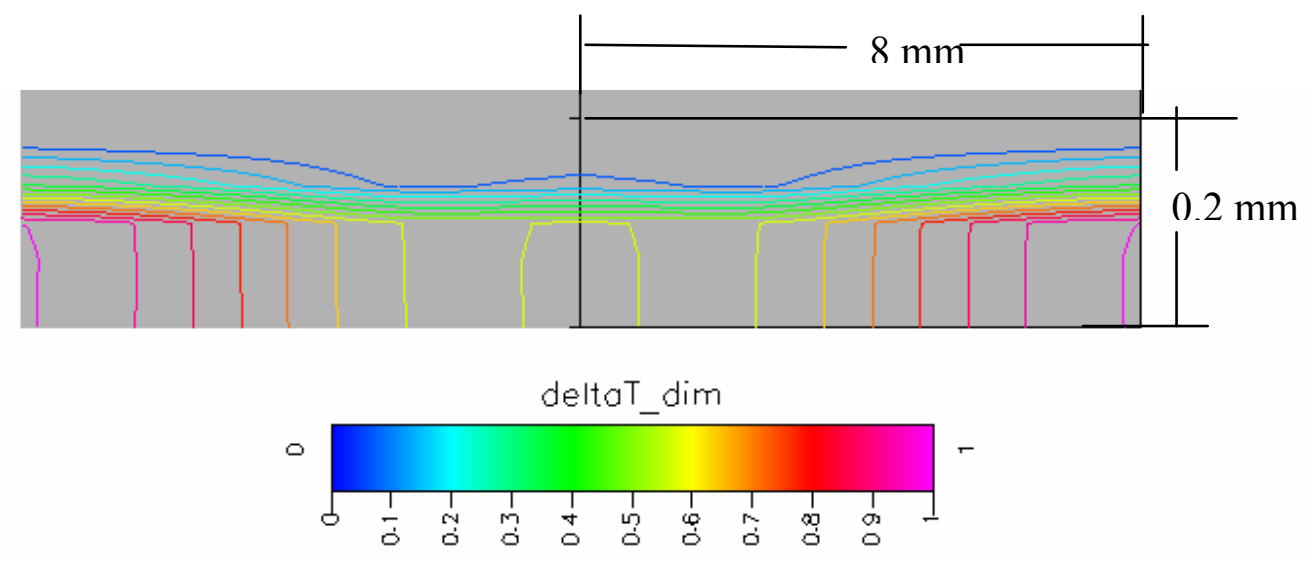

Figure 5.19 Case H6 steady state temperature distribution for $0.5 \mathrm{~g}$ high velocity regime. 


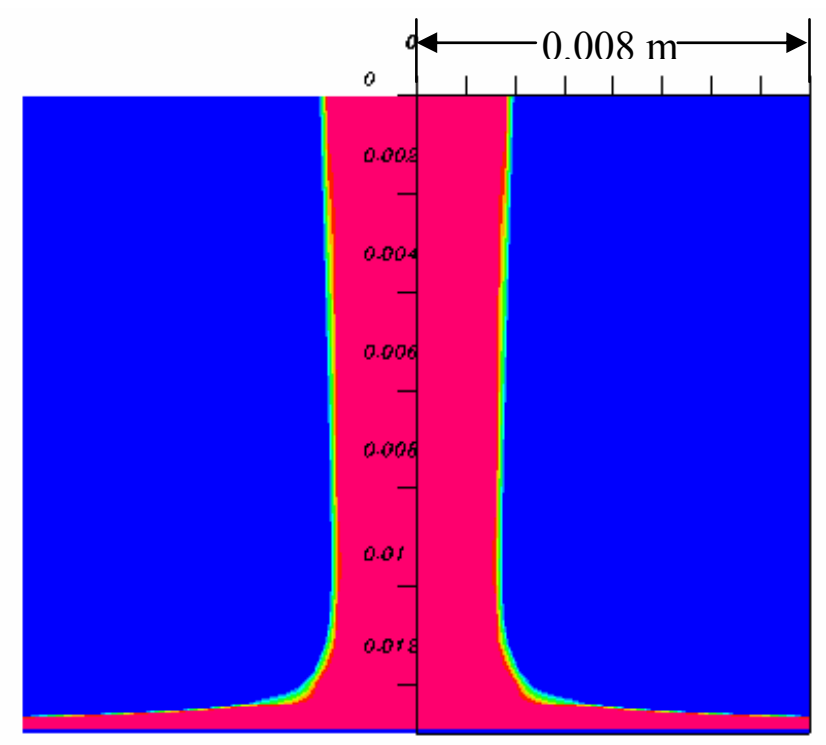

Figure 5.20 Case H7 steady state flow conditions for $1 \mathrm{~g}$ high velocity regime. (Red represents HFE 7000 and blue represents air)

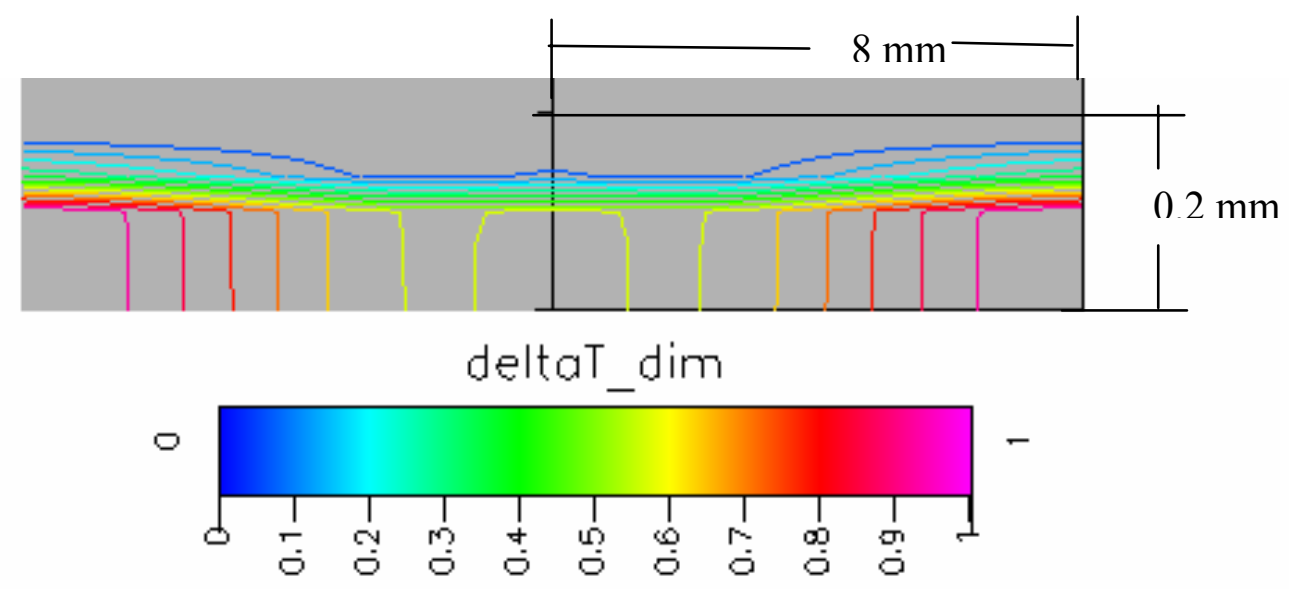

Figure 5.21 Case H7 steady state temperature distribution for $1 \mathrm{~g}$ high velocity regime. 


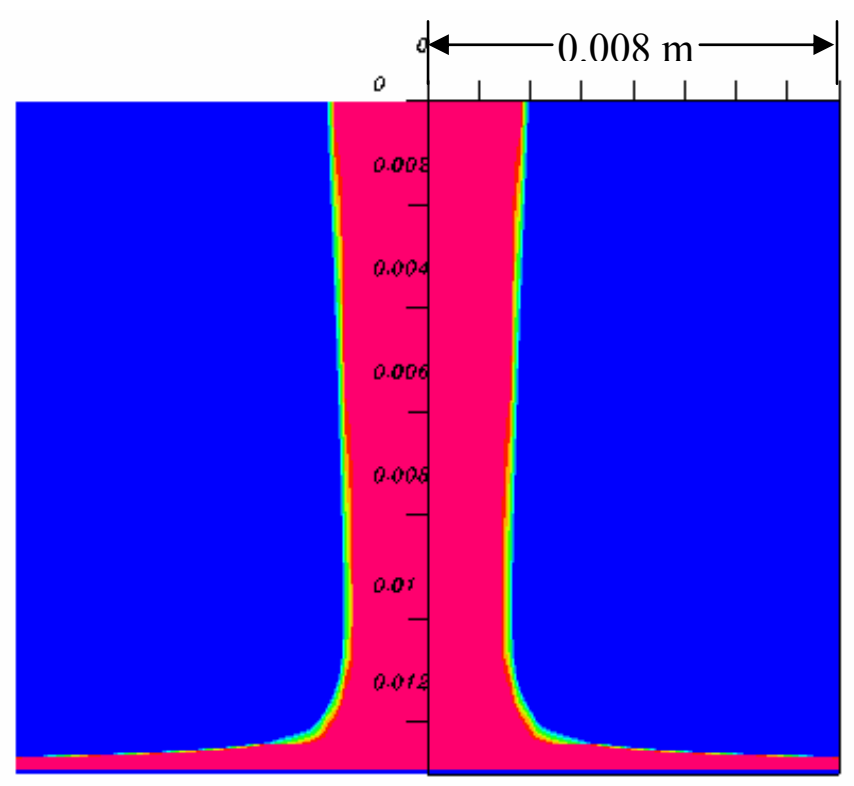

Figure 5.22 Case H8 steady state flow conditions for $1.5 \mathrm{~g}$ high velocity regime. (Red represents HFE 7000 and blue represents air)

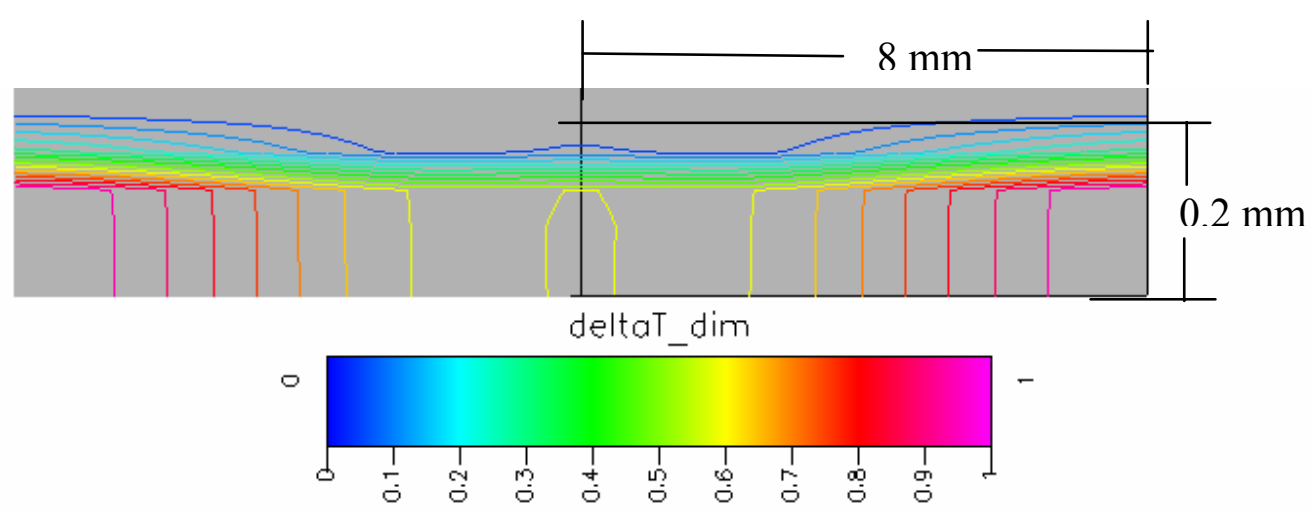

Figure 5.23 Case H8 steady state temperature distribution for $1.5 \mathrm{~g}$ high velocity regime. 
Figure 5.24 shows the free surface plots of the high velocity regime cases with varying gravity. Note that the contraction of the liquid jet when subjected to higher body forces is smaller relative to the cases simulated in the low velocity flow regime (Figure 5.11). This is because the initial velocity in the low velocity regime is so low that the applied body force accelerates the liquid jet significantly when compared to its initial velocity.

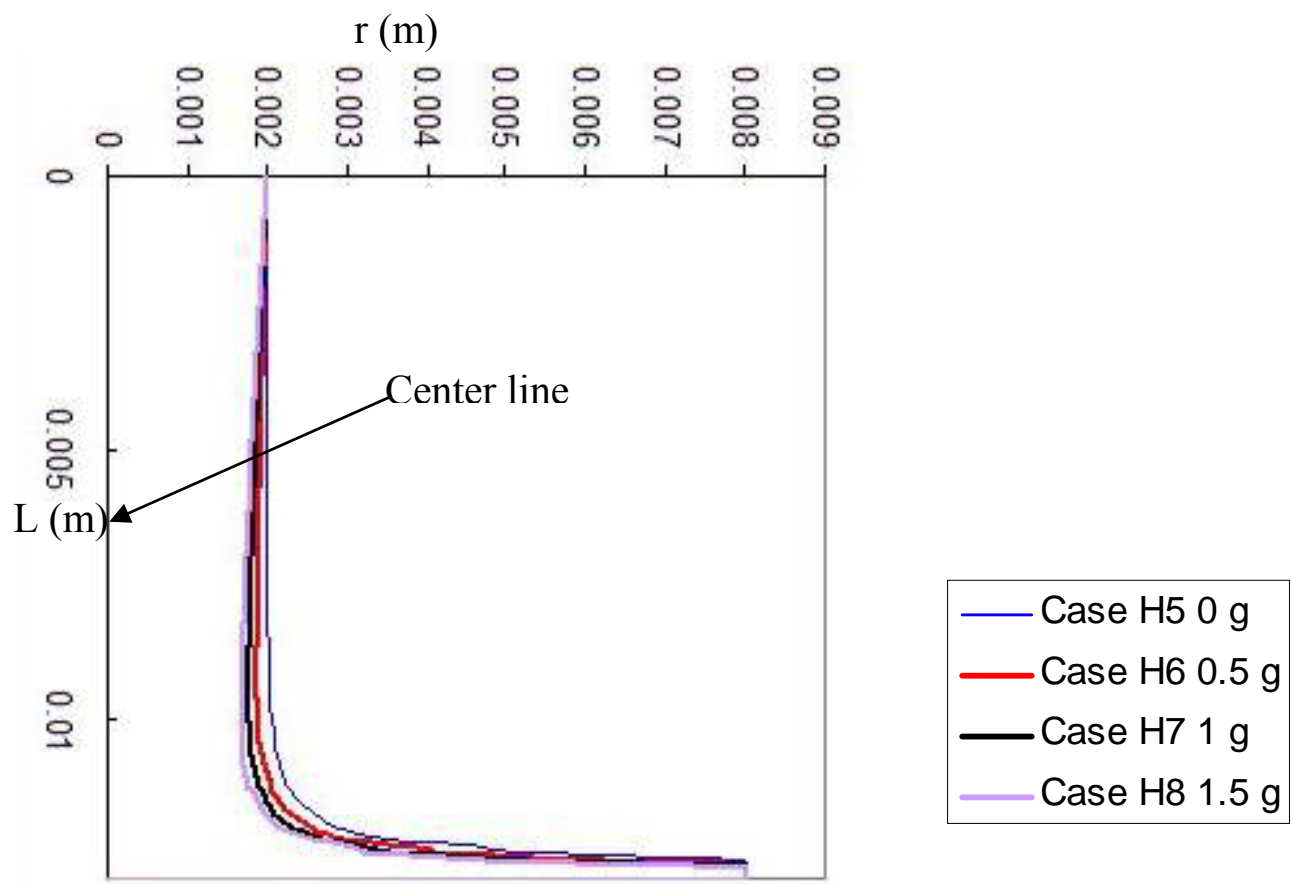

Figure 5.24 Free surface plots of high velocity regime with varying gravity. 


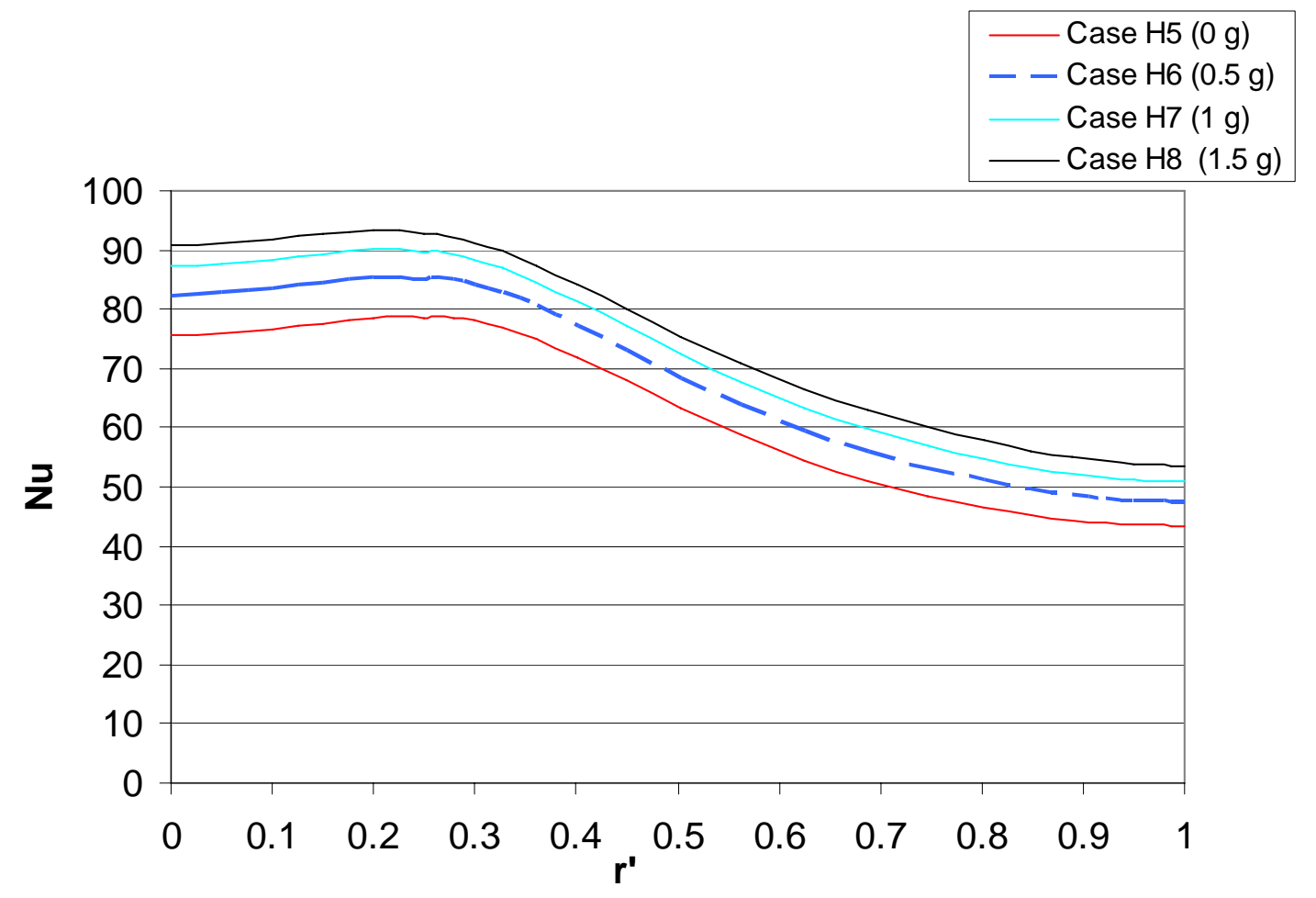

Figure 5.25 Nusselt number as a function of the dimensionless radius.

Figure 5.25 shows the trend of the local Nusselt numbers as a function of radius. The four curves represent different values of g. Note that the black curve here corresponding to 1.5 $\mathrm{g}$ case is similar to the black curve corresponding to low velocity $1.5 \mathrm{~g}$ case in Figure 5.12. However, the red curve corresponding to $0 \mathrm{~g}$ case here is significantly higher than the red curve corresponding to low velocity $0 \mathrm{~g}$ case in Figure 5.12. The lowest curve in Figure 5.25 represents the Nusselt number when there is no gravitational body force. As the gravitational body force is increased to $0.5 \mathrm{~g}$ the heat transfer is enhanced. Further increase in the body force causes further increase in Nusselt numbers as evident from the curves representing $1.5 \mathrm{~g}$ and $1 \mathrm{~g}$ cases. This increase is about $9.3 \%$ in the average Nusselt number from 0 to $0.5 \mathrm{~g}, 6.6 \%$ from 0.5 to $1 \mathrm{~g}$ and $4.9 \%$ from $1 \mathrm{~g}$ to $1.5 \mathrm{~g}$. The corresponding increases for the low velocity regime cases were $26 \%, 13 \%$ and $8 \%$ 
respectively. The increase in heat transfer from low velocity $0 \mathrm{~g}$ (Case $\mathrm{H} 1$ ) to low velocity $0.5 \mathrm{~g}(\mathrm{Case} \mathrm{H} 2)$ is higher than the corresponding increase from high velocity $0 \mathrm{~g}$ (Case H5) to high velocity $0.5 \mathrm{~g}$ (Case H6) because of the small initial velocity in the low velocity case. This low initial velocity is increased to a higher extent under the influence of gravity when compared to a corresponding case with higher initial velocity.

Figure 5.26 shows the variation of the heat transfer coefficient with the non dimensional radius. The heat transfer coefficient is highest in the $1.5 \mathrm{~g}$ case compared to cases with lesser values of gravity. Figure 5.27 shows the percentage increase in Nusselt numbers from one body force magnitude to another. It can be inferred from the figure that the maximum increase in heat transfer occurs when the body force is increased from 0 to 1.5

g.

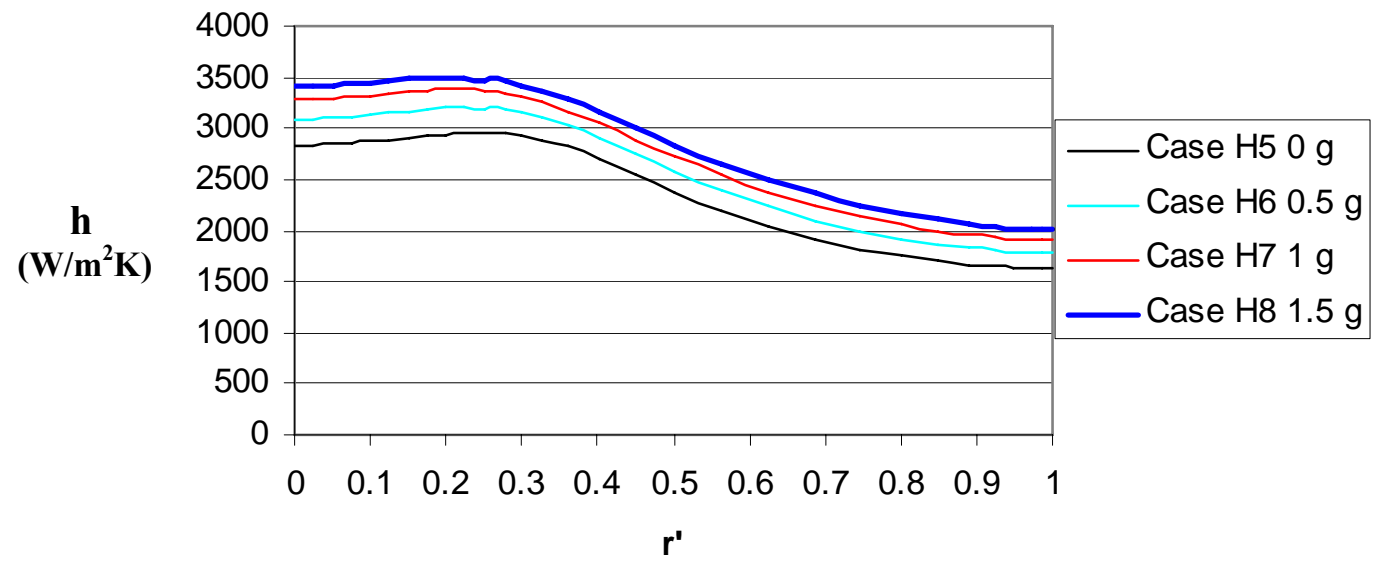

Figure 5.26 Heat transfer coefficient with dimensionless radial distance. 


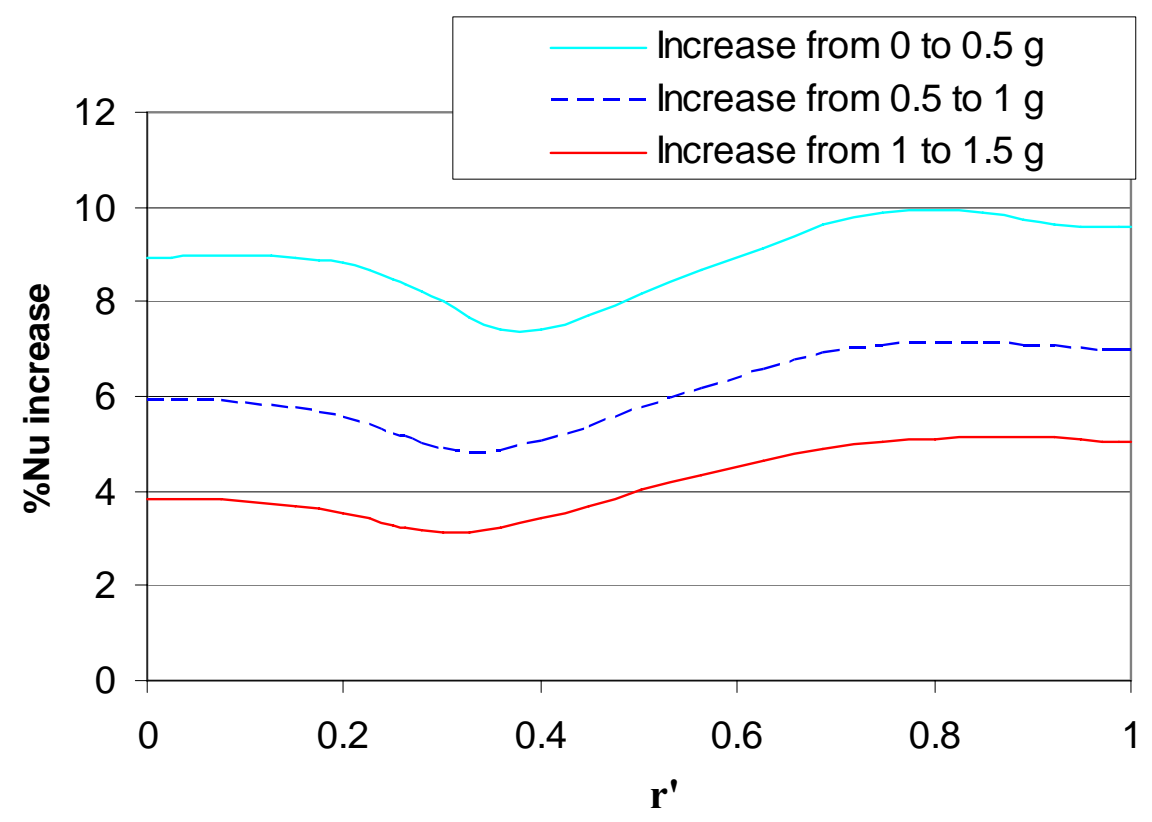

Figure 5.27 Percentage increase in Nusselt numbers with varying gravity.

The average Nusselt number trend with varying body forces is shown in Figure 5.28. It can be seen that the slope of the increase in heat transfer is less steep than the cases belonging to the low velocity regime, while the corresponding values of $\mathrm{Nu}$ are higher at each value of $1 /$ St. This indicates that the heat transfer is influenced less by body forces when the initial velocity of the jet is relatively higher. The average increase in the Nusselt number with the increase in reciprocal of Stokes number is shown in Figure 5.28. Upon fitting a curve to this data the following equation is obtained

$$
\overline{\mathrm{Nu}}=-2 \times 10^{-8} \mathrm{St}^{-2}+0.001 \mathrm{St}^{-1}+51.98 \text { and } \mathrm{R}^{2}=0.9999
$$




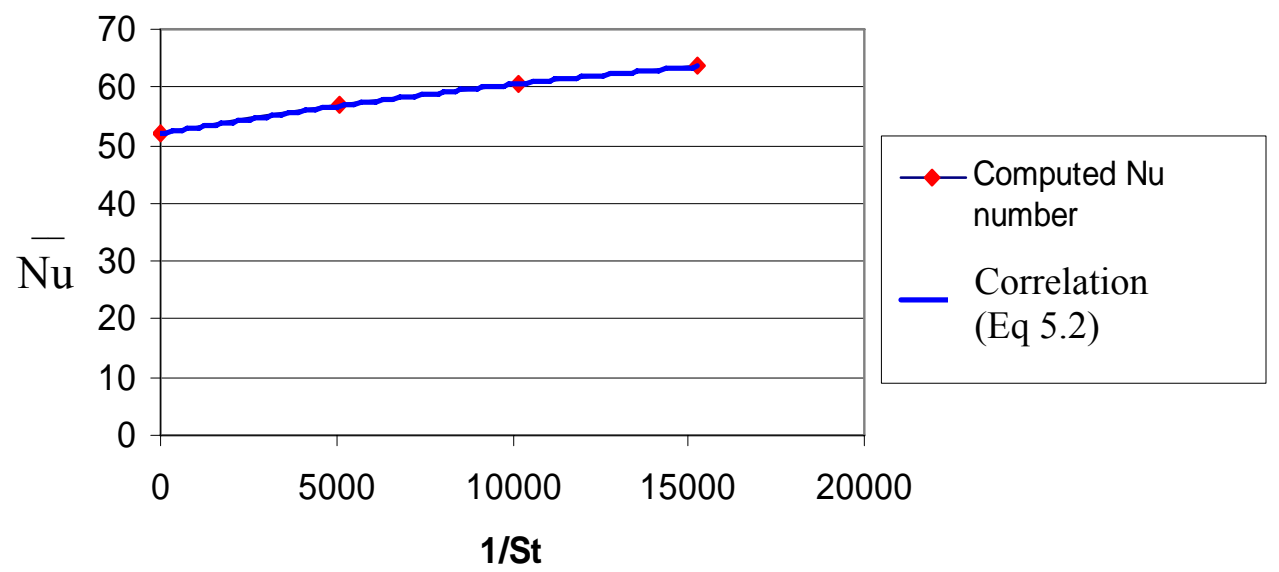

Figure 5.28 Increase in average Nusselt number as a function of reciprocal of Stokes number for high velocity cases.

Table 5.3 compares the Nusselt number obtained from the simulations with the Nusselt number correlations given by Womac et al. (1993) for the high velocity cases H5 to H8. The percentage discrepancy for these four cases is within $7 \%$ of the Nusselt number obtained from the correlations of Womac et al. (1993). 
Table 5.3 Comparison of computed $\mathrm{Nu}$ number with available correlations for Cases $\mathrm{H} 5$ to $\mathrm{H} 8$.

\begin{tabular}{|l|l|l|l|}
\hline Case number & $\begin{array}{l}\text { Nu} \\
\text { al. correlation }\end{array}$ & $\mathbf{N} \mathbf{u}_{1}$ computed & $\begin{array}{l}\text { Percentage } \\
\text { discrepancy }\end{array}$ \\
\hline H5 & 388 & 416 & 7 \\
\hline H6 & 428 & 455 & 6.3 \\
\hline H7 & 458 & 485 & 5.8 \\
\hline H8 & 483 & 509 & 5.2 \\
\hline
\end{tabular}

Two different correlations for Nusselt number are given in terms of the reciprocal of Stokes number and are valid for the Re based on jet exit velocity of $0.5 \mathrm{~m} / \mathrm{s}$ and 0.2263 $\mathrm{m} / \mathrm{s}$, and the gravitational force of 0 to $1.5 \mathrm{~g}$. The correlation for Nusselt number given by Womac et al. (1993) is a complex function of Re based on the jet impingement velocity thus including the effects of gravity in the correlation. A greater number of simulations at different Re based upon the jet inlet velocity would give more data points for obtaining a correlation which defines $\mathrm{Nu}$ as a function of Re and St. 


\section{Chapter 6}

\section{Conclusions and Recommendations}

\subsection{Conclusions}

The purpose of this research was two fold. One was to design an electrode which would provide an electrical body force against the direction of jet impingement to assess its effects on the flow configuration, and the second was to simulate a set of cases where the gravity was varied from $0 \mathrm{~g}$ to $1.5 \mathrm{~g}$ in increments of $0.5 \mathrm{~g}$ and to observe its effects on the resulting heat transfer. Hence an electrode was designed in this research which makes use of the gradient of $\mathrm{E}^{2}$ to generate an electric Kelvin force against the direction of an impinging liquid jet. This force was added as a source term to the $\mathrm{x}$ and $\mathrm{y}$ direction momentum equations. The transient effects were observed with and without this force. The impinging jet was influenced significantly by the presence of this force and also by the absence of gravity. The primary difference between the impinging liquid jet with and without gravity is that in the absence of gravity the impinging liquid jet would behave the same way in any orientation which would not be true in the case of gravity affected jet impingement.

The non isothermal simulations were performed with varying body forces for both the low velocity and the higher velocity regimes. The heat transfer increase with gravity decreases as the nozzle exit velocity is increased. The heat transfer was influenced due to the varying gravity levels more in the low velocity cases than in the high velocity cases. 
This was because the initial velocity in the low velocity cases was more significantly increased just before it hit the plate. This is apparent from Table 5.1 which shows the impingement velocity just before the jet hits the plate. The increase in velocity for the low velocity case was $144 \%$ for $1 \mathrm{~g}$ whereas in the case of high velocity regime it was only $42 \%$. The heat transfer increased as g was increased. The trend of the heat transfer was nonlinear for both the regimes. Based on the trend of heat transfer from the low velocity cases to the higher velocity cases it can be said that once the velocity is increased from the current level in the higher velocity case, the heat transfer would be less and less affected with the change in body forces. The heat transfer trend in the low velocity cases also suggests that the Nusselt number variation with gravity does not only depend on $\operatorname{Re}$ number based on jet exit velocity but also on the Stokes number. Correlations based on Stokes number for two different Re numbers have been given in Chapter 5 .

All of the simulated cases provided an average Nusselt number which was within $9 \%$ of the average Nusselt numbers obtained from the complex correlation of Womac et al. This correlation of Womac et al. (1993) is primarily a function of the Reynolds number based on jet impingement velocity and thus more accurately incorporate the effects of gravity on the heat transfer from the impinging jet. 


\section{Recommendations}

The electrode design currently provides a somewhat uniform electric Kelvin force against the direction of liquid jet impingement. Current recommendations are to increase the voltage up to $40 \mathrm{kV}$ in the experimental studies and remove the third electrode (the one attached to the pedestal). This will allow an increase in the electric Kelvin force. Since this is a high voltage, the voltage should be increased in as small increments as possible to prevent arcing.

The metal heater is a fixed potential electrode which means that the electric field will be normal to the heater surface. Since the electric Kelvin force is proportional to the gradient of the electric field squared it will be negligible next to the fixed potential surface of the metal heater. This is because $\mathbf{E}^{2}=(\nabla \boldsymbol{\Phi})^{2}$ where $\boldsymbol{\Phi}$ is the electric potential. The normal electric field lines to the heater would give constant $E^{2}$ if $(\nabla \Phi)^{2}$ is almost constant.

The heater was moved to a location slightly away from the impingement plane and the impingement plane was a dielectric instead a metal. It was thus possible to have a non normal electric field on the impingement surface. It was possible to have the heater to generate heat and its effect of reducing the electric Kelvin force at the required impingement plane was minimized. This suggests that the inclusion of a metal heater is possible along with the electric Kelvin force. 
This design can be improved to get more uniformity in the force lines. This will require a more sophisticated electrode geometry and shape of the experimental configuration. The best possible results will be obtained when the shape of the experimental configuration, shape of the electrode and the shape and material of the heater are selected so the maximum use of each component is made. This means taking into account the permittvities of all the materials, all the metals including the thermocouples, and the location of the heater.

It may be possible to reverse engineer the electric Kelvin force by specifying the required values of $\nabla E^{2}$. The estimated values of $E^{2}$ then may be used to obtain $(\nabla \boldsymbol{\Phi})^{2}$ and subsequently the electric potential. The electric potential on any metal must be specified to perform the electric field calculations.

A few simulations at higher velocities should be performed to find the effect of gravity at higher Re numbers based on the nozzle exit velocity. Also the trend of Nusselt number with varying gravity is expected to be different in two phase flows than in single phase flows and such cases should also be simulated. The two phase flow heat transfer results can then be compared with those in single phase heat transfer. 


\section{References}

3M Product Catalog for Oil and Gas Industry, 2006. www. 3m.com.

Barsanti, G., Faggiani, S., and Grassi, W., 1989. "Single phase forced convection cooling of heating surfaces by liquid jet impingement", Heat and Technology, v7, n2, pp 1-11.

Baysinger, K.M., Yerkes, K.L., Muchalk, T.E., Harris, R.J., and Mcquillen, J. 2004. "Design of a Microgravity Spray Cooling Experiment", AIAA Paper, 42 ${ }^{\text {nd }}$ Aerospace Sciences Meeting and Exhibit, pp 12031-12042

CFD/ESI ACE Manual for CFD ACE Solver, V 2004, 2005, 2006. ESI Incorporated, Huntsville, AL.

CFD/ESI ACE Manual for CFD Geom, V 2004, 2005, 2006. ESI Incorporated, Huntsville, AL.

CFD/ESI ACE Manual for CFD View, V 2004, 2005, 2006. ESI Incorporated, Huntsville, AL.

Van doormaal, J.P. and Raithby, G.D., 1984. "Enhancements of SIMPLE Method of Predicting Incompressible Fluid Flows”, Numer. Heat Transfer 7, pp, 147-163

Faggiani, S. and Grassi, W. 1990. "Impinging liquid jets on heated surfaces", Heat Transfer; Proceedings of the Ninth International Heat Transfer Conference, Jerusalem, Israel, pp 275-285.

Ferziger, J.H. and Peric, M. 1999. "Computational Methods for Fluid Dynamics", $2^{\text {nd }}$ edition, Springer- Verlag Berlin Heidelberg.

Glaspell, S. 2006 "Effects of the electric Kelvin force on spray cooling performance", MS thesis, Department of Mechanical and Aerospace Engineering, West Virginia University, Morgantown, WV.

Gray, D.D.., 2004. Class notes on Electromagnetodynamics of Fluids , West Virginia University, Morgantown, WV

Griffiths, D., 1999. "Introduction to Electrodynamics", $3{ }^{\text {rd }}$ edition, Prentice Hall, Upper Saddle River, New Jersey.

Hirt, C.W., and Nichols, B.D., May 1981. "A computational method for free surface hydrodynamics", Transactions of the ASME, Journal of Pressure Vessel Technology, v103, n2, pp 136-41. 
Hughes, W.F. and Young, F.J., 1988. "The Electromagnetodynamics of Fluids", John Wiley and Sons, Inc, New York.

Hunnell, C.A., 2005. "Design, construction and initial testing of experimental test package for convective spray cooling in terrestrial gravity conditions", MS thesis, Department of Mechanical and Aerospace Engineering, West Virginia University, Morgantown, WV.

Krietzer, P., 2006. "Experimental testing of convective spray cooling with the aid of an electric field using the Coulomb force", MS thesis, Department of Mechanical and Aerospace Engineering, West Virginia University, Morgantown, WV.

Labus, T. L., 1977. "Liquid jet impingement normal to a disk in zero gravity", NASA technical paper 1017, Lewis Research Center, Cleveland, OH.

Labus, T.L, DeWitt, K.J., June 1978. "Liquid jet impingement normal to a disk in zero gravity", Transactions of the ASME, Journal of Fluids Engineering, v100, n2, pp 204209.

Liu, X. and Lienhard, J.H., 1989. "Liquid jet impingement heat transfer on a uniform flux surface", National Heat Transfer Conference, HTD v106, Heat Transfer Phenomena in Radiation, Combustion and Fires, pp 523-530.

Ma, C.F., Gan, Y.P., Tian, Y.C., and Lei, D.H., 1993. "Liquid jet impingement heat transfer with or without boiling", Journal of Thermal Science, v2, n1, pp 32-49.

Patankar, S.V., 1980. "Numerical heat transfer and fluid flow", McGraw Hill, ISBN 0070487405.

Webb, B.W. and Ma, C.F., 1995. "Single phase liquid jet impingement heat transfer", Advances in Heat Transfer, v26, pp 104-217.

Womac, D.J., Aharoni, G., Ramdhyani, S., and Incropera, F.P., 1990. "Single phase liquid jet impingement cooling of small heat sources", International Heat Transfer Conference, pp 149-154.

Womac, D.J., Aharoni, G., Ramdhyani, S., and Incropera, F.P., 1993. "Correlating Equations for Impingement Cooling of Heat Sources With Single Circular Liquid Jets", Transactions of the ASME, v 115, pp 106- 115. 


\section{Biographical Sketch}

Deepak Mehra was born to Parkash and Richhpal Mehra on January 4, 1979. He was born and raised in Rohtak in the state of Haryana, India, until the age of 17 attending Model School and graduating from Model School in 1996.

Deepak Mehra attended Punjab University in Chandigarh, India and received the Bachelor of Engineering (Aeronautical Engineering) in 2000. He entered West Virginia University in the USA in 2001 and received his Master of Science from the College of Engineering and Mineral Resources in 2003. He has continued his studies since that time and is currently teaching at Potomac State College of West Virginia University. 